\title{
Part A: Enantioselective Synthesis of C9 and C10 Deuterio-Labelled Dihydrodrosterculic Acids Part B: Efficient, and Scalable Preparation of bis(Deuterium)- and ${ }^{13} \mathrm{C}$-Labelled Diazomethane
}

\section{by}

Samuel W. J. Shields

A thesis submitted to the Faculty of Graduate and Postdoctoral Affairs in partial fulfillment of the requirements for the degree of

\author{
Master of Science \\ in \\ Chemistry \\ Carleton University \\ Ottawa, Ontario
}

(C) 2014

Samuel W. J. Shields 


\section{Abstract}

\section{Part A:}

We report the first efforts toward regiospecifically and stereospecifically or stereoselectively C9 and C10 deuterio labelled dihydrosterculic acids. The acids were prepared from $\left(S_{\mathrm{S}}, S_{\mathrm{S}}\right)$-1,1-bis $(p$-tolylsulfinyl)methane in a sequence involving an asymmetric Corey-Chaykovsky cyclopropanation and two sulfoxide-lithium exchange reactions. By using a $d$-1-aldehyde we obtained 9- $d$-dihydrosterculic acid, with a remote mass label at C18, in a 14\% yield and 98\% D incorporation (at C9) over 7 linear steps. We also prepared a $d-10$ alkene, which was readily converted to $d-10$ dihydrosterculic acid. The deuterium label was installed via a stereospecific lithium-sulfoxide exchange and subsequent quenching with MeOD. Transformation to the $d-10$ dihydrosterculic acid was completed in analogy to the $d-9$ congener.

\section{Part B:}

A method for the preparation of gram quantities of $N$-methyl- $d_{3}-\mathrm{N}$-nitroso- $p$-toluene sulfonamide (Diazald- $d_{3}$ ) and $N$-methyl- ${ }^{13} C$-N-nitroso- $p$-toluene sulfonamide (Diazald${ }^{13} \mathrm{C}$ ) and their conversion to labelled diazomethanes is presented. This method uses robust and straightforward chemistry, and employs readily commercially available and inexpensive methanol as a methyl label source. 


\section{Acknowledgements}

I would like to sincerely thank Jeff Manthorpe and Peter Buist for all the wonderful guidance and mentorship they have provided to me over the years, for without them I would have not had the opportunity to follow my ambitions of being an organic chemist. I would like to sincerely thank all of the members of the Manthorpe research group (past and present) for their kind and helpful guidance. That is to say a special thank you to Monica Gill and John Palko, and for not only teaching me chemistry, but for teaching me how to become a chemist. I hold each of these people in the highest regard for giving their time and having the patience to work with me.

I would also like to thank my friends and family for the care and support they have provided me with over the years. Most notably my parents, whom not only inspired my interest in science, but have provided the means to become the person I am today. Diane Jodoin deserves enormous thanks as well, since if it were not for her support, I would have most likely lost all hope of ever achieving anything.

Lastly, the following funding agencies should be thanked for the providing the loot: NSERC, Ontario Research Fund, Canadian Foundation for Innovation, and Carleton University.

... Sam out (drops mic) 
"If I have seen further it is by standing on the shoulders of giants"

Isaac Newton 


\section{Table of Contents}

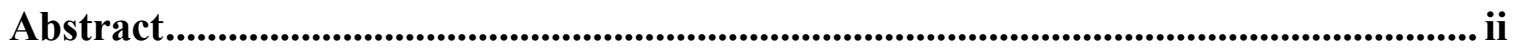

Acknowledgements .................................................................................................ii

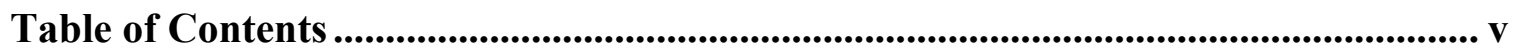

List of Tables .............................................................................................................................. $\mathrm{x}$

List of Figures.......................................................................................................................... $\mathrm{x}$

List of Schemes ............................................................................................................................... $\mathrm{x}$

List of Abbreviations ................................................................................................................ xiii

1 Chapter: Introduction (part A) .......................................................................... 1

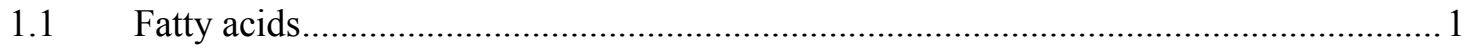

$1.2 \quad$ Fatty acid desaturases ...................................................................................

1.3 Mechanistic investigations of desaturases ...........................................................

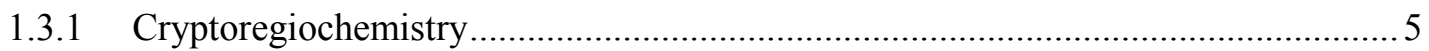

1.3.2 Enantioselectivity and of $\Delta^{9}$ desaturases...........................................................

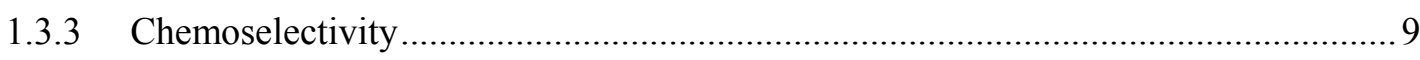

1.3.4 Synthesis of mechanistic probes (Sulfur and chiral methylene groups)...................11

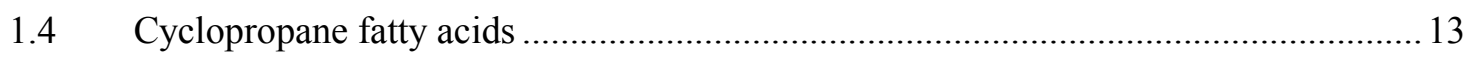

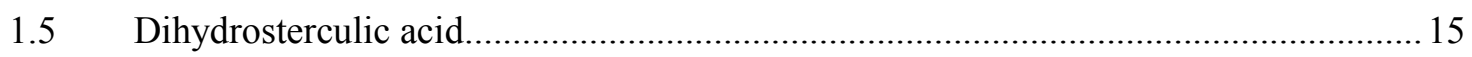

1.5.1 Structure determination $9 R, 10 S$-dihydrosterculic acid............................................. 16

1.5.2 Proposed biosynthesis of dihydrosterculic acid ..................................................... 18

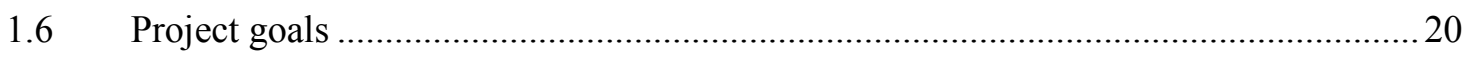

2 Chapter: Results and Discussion (part A) ............................................................... 21

$2.1 \quad$ Introduction to synthetic methods .....................................................................21

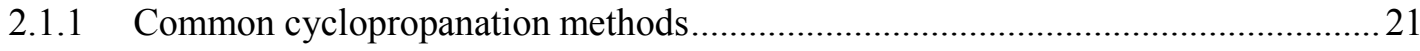




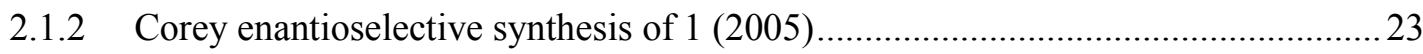

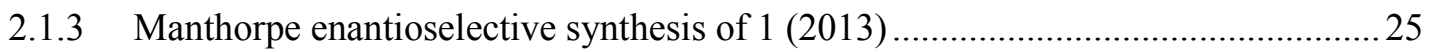

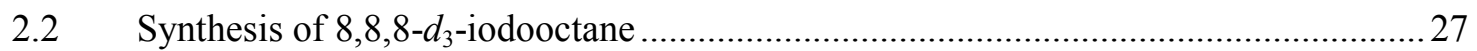

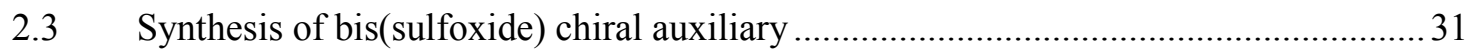

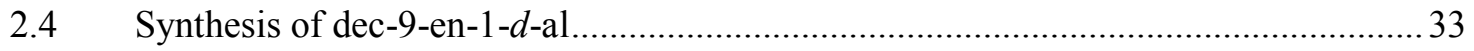

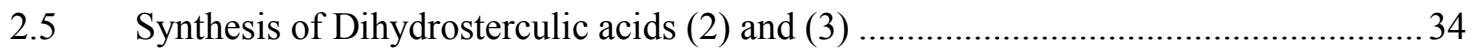

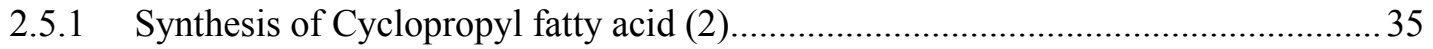

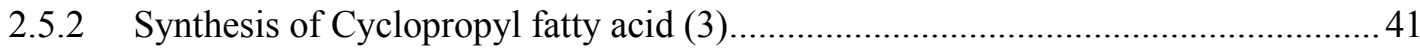

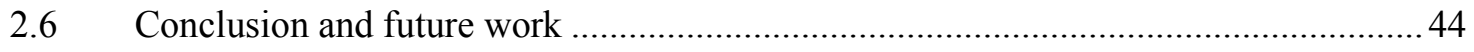

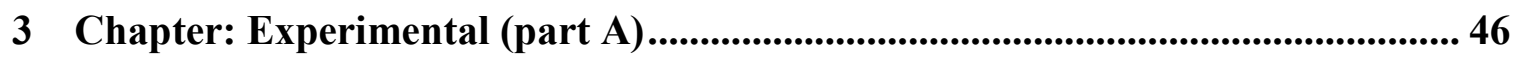

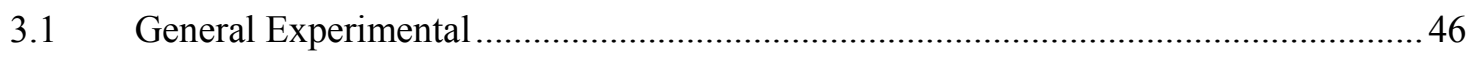

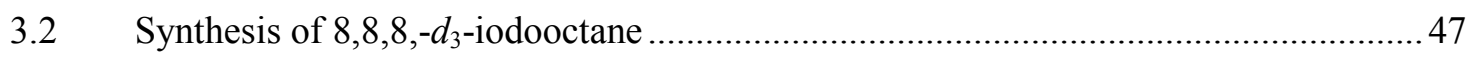

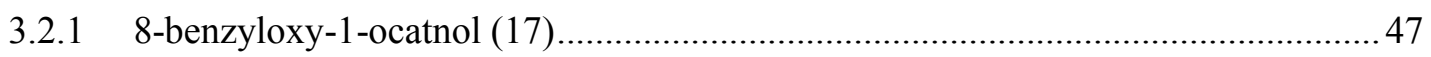

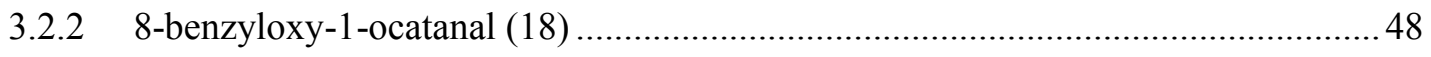

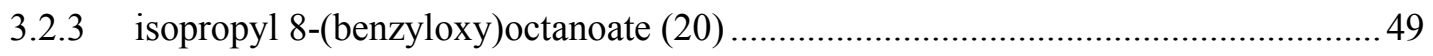

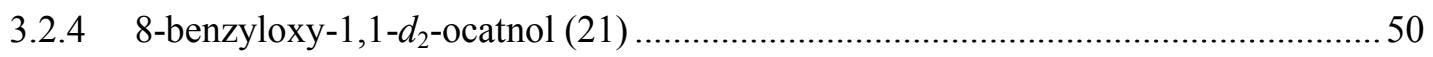

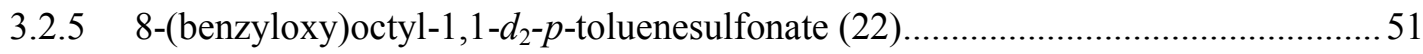

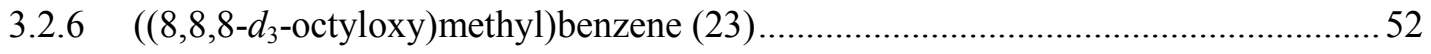

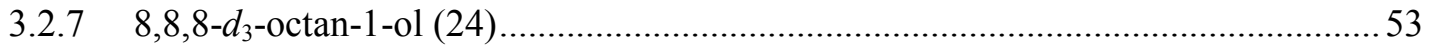

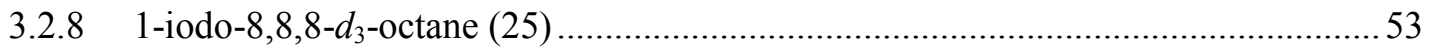

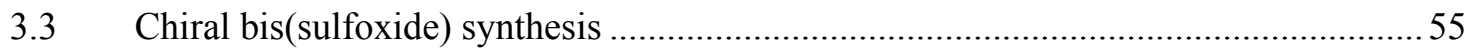

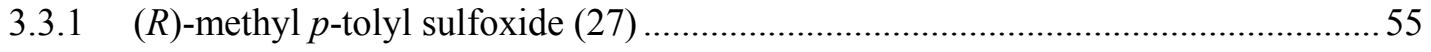

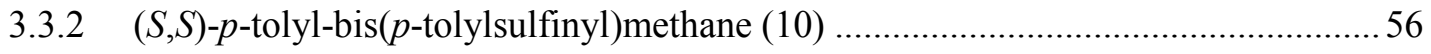

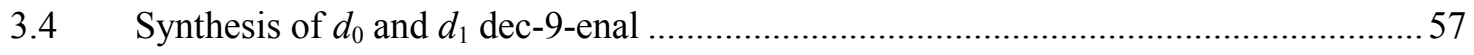

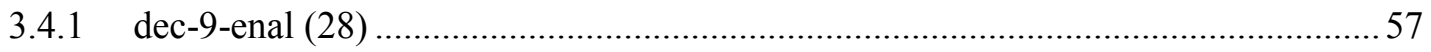

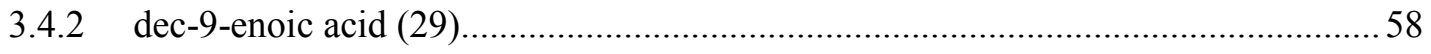




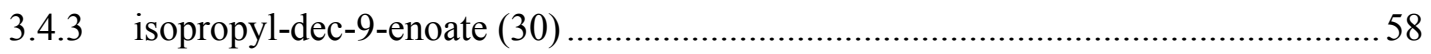

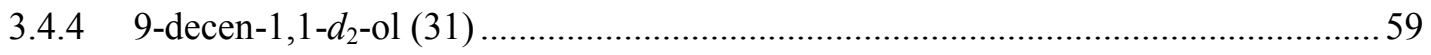

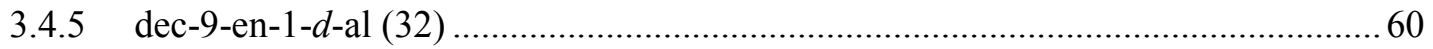

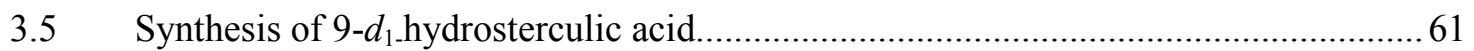

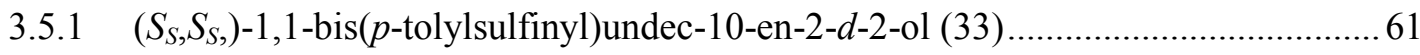

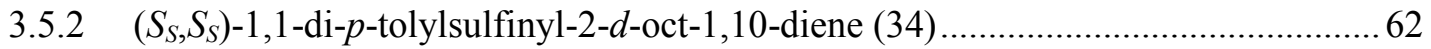

3.5.3 $\left(S_{S}, S_{S}, 2 R\right)$-1,1-bis- $p$-tolylsulfinyl-2-d-2-dec-10-enylcyclopropane (35) ...................62

3.5.4 $\left(S_{S}\right)$-1-p-tolylsulfinyl-(1 $\left.R, 2 R\right)-2-d-2$-(non-8-en-1-yl)-1-(8,8,8- $d_{3}$-octyl)cyclopropane

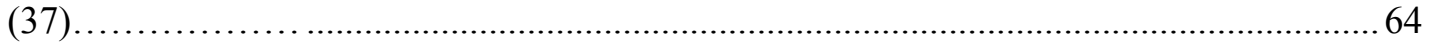

3.5.5 (1R,2S)-1- $d$-1-(non-8-en-1-yl)-2-(8,8,8- $d_{3}$-octyl)cyclopropane (38) ........................65

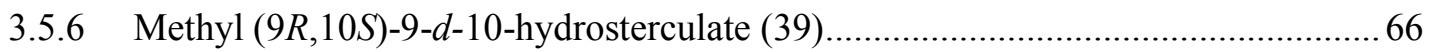

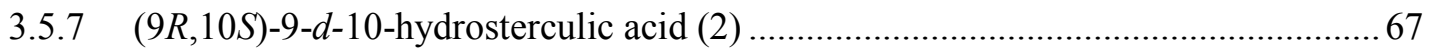

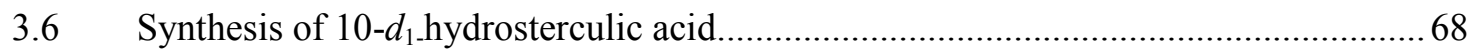

3.6.1 $\left(S_{S}, S_{S}, 2 R\right)$-1,1-bis- -tolylsulfinyl-2-dec-10-enylcyclopropane (13) ......................... 68

3.6.2 $\left(S_{S}\right)-1$-p-tolylsulfinyl-(1R,2R)-2- $d$-2-(non-8-en-1-yl)-1-(8,8,8- $d_{3}$-octyl)cyclopropane

(42) 68

3.6.3 (1R,2S)-1-(non-8-en-1-yl)-2-2-d -(8,8,8-d $d_{3}$-octyl)cyclopropane (43) ...................... 69

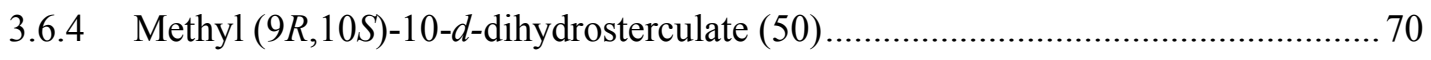

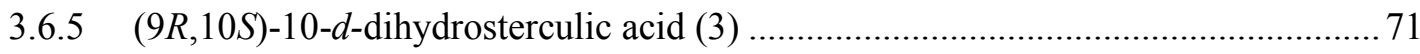

Prepared analogously to 3. Product was light yellow solid (43 mg, 54\%).......................... 71

4 Chapter: Introduction (part B)............................................................................... 73

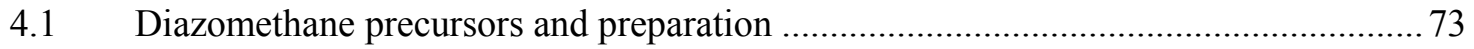

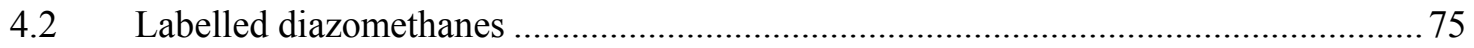

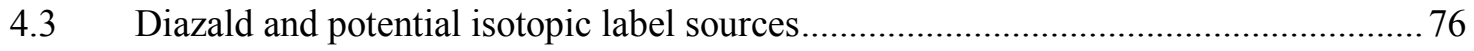

5 Chapter: Results and discussion (part B) ....................................................... 77

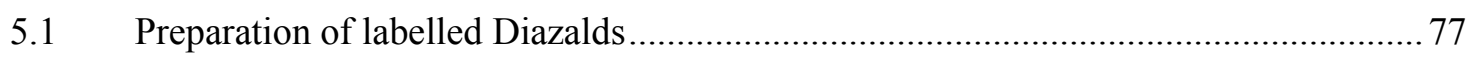


5.2 Preparation and use of diazomethane $-{ }^{13} C$

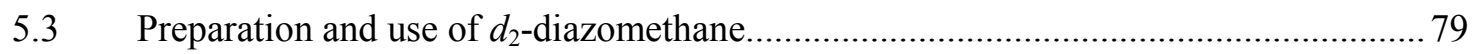

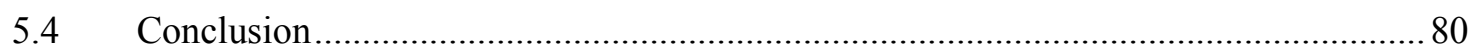

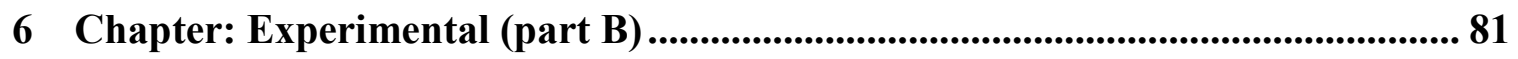

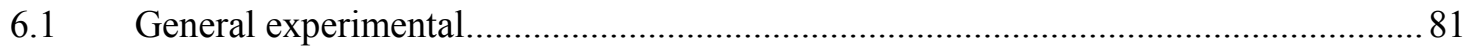

6.2 Preparation of labelled Diazalds and their conversion to isotopically enriched

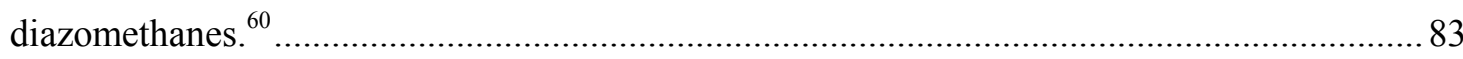

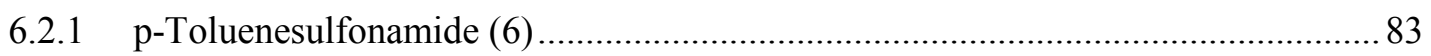

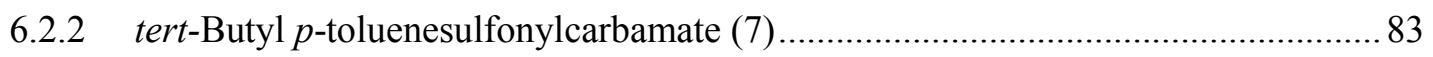

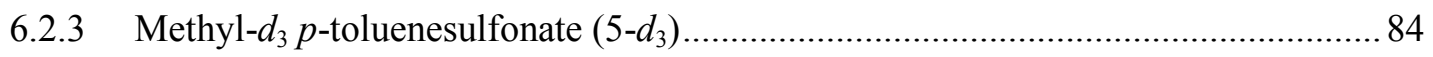

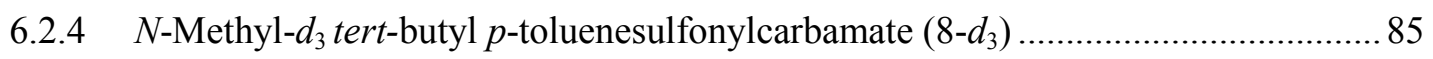

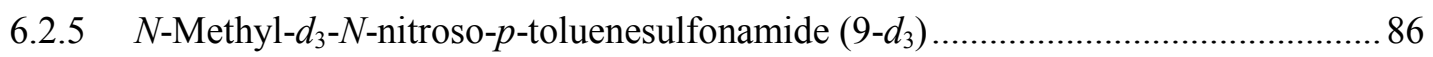

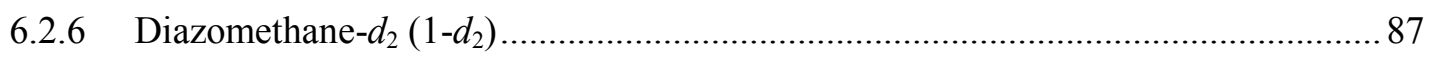

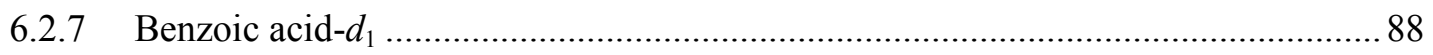

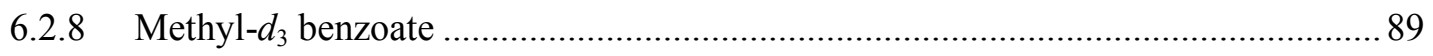

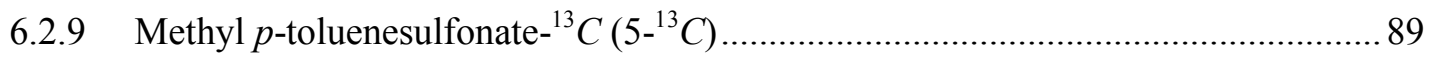

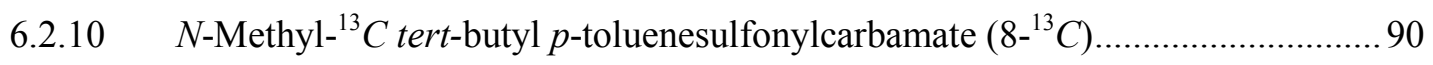

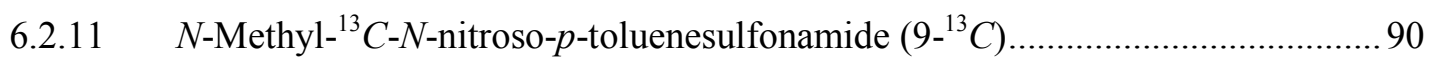

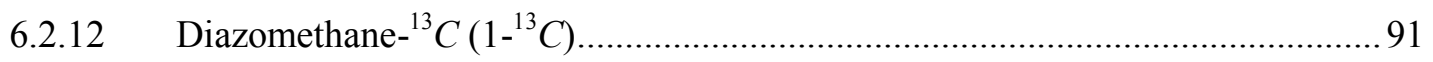

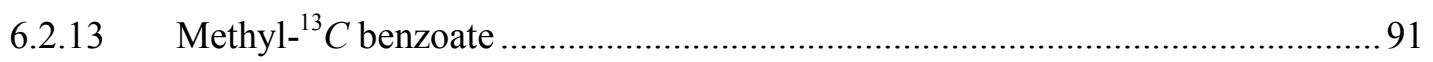

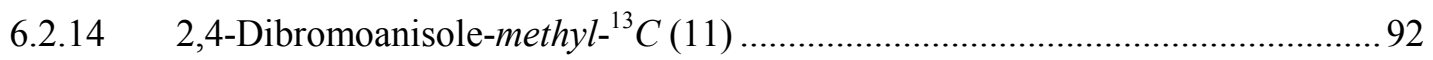

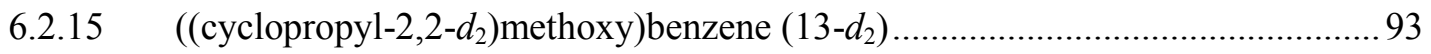

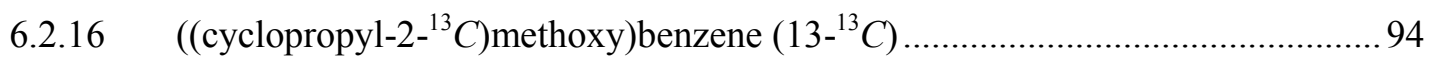

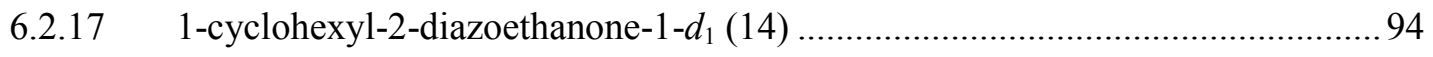

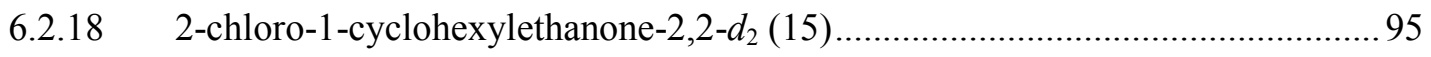




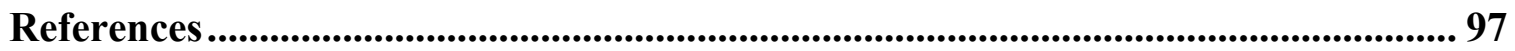




\section{List of Tables}

Table 1 Deprotection of benzyl ether (23) 30

Table 2 Prices of labelled methyl sources $\quad 77$

List of FiguresFigure 1.1 Examples of some naturally occurring fatty acids .................. 1

Figure 1.2 General structure of TAGs and phosphatidylcholines................................ 2

Figure 1.3 The three topics of investigation for $\mathrm{C}-\mathrm{H}$ activation in desaturases................ 4

Figure 1.4 Labelled substrates for the competitive, deuterium KIE experiments of Buist

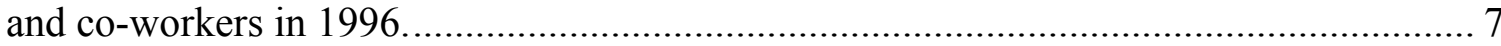

Figure 1.5 Dehydrogenation (1.) and Hydroxylation (2.) ......................................... 10

Figure 1.6 Examples of naturally occurring cyclopropane fatty acids ......................... 13

Figure 1.7 Generally accepted numbering system of dihydrosterculic acid (1) ............. 15

Figure 1.8 The two enantiomeric forms of dihydrosterculic acid............................... 15

Figure 2.1 Synthetic targets of this research project ............................................. 21

Figure 4.1 Diazomethane and it most commonly used precursors .............................. 74

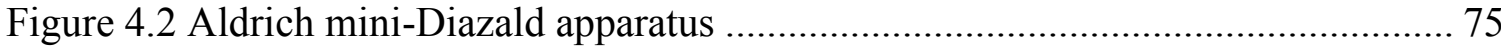

\section{List of Schemes}

Scheme 1.1 Desaturation of stearic acid to oleic acid ................................................. 3

Scheme 1.2 Proposed general mechanism for the formation of unsaturated fatty acids .... 5

Scheme 1.3 An example of a deuterium KIE experiment. ......................................... 5

Scheme 1.4 Novel thia-stearoyl substrates from Buist and co-workers in 2001 .............. 7 
Scheme 1.5 Examples of the desaturation of stereospecifically labelled stearoyl

substrates. 9

Scheme 1.6 Synthesis of regiospecific bis(deuterium) 7-thia stearic acids .................... 11

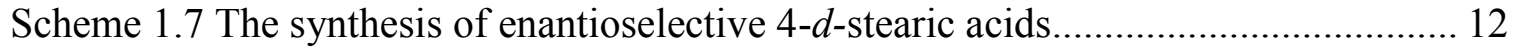

Scheme 1.8 General biosynthetic pathway of cyclopropenyl fatty acids ....................... 14

Scheme 1.9 Comparison of $[\Phi]_{\mathrm{D}}$ values obtained for ketones derived from

dihydrosterculate (1) and its 11,12-positional isomer, lactobacillic acid 17

Scheme 1.10 Proposed SAM-cyclopropanation mechanism of cis-unsaturated fatty acid

Scheme 1.11 Suggested reversible protonation/deprotonation mechanism in the formation of CFAs 19

Scheme 1.12 The proposed KIE experiments with labelled dihydrosterculic acids........ 20

Scheme 2.1 Insertion of a dihalocarbene into cyclohexene ....................................... 22

Scheme 2.2 Simmons-Smith reaction (Furukawa modification) ................................. 22

Scheme 2.3 Mechanism of the Corey-Chaykovsky cyclopropanation .......................... 23

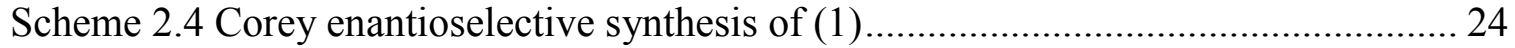

Scheme 2.5 Retrosynthetic analysis of (2) using Corey's catalytic cyclopropene

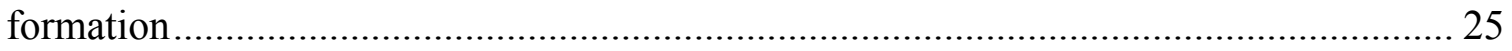

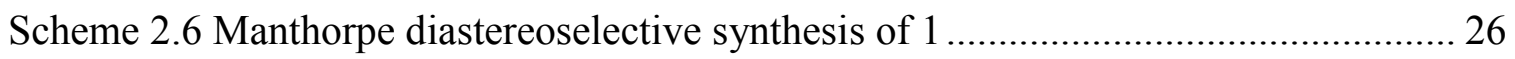

Scheme 2.7 Protection and oxidative sequence en route to labelled iodooctane............. 27

Scheme 2.8 Reductive sequence, deprotection and iodination steps toward remote mass

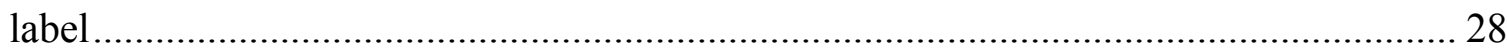

Scheme 2.9 Catalytic cycle of trimethyl amine in Tanabe's protocol ........................... 29 
Scheme 2.10 Andersen-type preparation of chiral sulfoxide 27 and conversion to

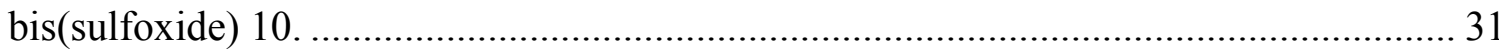

Scheme 2.11 Epimerization of chiral sulfinate with $\mathrm{HCl}$........................................... 32

Scheme 2.12 Preparation of $d_{1}$ and $d_{0}$-aldehydes .......................................................... 33

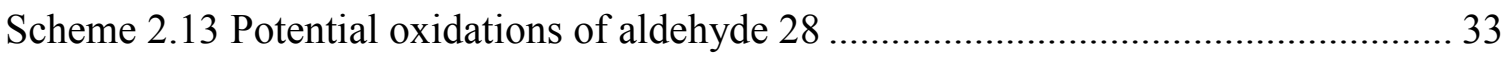

Scheme 2.14 Preparation of cyclopropyl bis(sulfoxide) (35) ........................................ 35

Scheme 2.15 Proposed degradation of bis(sulfoxide) (33) and (34) ............................... 36

Scheme 2.16 Selective lithium sulfoxide cleavages of (35) and (37) ............................ 37

Scheme 2.17 Completion of (2) via Ozonolysis and Hydrolysis progression ................... 39

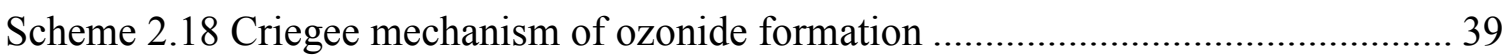

Scheme 2.19 Proposed Marshall ozonolysis mechanism. .............................................. 40

Scheme 2.20 Preparation of cyclopropyl bis(sulfoxide) (13) en route to (3) ................... 41

Scheme 2.21 Selective lithium sulfoxide exchanges of (13) and (42)........................... 42

Scheme 2.22 Protonation of lithium cyclopropyl sulfoxide (46)..................................... 43

Scheme 2.23 Undesired protonation pathway of lithiated cyclopropane ........................ 43

Scheme 2.24 Completion of cyclopropane fatty acid 3 ................................................ 44

Scheme 2.25 KIE experiments with labelled and unlabelled dihydrosterculic acids ....... 45

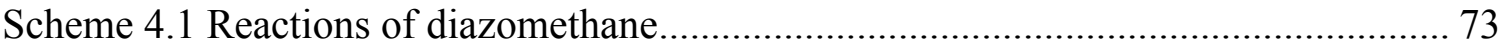

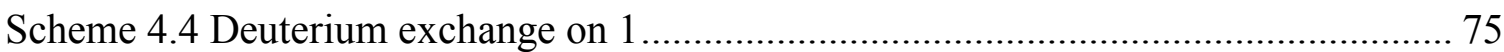

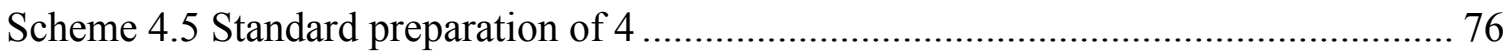

Scheme 5.1 Synthesis of deuterium and ${ }^{13} \mathrm{C}$ labelled Diazalds ..................................... 78

Scheme 5.2 Phenol alkylation and alkene cyclopropanation with $1-{ }^{13} C \ldots \ldots \ldots \ldots \ldots \ldots \ldots \ldots \ldots . . .79$

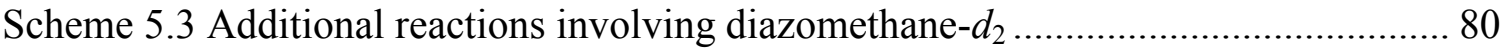




\section{List of Abbreviations}

\begin{tabular}{|c|c|}
\hline $\mathrm{ACP}$ & Acyl carrier protein \\
\hline $\mathrm{CoA}$ & Coenzyme A \\
\hline CFA & Cyclopropyl fatty acid \\
\hline $\mathrm{d}$ & Doublet \\
\hline $\mathrm{DCM}$ & Dichloromethane \\
\hline $\mathrm{DCVC}$ & Dry column vacuum chromatography \\
\hline DIPA & Diisopropylamine \\
\hline DIPEA & Diisopropylethylamine \\
\hline DMAP & 4-(N,N-dimethylamino)pyridine \\
\hline DMF & $N, N$-Dimethylformamide \\
\hline DMSO & Dimethylsulfoxide \\
\hline DPTI & Diphenyltriflylimidazolidinone \\
\hline$d r$ & Diastereomeric ratio \\
\hline EDTA & Ethylenediaminetetraacetic acid \\
\hline$e e$ & Enantiomeric excess \\
\hline FTIR & Fourier transform infrared \\
\hline FCC & Flash column chromatography \\
\hline $\mathrm{GC}$ & Gas chromatography \\
\hline GC/MS & Gas chromatography mass spectrometry \\
\hline HRMS & High resolution mass spectrometry \\
\hline
\end{tabular}




\begin{tabular}{|c|c|}
\hline ICP & Inductively coupled plasma \\
\hline imid & Imidazole \\
\hline KIE & Kinetic isotope effect \\
\hline LDA & Lithium diisopropylamide \\
\hline LiDBB & Lithium 4,4'-di-tert-butylbiphenylide \\
\hline $\mathrm{m}$ & Multiplet \\
\hline menth & Menthyl \\
\hline$m$-CPBA & meta-Chloroperbenzoic acid \\
\hline Morpho-CDI & $\begin{array}{l}N \text {-Cyclohexyl- } N^{\prime} \text {-(2-morpholinoethyl)carbodiimide methyl-para- } \\
\text { toluenesulfonate }\end{array}$ \\
\hline MIRC & Michael-induced ring closure \\
\hline MMO & Methane monooxygenase \\
\hline MS & Mass spectrometry \\
\hline NMR & Nuclear magnetic resonance \\
\hline $\mathrm{PCC}$ & Pyridinium chlorochromate \\
\hline PDC & Pyridinium dichromate \\
\hline PL & Phospholipid \\
\hline PTSA & para-Toluenesulfonic acid \\
\hline PG & Protecting group \\
\hline pyr & Pyridine \\
\hline q & Quartet \\
\hline $\mathrm{RaNi}$ & Raney Nickel \\
\hline $\mathrm{s}$ & Singlet \\
\hline
\end{tabular}




$\begin{array}{ll}\text { SAM } & \text { S-Adenosyl methionine } \\ \text { SCD } & \text { Steroyl CoA desaturase } \\ \text { SOMO } & \text { Singly occupied molecular orbital } \\ \mathrm{t} & \text { Triplet } \\ \text { TAG } & \text { Triacylglicerides } \\ \text { TEMPO } & \text { (Tetramethylpiperdinyl)oxy radical } \\ \text { THF } & \text { Tetrahydrofuran } \\ \text { TLC } & \text { Thin layer chromatography } \\ \text { TMS } & \text { Tetramethyl silane } \\ \text { TsCl } & \text { para-Toluenesulfonyl chloride }\end{array}$




\section{Part A: Enantioselective Synthesis of C9 and C10}

\section{Deuterio-Labelled Hydrosterculic Acids}




\section{Chapter: Introduction (part A)}

\subsection{Fatty acids}

Fatty acids are long chain carboxylic acids that typically consist of 14-20 carbons. Apart from the carboxyl moiety, fatty acids can have a variety of other functionalities including alkenyl, alkynyl, cyclopropyl, hydroxyl, and epoxy groups usually arising from their saturated counterparts (Figure 1.1). ${ }^{1}$

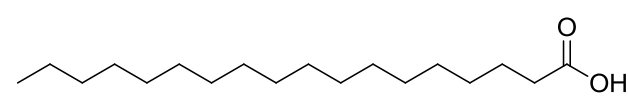

Stearic Acid

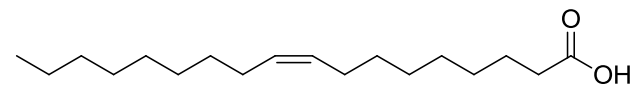

Oleic Acid

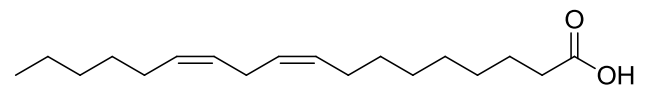

Linoleic Acid

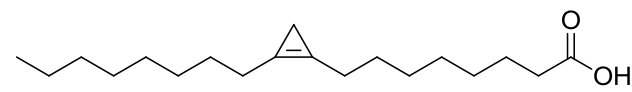

Sterculic Acid

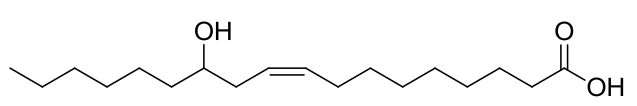

Rincinoleic Acid

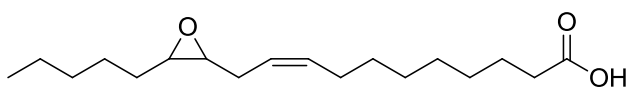

Vernolic Acid

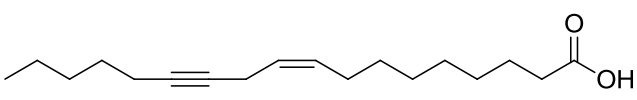

Crepenynic Acid

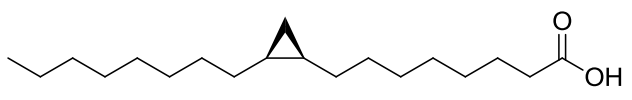

Dihydrosterculic acid

Figure 1.1 Examples of some naturally occurring fatty acids

Fatty acids are crucial to the biological systems of virtually all life forms on earth since they are the main constituents of lipids. Lipids generally consist of a glycerol backbone that is esterified with varying fatty acids, and are used as the energy storage and structural biomolecules of plants, animals and bacteria. ${ }^{1}$ Triacylglycerides (TAGs) are one of the major reserves of chemical potential energy that can be mobilized for catabolic processes. Phospholipids like phosphatidylcholine are the main component in biomembranes that allow cells to retain their structure. Other biological functions performed by lipids include antifeedant activity and chemical signaling. ${ }^{2}$ 


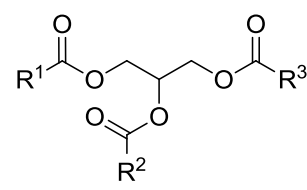

Triacylgliceride (energy storage)

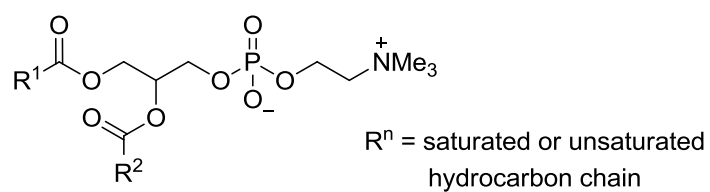

Phosphatidylcholine
(structural)

Figure 1.2 General structure of TAGs and phosphatidylcholines

Over 300 structurally different fatty acids have been isolated from plant seed oils alone. A few of these acids have been put to use in an industrial setting as green source of feed stock hydrocarbons for lubricants, plasticizers, adhesives, and paints. ${ }^{3,4}$ Due to the ever-increasing cost of petrochemicals, plant and seed oils are extensively being regarded as practical bio-fuels. These oils, which are rich in fatty acids, have higher energy content than other green resources like ethanol and have $90 \%$ of the heat content of fossil fuelderived diesel. ${ }^{3}$ As such, funding into fatty acid research has increased exponentially over that last five years.

Other growing problems in today's society are the increasing number of people with metabolic disorders. Occurrence of metabolic diseases like obesity and diabetes directly relates to the processing of fatty acids and lipids in human biochemical pathways. For example, in 2005 Ntambi et al. showed that steroyl co-enzyme A (CoA) $\Delta^{9}-$ desaturase (SCD) is implicated to be involved in metabolic diseases such as obesity and diabetes. $^{5}$ This makes desaturases, an ever-growing family of enzymes, exceptional biological targets to help understand the nature of the above disorders, since much of the diversity of lipids and fatty acids is governed by the actions of various desaturase enzymes. $^{2}$ 


\subsection{Fatty acid desaturases}

Most naturally occurring monounsaturated fatty acids are produced biosynthetically by an $\mathrm{O}_{2}$-dependent dehydrogenation by a family of enzymes called desaturases (Scheme 1.1). ${ }^{6}$ Alkene formation at the 9,10 position in oleic acid is catalyzed by two distinct enzymes. One is the soluble steroyl-acyl carrier protein (ACP) $\Delta^{9}$-desaturase enzymes found only in plants and the other is a universal membrane-bound enzyme. $^{7}$ These enzymes are crucial to producing oleyl phospholipids, the major component in membrane bilayers, and are necessary for optimizing cellular membrane fluidity.
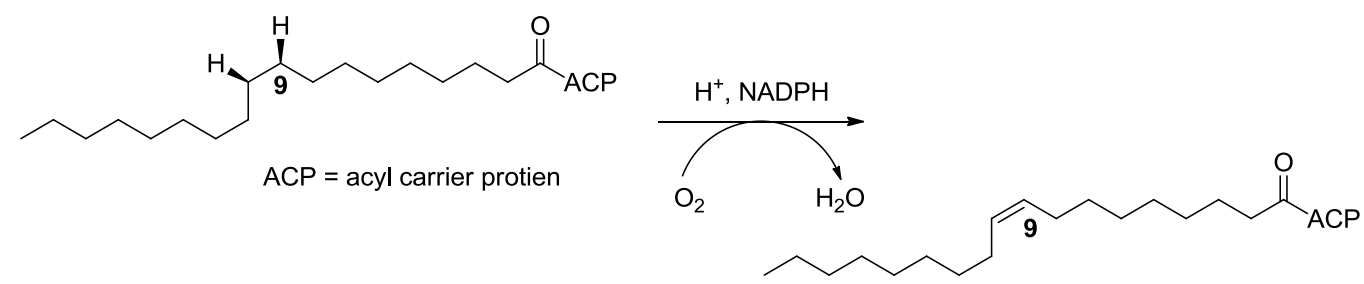

Scheme 1.1 Desaturation of stearic acid to oleic acid

A critical step in studying soluble plant desaturases came about in the 1990s when steroyl-ACP $\Delta^{9}$ desaturase was isolated from the castor plant (Ricinus communis) and could be overexpressed in Saccharomyces cerevisiae, then purified. ${ }^{8}$ Crystal structures of steroyl-ACP $\Delta^{9}$ desaturase were obtained and showed the presence of a non-heme, carboxylate bridged, diiron core and a proposed hydrophobic binding pocket. It is thought that the ACP-bound substrate docks into a boomerang shaped active site, forcing the substrate into the energetically disfavoured gauche conformation where the aerobic oxidation takes place nearest the diiron center. ${ }^{9}$ With this new knowledge into the structure of plant desaturases many questions were raised about mechanism of this 
energetically difficult $\mathrm{C}-\mathrm{H}$ activation, especially since other similar diiron systems were discovered in very different enzymes, such as methane monooxygenase (MMO), which catalyzes the production of methanol from methane. ${ }^{7}$

The three pertinent questions which arose upon the isolation of soluble steroylACP $\Delta^{9}$ desaturase are:

a) What is the site of initial oxidation? (cryptoregiochemistry)

b) What is the stereochemistry of hydrogen removal? (pro $R$ or pro $S$ )

c) What factors prevent the competitive hydroxylation pathway? (chemoselectivity)

By addressing the above three questions development of novel desaturase enzymes and inhibitors could be exploited in the field of biotechnology as well as medicinal chemistry.

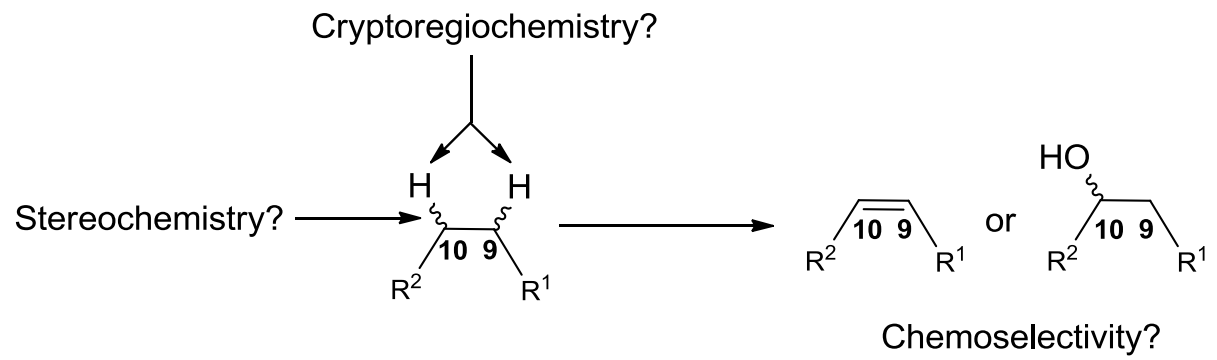

Figure 1.3 The three topics of investigation for $\mathrm{C}-\mathrm{H}$ activation in desaturases

\subsection{Mechanistic investigations of desaturases}

A general reaction mechanism for the desaturation by steroyl-ACP $\Delta^{9}$ desaturase is depicted in Figure 1.4. It has been proposed that desaturation is initiated via a hydrogen abstraction by a diiron-oxo species to form a secondary radical Fe/OH pair. ${ }^{7}$ This newly formed carbon centered radical now undergoes a rapid, second hydrogen abstraction to form an unsaturated product in only the cis configuration. ${ }^{2,7}$ Given that a secondary aliphatic $\mathrm{C}-\mathrm{H}$ bond has an average bond energy of $\sim 98 \mathrm{kcal} / \mathrm{mol}$ and a $\mathrm{C}-\mathrm{H}$ bond $\alpha$ to a 
radical is $\sim 35 \mathrm{kcal} / \mathrm{mol}$ the assumption can be made that the first hydrogen abstraction has a greater activation energy and is the rate determining step. ${ }^{10,11}$ From this assumption certain mechanistic probes can be synthesized to elucidate the stereochemical and cryptoregiochemical outcome of these desaturation reactions.

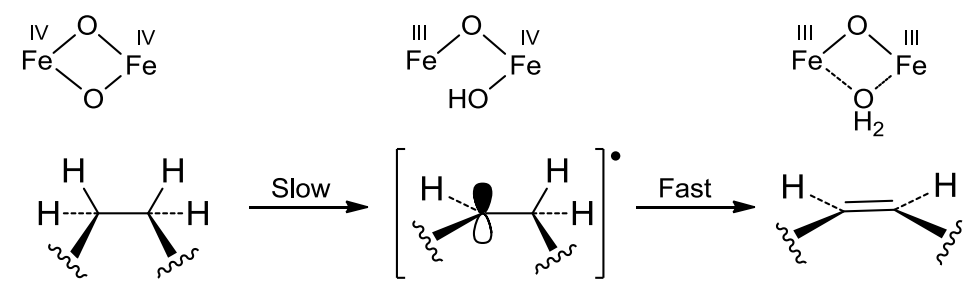

Scheme 1.2 Proposed general mechanism for the formation of unsaturated fatty acids

\subsubsection{Cryptoregiochemistry}

The cryptoregiochemistry (initial site of oxidation) of desaturation reactions has been commonly elucidated by using deuterium kinetic isotope effect (KIE) methodology. ${ }^{12}$ This type of approach relies on the fact that a C-D bond has a higher energy cost to cleave than the corresponding $\mathrm{C}-\mathrm{H}$ bond. This energy difference results in a slower rate of cleavage if breaking the C-D bond is kinetically significant (rate determining step). An example of a KIE experiment is depicted in Scheme 1.2.

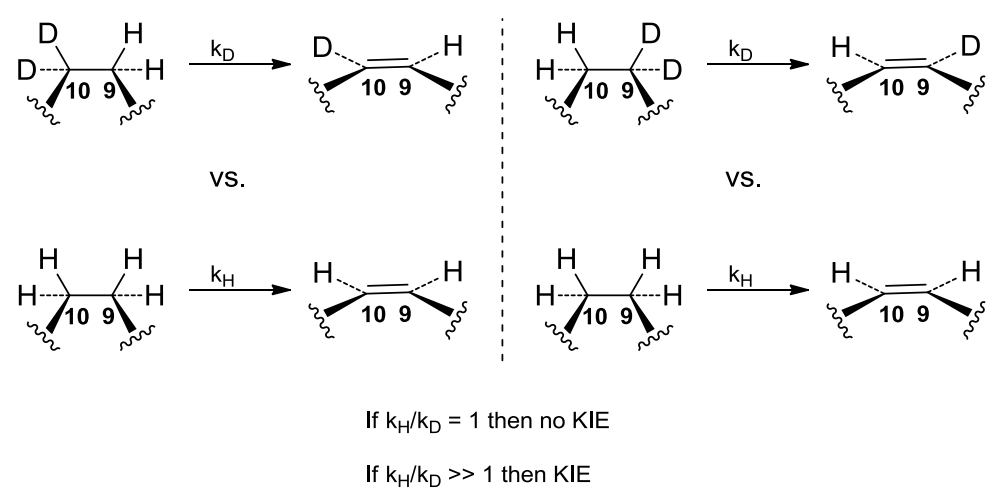

Scheme 1.3 An example of a deuterium KIE experiment. 
Generally a 1:1 mixture of regioselectively deuterated and non-labelled substrates are incubated with a desaturase. The KIE is measured by quenching the reaction prior to completion and then measuring the relative amounts of labelled vs. non-labelled products, usually via gas chromatography/mass spectrometry (GC/MS). ${ }^{12}$ Once the mol\% of the products and substrates is determined then the KIE can be calculated by the ratio of $\mathrm{k}_{\mathrm{H}} / \mathrm{k}_{\mathrm{D}}$. If the ratio is greater than one then a significant KIE is observed, but if the KIE is equal (or approximately equal) to one then no KIE is observed. To have a complete cryptoregiochemical analysis both regiospecific labelled substrates must be submitted to the reaction conditions. That is performing the left-side experiment of Scheme $\mathbf{1 . 3}$ without the right-side experiment gives no conclusive results. Interestingly, in the case of soluble plant desaturases the initial oxidation event of steroyl-ACP is insignificant compared to substrate binding/release $;{ }^{13}$ thus other techniques must be developed for soluble desaturases (see below).

A notable series of experiments to determine the cryptoregiochemistry of $\Delta^{9}$ desaturases was performed by Buist et al. in 1996. By using regiospecifically deuterated 7-thia-stearates (Figure 1.5) in direct competitive KIE experiments, they were able to probe the mechanism of membrane bound desaturation. ${ }^{12}$ The substrates were synthesized with a 7-thia mass tag, so mass spectral interference with endogenous stearates was minimized. This report concluded that there was a large KIE enhancement $\left(\mathrm{k}_{\mathrm{H}} / \mathrm{k}_{\mathrm{D}} \sim 7.0\right)$ with the 9- $d_{2}$ substrate, indicating that the initial oxidative event was most likely at $\mathrm{C} 9$ for membranous $\Delta^{9}$ desaturases. 


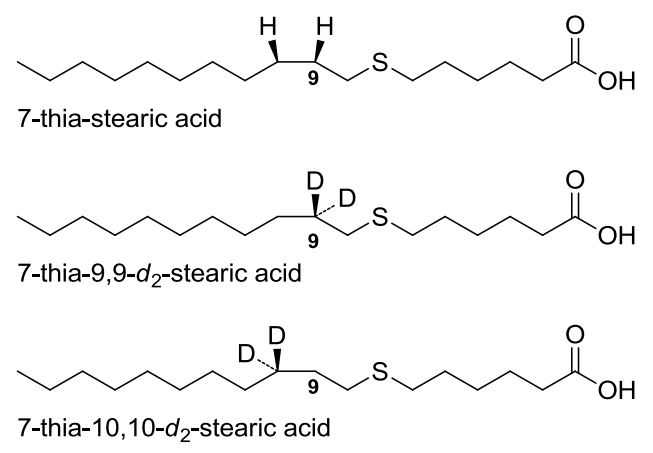

Figure 1.4 Labelled substrates for the competitive, deuterium KIE experiments of Buist and coworkers in 1996.

Advances in determining the cryptoregiochemical outcome of soluble steroylACP $\Delta^{9}$ desaturases was brought about in 2001 by Buist et al. ${ }^{13}$ Earlier deuterium KIE experiments with soluble plant desaturase enzymes were inconclusive due to the nature of soluble enzyme vs. membrane bound enzyme kinetics. However, by comparing the efficiency of oxo transfer to 9-thia and 10-thia stearates the researchers could probe the relative distance between the diiron oxidant and the substrate methylene groups (Scheme 1.4).
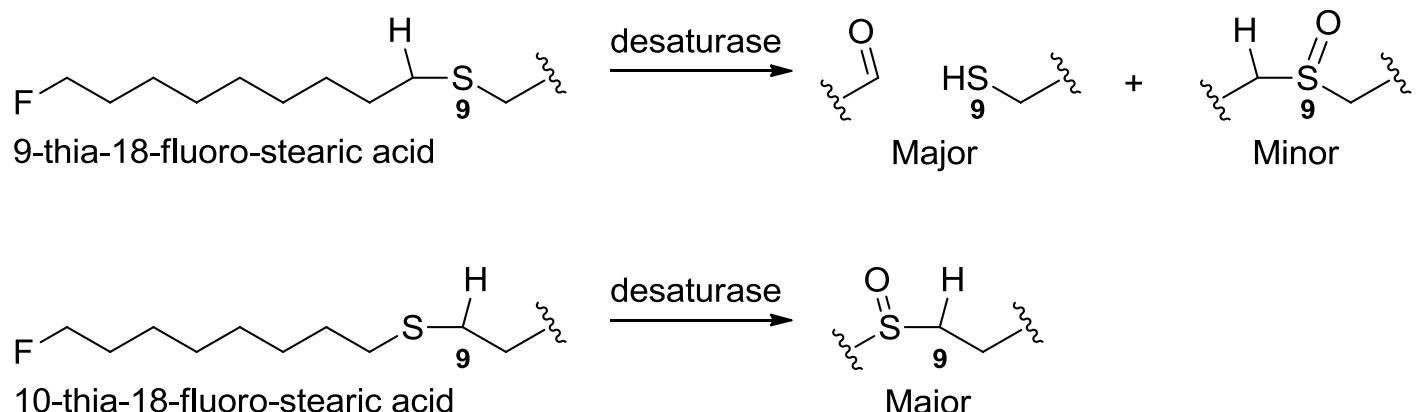

Scheme 1.4 Novel thia-stearoyl substrates from Buist and co-workers in 2001

It was found that 10-thiastearoyl analogue was converted cleanly to the corresponding sulfoxide while oxidation of the 9-thia isomer gave the corresponding 
sulfoxide in lower yield $(\sim 10 \%)$; therefore one can conclude that with soluble $\Delta^{9}$ desaturase the initial site of oxidation appears to be at the $\mathrm{C}_{10}$ position. It is postulated that a complete reversal of cryptoregiochemistry is observed with soluble plant stearoylACP $\Delta^{9}$ desaturase. This infers that not all desaturases have similar mechanisms in the initial site of oxidation and that proximity of the diiron-oxo core to the substrate is relevant in determining cryptoregiochemistry. Further investigations into the nature of all desaturase mechanisms must be conducted to grasp the complexity of this enzymatic family.

\subsubsection{Enantioselectivity and of $\Delta^{9}$ desaturases}

The enantioselectivity of hydrogen abstraction in the stearoyl-ACP desaturation is traditionally studied by using stereospecifically or highly stereoselectively deuterated or tritiated substrates. ${ }^{2}$ Generally these substrates are incubated with the appropriate desaturase, hydrolyzed, and esterified to give fatty methyl esters, which can be readily analyzed by GC/MS. An example is the use of $9-(R)-d_{1}$-stearoyl-ACP to determine the fate of the deuterium label (Scheme 1.5) resulted in loss of the isotopic label to give unlabelled olefin. ${ }^{2}$ To further prove the possibility of a pro- $R$ removal, one could initiate a KIE experiment with 1:1 mixtures of unlabelled materials and stereochemically enriched $d_{1}$ substrates both bearing a remote mass label. For all stearoyl-ACP $\Delta^{9}$ desaturases studied to date, it has been show that hydrogen abstraction occurs in a syn fashion with pro- $R$ (or equivalent) selectivity, providing the Z-alkene. 


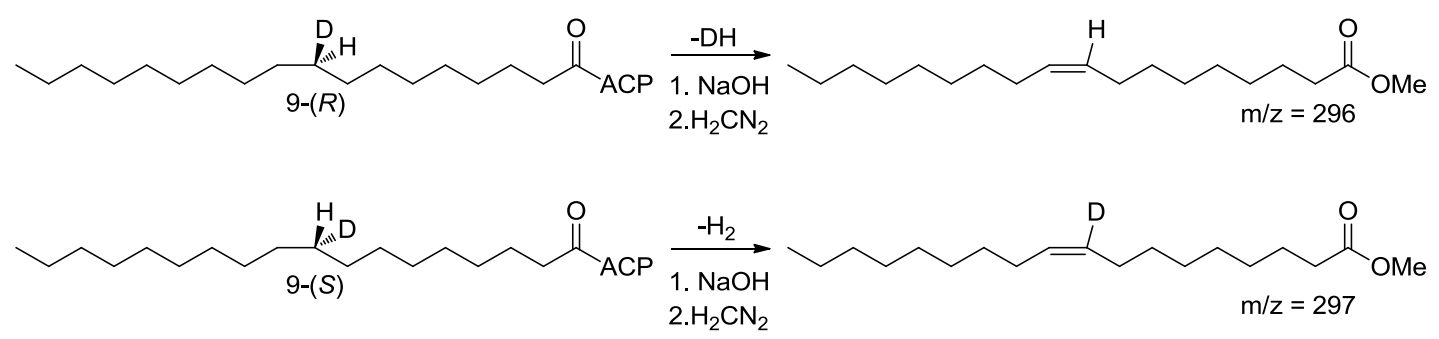

Scheme 1.5 Examples of the desaturation of stereospecifically labelled stearoyl substrates.

\subsubsection{Chemoselectivity}

The generally agreed upon model for the mechanism of the desaturation of ACPbound stearic acid is an initial hydrogen abstraction (pro- $R$ ) at the $\mathrm{C}_{9}$ or $\mathrm{C}_{10}$ positions by a high-valent diiron catalytic center to give a carbon center radical $\mathrm{Fe} / \mathrm{OH}$ pair. This radical soon collapses to the $Z$-alkene, two molecules of $\mathrm{H}_{2} \mathrm{O}$, and the reduced diiron center. However, another competing pathway involves hydroxyl rebound following the initial hydrogen abstraction to yield a minor alcohol byproduct is observed in membrane bound desaturases. ${ }^{2,7}$ This alternate pathway (Scheme 1.5) can be rationalized by observation of a similar catalytic system in MMO enzymes. The question of chemoselectivity as it applies to desaturases remains largely unanswered, but the answer could bring huge advancements to industrial and medicinal chemistry. 
1.
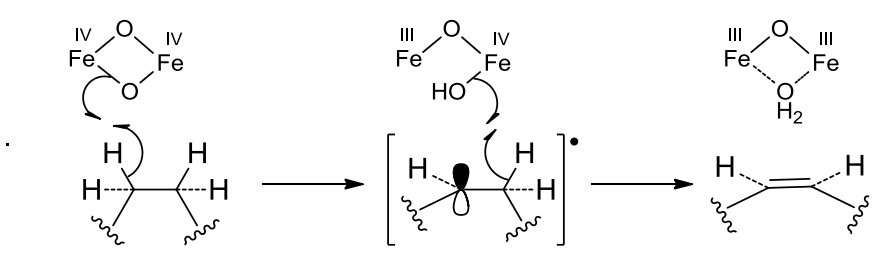

2.

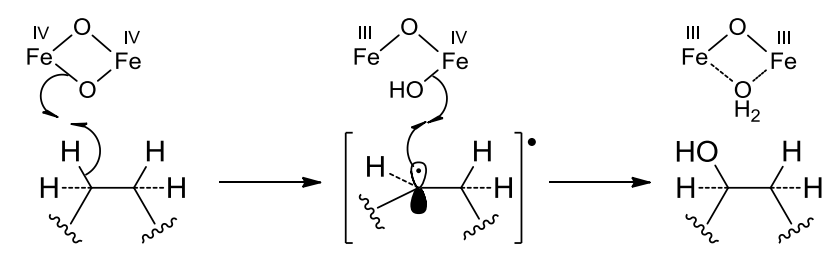

Figure 1.5 Dehydrogenation (1.) and Hydroxylation (2.)

There are three possible factors influencing the energetics of the two oxidative pathways. (1) The stabilization of carbocationic intermediates from nearby enzyme residues favor desaturation whilst radical intermediates favor hydroxyl rebound. (2) Stereoelectronic effects relating to the alignment of the $\mathrm{C}-\mathrm{H}$ bond $\alpha$ to the singly occupied molecular orbital (SOMO) of the radical intermediate. (3) The driving force of each reaction depends on the energetics of coordination of the diiron center by water (leading to desaturation) versus no ligand (leading to hydroxylation). ${ }^{7,14}$ That is to say that the enzyme residues surrounding the catalytic center adjust the preference of binding water or being free of water in the active site. Any of these three considerations have yet to be experimentally or computationally ruled out and the question of chemoselectivity of desaturase enzymes remains largely inconclusive. 


\subsubsection{Synthesis of mechanistic probes (Sulfur and chiral methylene groups)}

The synthesis of mechanistic probes is an integral part of the research on fatty acid desaturases. In this section we will discuss selected syntheses of labelled fatty acids since many of the synthetic techniques used relates to general isotopic labelling methods.
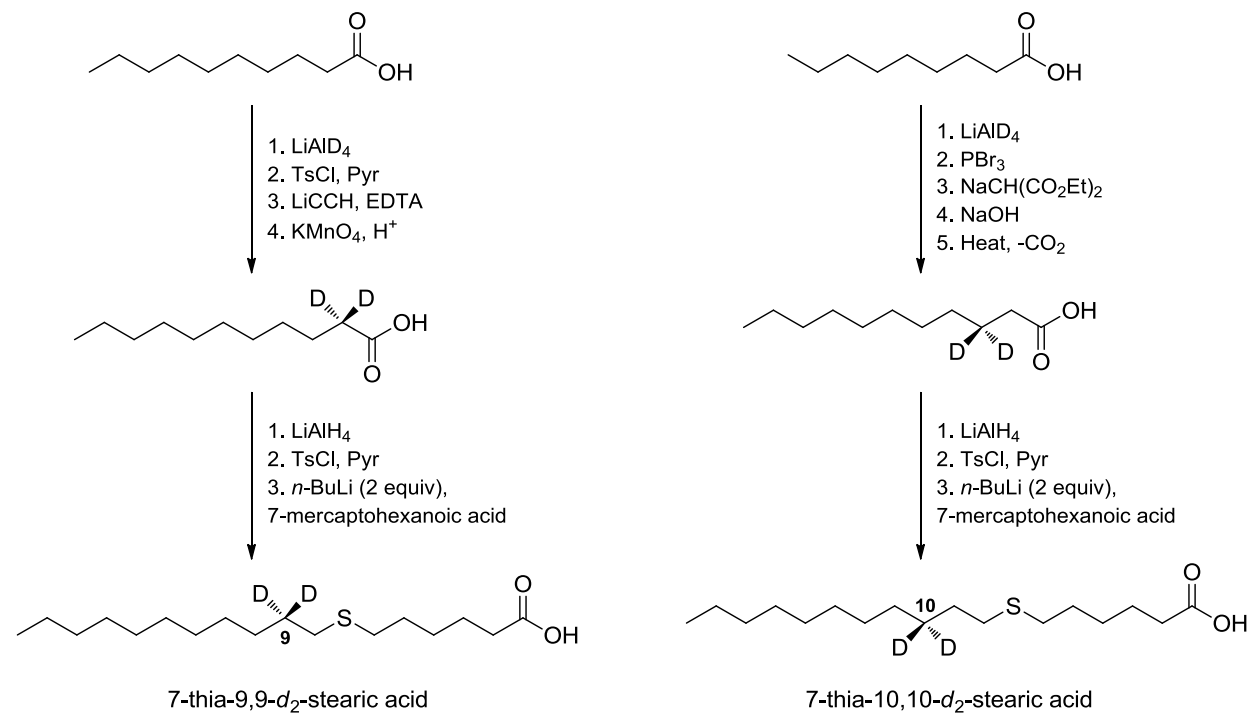

Scheme 1.6 Synthesis of regiospecific bis(deuterium) 7-thia stearic acids

The first is the regiospecific 9- $d_{2}$-7-thia isomer reported by Buist et al. in 1996 and depicted in Scheme 1.6. Through the use of $\mathrm{LiAlD}_{4}$ as their isotopic label source Buist et al. were able to produce the two regiospecifically labelled 7-thia-stearic acids as seen in Chapter 1.3.1. Upon synthesizing the requisite tosylate the Buist group opted to use 7-mercaptohexanoic acid to incorporate sulfur at $\mathrm{C}_{7}$ as a remote mass label. By using well-known chemistry, regiospecifically labelled compounds could be prepared efficiently.

In the case of generating labelled compounds with stereopurity and/or regiospecificity, many transformations must be performed to ensure high label incorporation as well as enantiomeric purity. 
An example of a stereoselective synthesis of a fatty acid was accomplished in 2007 by Buist et al. ${ }^{15}$ The synthesis depicted in Scheme $\mathbf{1 . 7}$ was performed to probe the enantioselectivity of hydrogen abstraction of the palmitoyl-ACP $\Delta^{4}$ desaturase isolated from the ivy Hedera helix. This synthesis features a Jacobsen hydrolytic kinetic resolution ${ }^{16}$ of racemic 2-dodecyloxirane as the key step in constructing a chiral center at position $\mathrm{C}_{4}$ of the palmitic acids. Upon epoxide ring opening with allyl Grignard, tosylation and subsequent reduction with $\mathrm{LiAlD}_{4}$ the construction of a chiral methylene group was accomplished.

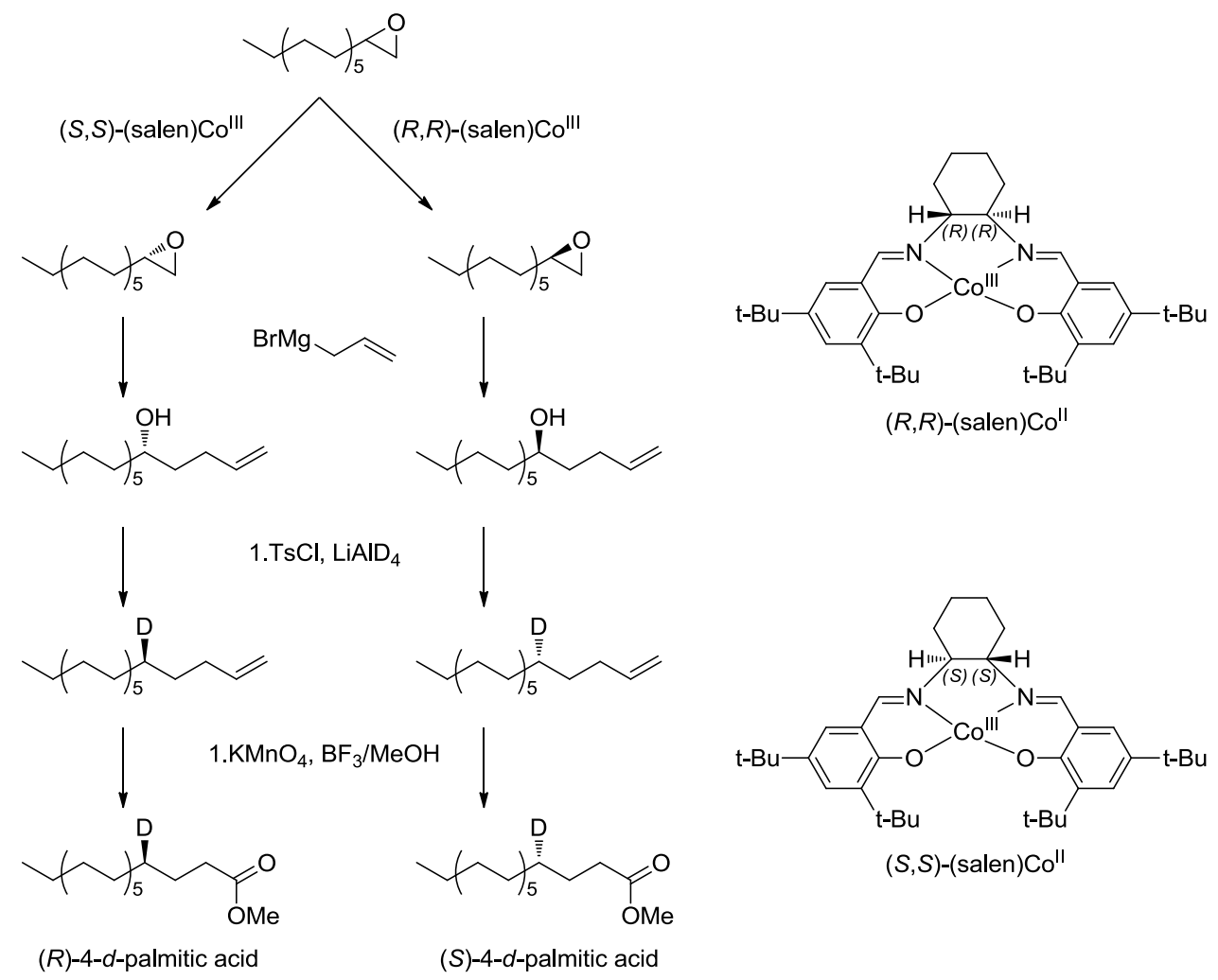

Scheme 1.7 The synthesis of enantioselective 4- $d$-stearic acids 


\subsection{Cyclopropane fatty acids}

Among the fatty acids shown in Figure $\mathbf{1 . 1}$ are some naturally occurring cyclopropane fatty acids (CFA). These unique fatty acids usually have one or more cyclopropane rings within the aliphatic chain. These unusual fatty acids were first observed by Hofmann and Lucas ${ }^{17}$ in 1950 when they isolated lactobacillic acid from huge quantities of Lactobacillus arabinosus. This novel fatty acid was eventually determined to be cis-11,12-methyleneoctadecanoic acid, a cyclopropanoid derivative of vaccenic acid. During the next decade many more CFAs were observed to be a component in cell membranes of many bacterial species. ${ }^{18} \alpha$-Mycolic acid is an example of a long chain CFA with multiple cyclopropane functionalities, and is a component in the cell wall lipids of Mycobacterium tuberculosis, a bacterial species responsible for tuberculosis. ${ }^{19}$ Realizing that cyclopropane fatty acids could be useful motifs in medicinal sciences, a systematic study of the natural occurrence CFAs was initiated. From this continuing study CFAs were observed to be present in the seed oils of Steruliaceae, Malvaceae, Tiliaceae, and Bombacaceae plant families. ${ }^{20}$

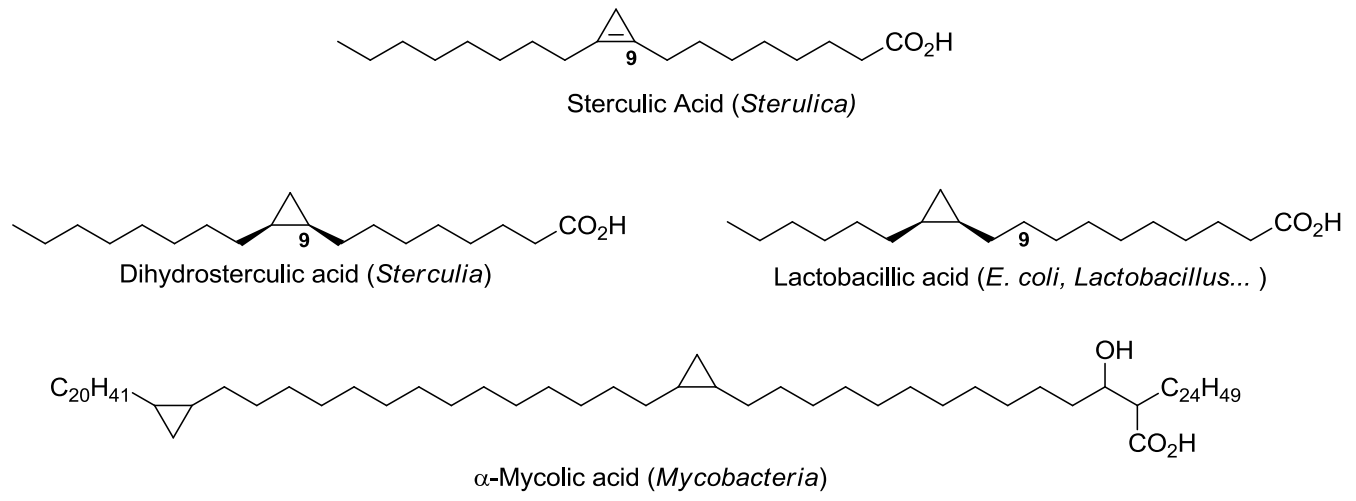

Figure 1.6 Examples of naturally occurring cyclopropane fatty acids 
In 1952 Nunn correctly elucidated the structure of sterculic acid, a rare example of highly strained cyclopropene natural product isolated from the seeds of Sterculia foetida. ${ }^{21}$ Along with sterculic acid, the saturated analog - dihydrosterculic acid - can be found in many of the above plant species. However, the seed oil of this tropical plant contains the highest amounts of sterculic acid (78\%) and cottonseed oil (Malvaceae) contains minor amounts $(\sim 1 \%)$.

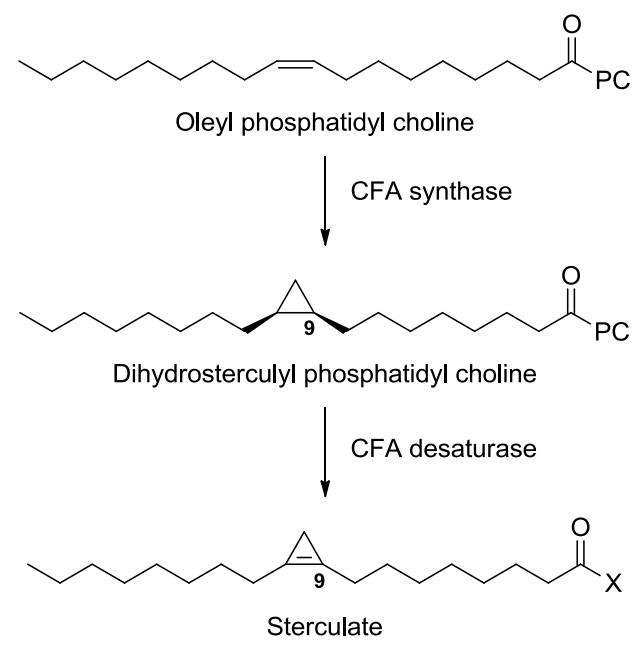

Scheme 1.8 General biosynthetic pathway of cyclopropenyl fatty acids

The current hypothesis regarding the formation of sterculic acid begins with the cyclopropanation of oleic acid following a desaturation of at $\mathrm{C}_{9}$ and $\mathrm{C}_{10}$ (Scheme 1.8). The desaturation of dihydrosterculate is novel in that it is the only known fatty acid desaturase to act upon two tertiary chiral centers rather than prochiral methylene centers (see Section 1.5.2). 


\subsection{Dihydrosterculic acid}

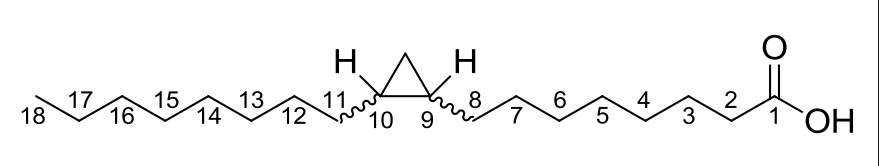

Figure 1.7 Generally accepted numbering system of dihydrosterculic acid (1)

The structure of dihydrosterculic acid is a $\mathrm{C}_{19}$ fatty acid with one cyclopropane ring at positions 9 and 10 in the cis configuration. This means that there are 2 stereocenters within the molecule and thus the possibility of having to enantiomeric forms (Figure 1.8).

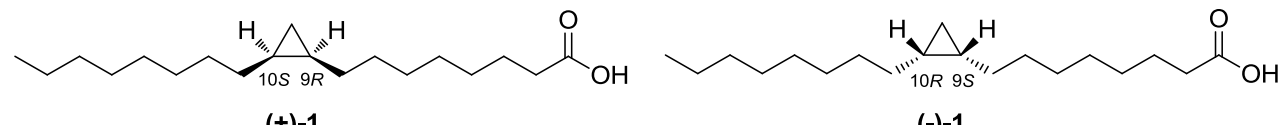

$(+)-1$

$(-)-1$

Figure 1.8 The two enantiomeric forms of dihydrosterculic acid.

The first of these isomers (+)-1 has the $9 R$ and $10 S$ configuration and can be isolated from the seeds of Litchi chinensis. ${ }^{22}$ Approximately $40 \%$ of the seed oil from the lychee fruit is composed of $9 R, 10 S$-dihydrosterculic acid. ${ }^{23}$ The second isomer (-)-1, which can be isolated from Lactobacillus plantarum, has the $9 S$ and $10 R$ configuration,. ${ }^{22}$ The fact that both of these enantiomers occur naturally suggests that both the cyclopropanation by CFA-synthase, and the desaturation by CFA-desaturase are stereospecific. However, the gene responsible for this desaturase-mediated process has not been positively identified.

The compound (+)-1 is of great to us interest due to its biological activity, and unique desaturase enzymes. This enantiomer of dihydrosterculic acid is a known inhibitor 
of SCD in animals. The exact mechanism of inhibition is not known, but a reasonable proposed pathway is that after the desaturation event the highly strained cyclopropene ring reacts irreversibly with the active site of $\mathrm{SCD} .{ }^{24}$ Unfortunately this biological activity has a large impact on the economy in terms of the agricultural industry because animals that are fed large quantities of cottonseed often succumb to physiological disorders. Therefore we can surmise that the biological activity of $9 R, 10 S$ dihydrosterculic acid has evolved as an antifeedant strategy by the above plant species.

\subsubsection{Structure determination $9 R, 10 S$-dihydrosterculic acid}

The structure of dihydrosterculic acid was first deduced by Hofmann in 1957 through synthesis and degradation methodology. ${ }^{25}$ This structure that was proposed in the 1950s was later corroborated with the development of nuclear magnetic resonance (NMR) spectroscopy and GC/MS technology.

But it was not until 2004 that the absolute stereochemistry of $L$. chinensis derived dihydrosterculic acid was elucidated by Buist et al. ${ }^{22}$ The comparison of chiroptical properties of other long chain fatty acids has been previously determined by Tocanne. ${ }^{26}$ This method involves the oxidation of cyclopropyl fatty acids to the corresponding 8-, and 11-keto carboxylic acid (Scheme 1.9). Then by separating the two regioisomers, the molar rotation $\left([\Phi]_{\mathrm{D}}\right)$ could be measured and compared to a synthetic standard. In the case of Buist et al. the chiroptical properties of $\mathbf{1 a}$ and $\mathbf{1 b}$ were in good agreement with the previously reported $12 S, 11 R$-lactobacillic acid derived keto compounds.

Within the next decade an enantioselective synthesis of $9 R, 10 S$-dihydrosterculic acid by Palko, Buist and Manthorpe. ${ }^{27}$ After undergoing Tocanne's procedure the 
chiroptical properties of their synthetic fatty acid were in good agreement with the naturally occurring product.

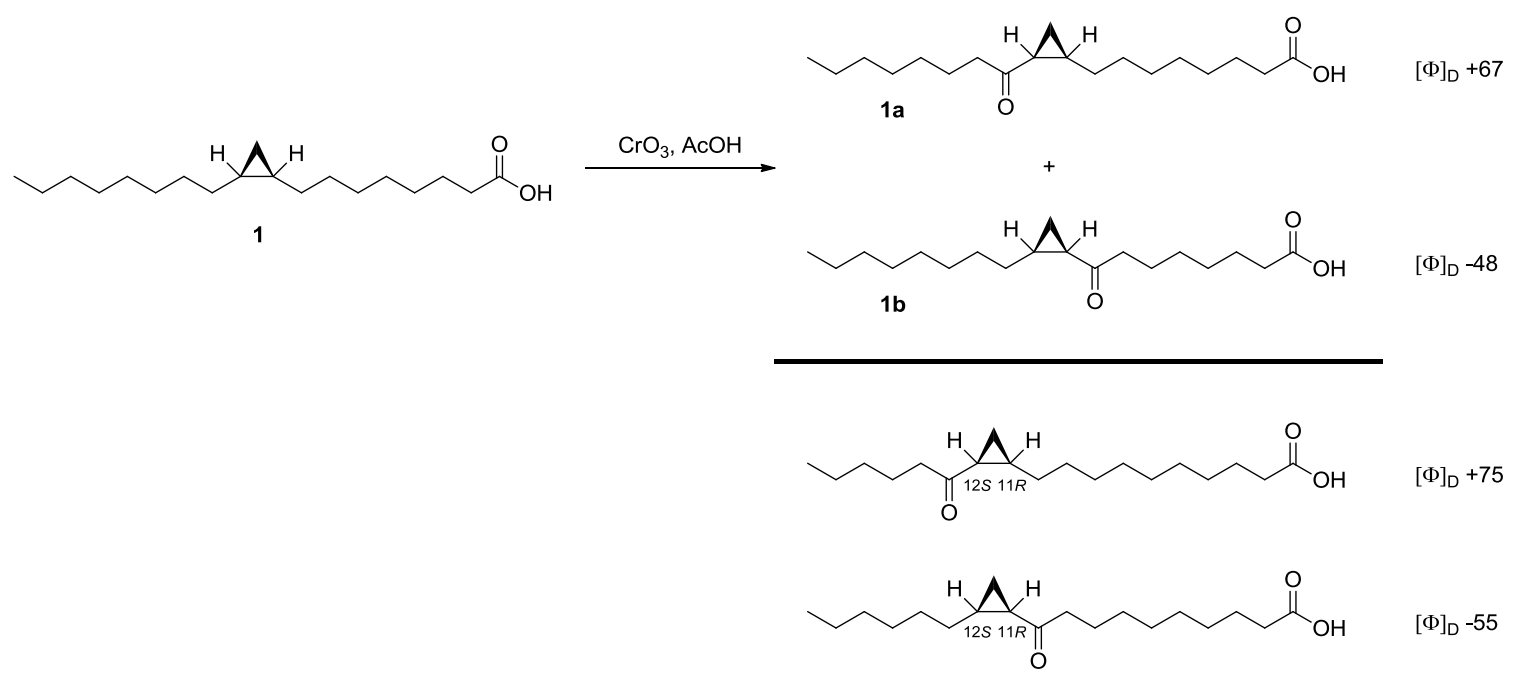

Scheme 1.9 Comparison of $[\Phi]_{D}$ values obtained for ketones derived from dihydrosterculate (1) and its 11,12-positional isomer, lactobacillic acid 


\subsubsection{Proposed biosynthesis of dihydrosterculic acid}
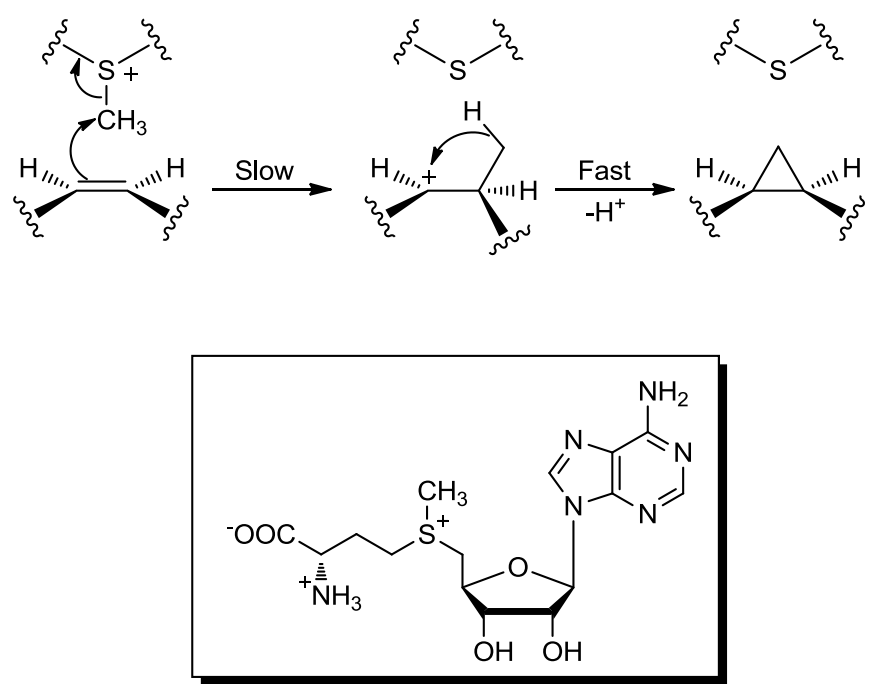

$S$-adenosyl methionine

(SAM)

Scheme 1.10 Proposed SAM-cyclopropanation mechanism of cis-unsaturated fatty acid

The methylene carbon of cyclopropyl fatty acids derives from $S$-adenosylmethionine (SAM). This activated methyl source is composed of the nucleic acid adenine, a ribose sugar, and a methyl sulfonium methionine residue (Scheme 1.10). How the bridging $\mathrm{CH}_{2}$ of the cyclopropyl group is introduced to a cis-alkene of unsaturated fatty acids was the subject of some debate in the literature. ${ }^{28}$ The leading proposed mechanism is a short-lived secondary carbocation being produced from methyl transfer. This reactive cation has been suggested to undergo a partially reversible ring closure to give the cyclopropanated product and a proton (see below).

Support for the above mechanism can be found in the results of deuterium labelling studies with Lactobacillus plantarum in the 1980's. The experiments performed by MacLean et al. used vinylic and allylic labels incorporated into oleic acid. ${ }^{29}$ The feeding experiments resulted in no loss of deuterium content indicating the lack of 
activation of these positions makes an unsaturated intermediate unlikely. Interestingly, the results of a methionine- $d_{3}$ feeding experiment were up to $17 \%$ of a $d_{1}$ (at the methylene position of the cyclopropane) product was observed along with the $d_{2}$ product. These results indicate the possibility of a fast, reversible protonation/deprotonation step after the slower methyl group transfer (Scheme 1.11). Unfortunately the manner in which CFA-synthase stabilizes the intermediate carbocation has not been elucidated.

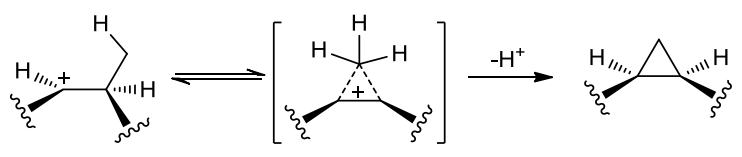

Scheme 1.11 Suggested reversible protonation/deprotonation mechanism in the formation of CFAs

Two other cyclopropanation mechanisms of oleic substrates have been described in the literature. ${ }^{28}$ The first is the insertion of a metal carbene into the olefinic fatty acids, and the second is a sulfur ylide as the activated methyl transfer regent. The presence of a metal carbene has been disproved by the absence of $\mathrm{Cu}, \mathrm{Zn}, \mathrm{Co}, \mathrm{Fe}, \mathrm{Ni}$, and $\mathrm{Mn}$ from inductively coupled plasma (ICP) analyses of cellular fractions containing CFAsynthase. ${ }^{30}$ Also with the treatment of CFA-synthase with a metal chelator like ethylenediaminetetraacetic acid (EDTA) shows no effect on turnover of the catalyst.

In the same report by Booker et al. in 2005, evidence against a mechanism involving a sulfur ylide derived deprotonation of SAM, was provided by elemental substitution experiments. First the pKa values of SAM and a selenium analogue were experimentally determined to be 11.5 and 14.1 respectivly. ${ }^{30}$ This difference of 2.6 units should in theory correspond to a 400 -fold decrease in reaction rate if SAM was deprotonated prior to methyl transfer. However, it was found that the CFA synthesis 
proceeds with a two-fold increase when using the selenium-derived isomer, and this therefore, argues against a sulfur ylide as the source of methyl transfer.

In conclusion, the most likely mechanism of SAM-mediated cyclopropanation is the formation of a secondary carbocation and collapse to the cyclic product shown in Scheme 1.10.

\subsection{Project goals}

The ultimate goal of this project is to determine the cryptoregiochemistry dihydrosterculic acid desaturase. To accomplish this, two separate stages must be completed. The first task is the isolation of the gene responsible for coding for the CFAdesaturase enzyme. And the second is the deuterium KIE studies on such an enzyme using synthetic deuterated fatty acids (Scheme 1.12). Our part in fulfilling the end goal is the synthesis of two regiospecifically and stereospecifically or stereoselectively labelled dihydrosterculic acids. Since the results of the cryptoregiochemical studies will be analyzed by $\mathrm{GC} / \mathrm{MS}$, a remote mass label $\left(\mathrm{CD}_{3}\right)$ must be installed to distinguish between the $d_{0}(\mathbf{1})$ and the $d_{1}(\mathbf{2}$ and $\mathbf{3})$ substrates.

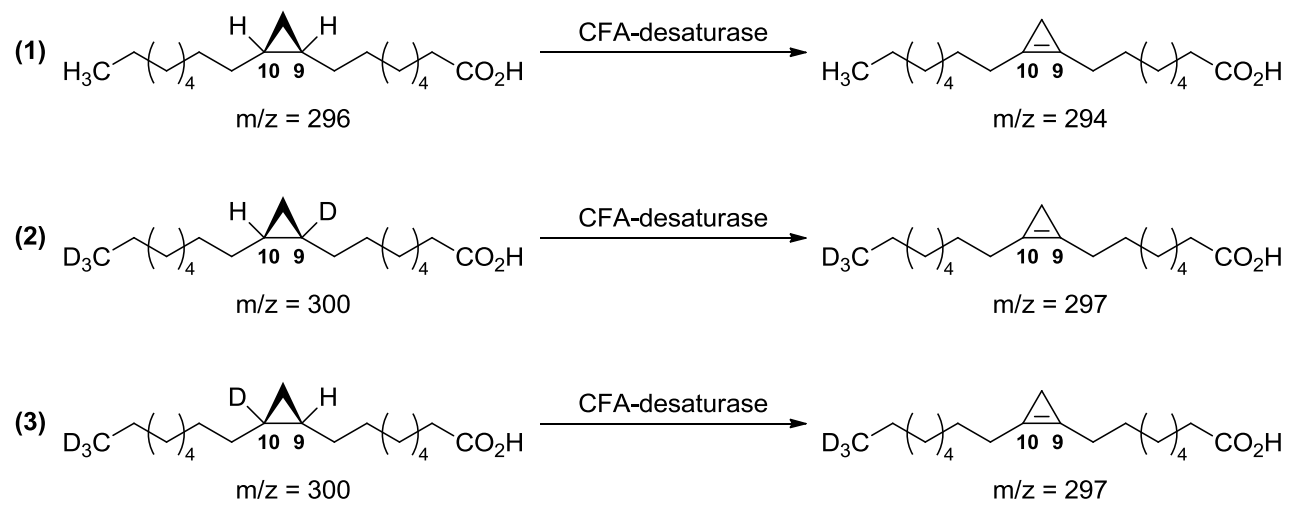

Scheme 1.12 The proposed KIE experiments with labelled dihydrosterculic acids. 


\section{Chapter: Results and Discussion (part A)}

\subsection{Introduction to synthetic methods}

This section will briefly introduce general methods of cyclopropane ring formation with focus on enantioselective methods and the review of two modern syntheses of $(9 R, 10 S)$-dihydrosterculic acid. These two syntheses will be reviewed for the capability of entry into the properly labelled compounds $\mathbf{2}$ and $\mathbf{3}$ in Scheme 1.12. That is, for our purposes we require a synthesis that can be modified to regiospecifically and stereoselectively incorporate deuterium. In addition, we must include a remote mass tag to determine the fate of our synthetic CFA after desaturation.

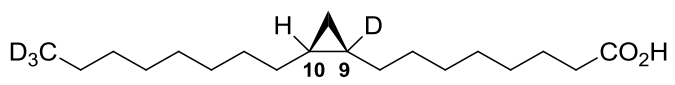

(2)

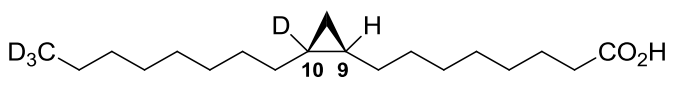

(3)

Figure 2.1 Synthetic targets of this research project

\subsubsection{Common cyclopropanation methods}

Cyclopropanes are a unique member of cyclic alkanes/alicyclics, having unusual bond angles and orbital hybridization and thus are of great interest in the synthetic community. They are valuable motifs for the synthesis of pharmaceuticals due to their enhanced oxidative stability compared to alkenes. ${ }^{31}$ Many techniques are used to prepare cyclopropanes, but the most common is the cyclization of alkenes either by the cycloaddition of a carbene or by Michael-induced ring closure (MIRC).

Dihalocarbenes have been known to cyclize alkenes to cyclopropanes since first reported by Doering in $1954 .{ }^{32}$ Although this reaction is not diastereoselective, it was an important milestone for cyclopropyl ring formation. Generally the dihalocarbene is prepared in situ from the desired haloform and potassium tert-butoxide (Scheme 2.1). 
The reaction produces a dihalocyclopropyl species which can then be used for other reactions like $\mathrm{S}_{\mathrm{N}} 2$, reduction with Raney nickel or zinc to the corresponding methylene, and the Doering-Laflamme allene synthesis. ${ }^{33}$

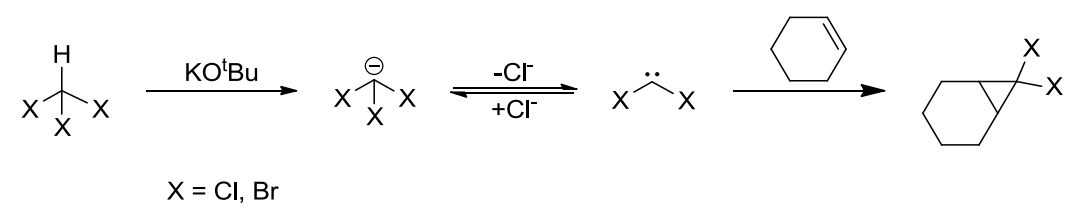

\section{Scheme 2.1 Insertion of a dihalocarbene into cyclohexene}

Another type of carbene cyclopropanation is the metal-stabilized carbene insertion into unactivated alkenes. A variety of metals and reagents can be used; examples include palladium/diazomethane and rhodium/diazoacetate systems. ${ }^{33}$ But earlier versions use $\mathrm{Zn}$ metal (or dialkyl zinc) and diiodomethane to produce a carbeneoid species. The Simmons-Smith reaction was first reported in 1959, and involves a concerted diastereoselective cyclopropanation of a variety of alkenes, where electron rich alkenes have a significant rate enhancement. ${ }^{34}$ The Furukawa modification uses the more reactive diethylzinc to help enhance the rate for tetrasubstituted and electron poor alkenes (Scheme 2.2).

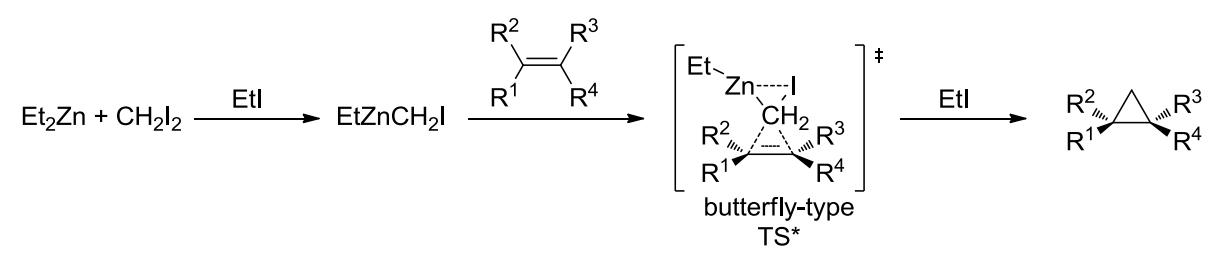

Scheme 2.2 Simmons-Smith reaction (Furukawa modification)

Lastly, the Corey-Chaykovsky cyclopropanation of $\alpha, \beta$-unsaturated carbonyl compounds is worth discussing. This reaction entails the Michael addition of a 
sulfoxonium ylide, followed by the displacement of the intermediate sulfoxonium species by the resultant enolate intermediate (Scheme 2.3) ${ }^{33}$ Although this reaction was reported by Corey et al. in 1965, recent modifications have kept it relevant. A 2008 article describes a cyclopropanation of bis(sulfoxide) alkylidenes as a diastereoselective variant. ${ }^{35}$ Through the use of a chiral sulfoxide auxiliary (and subsequent auxiliary removal) high enantiomeric excess (ee) could be obtained.

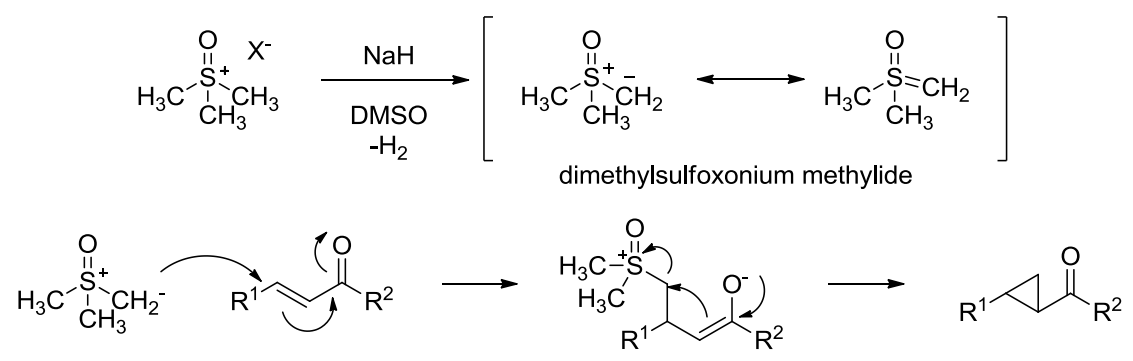

Scheme 2.3 Mechanism of the Corey-Chaykovsky cyclopropanation

\subsubsection{Corey enantioselective synthesis of 1 (2005)}

The first stereoselective synthesis of $(9 R, 10 S)$-dihydrosterculic acid was presented in 2005 by E. J. Corey and co-workers (Scheme 2.4). ${ }^{36}$ This reaction involves a key cyclopropenation step with the use of a novel dirhodium tris(diphenyltriflylimidazolidinone, DPTI) catalyst. Cyclopropenation of terminal alkynes was the primary focus of this report, showing a high ee (89-95\%) for a variety of alkynes with only $0.5 \mathrm{~mol} \%$ catalyst loading. This was the first step in the synthesis of $\mathbf{1}$ yielded cyclopropene 4 in $90 \%$ yield and $89 \%$ ee. From the cyclopropene intermediate a facially selective hydrogenation was conducted to afford cyclopropane $\mathbf{5}$ in a $90 \%$ yield. After reduction of the intermediate ester, oxidation and Wittig olefination the requisite cyclopropyl alkene (6) was attained in good yield with a cis:trans ratio of $\sim 4: 1$. The 
final reaction gave $9 R, 10 S$-dihydrosterculic acid as a white solid in an overall yield of $37 \%$ (6 steps).

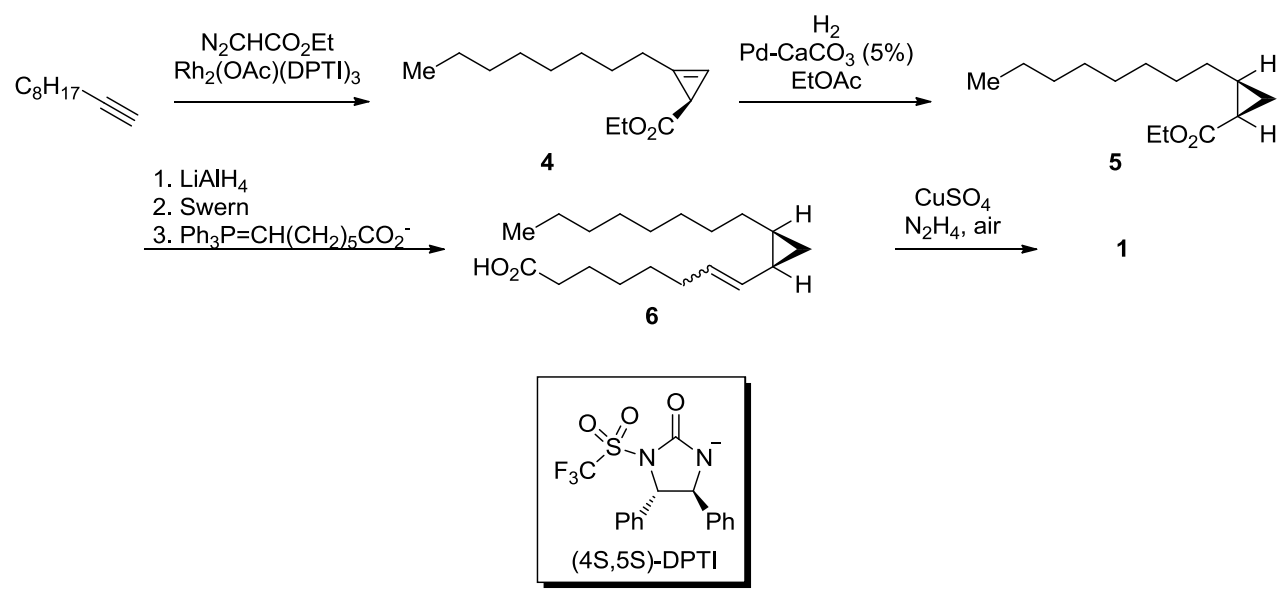

Scheme 2.4 Corey enantioselective synthesis of (1)

Although the Corey synthesis has a high overall yield, the potential of using it for incorporating of deuterium labels at the 9,10 and remote positions of dihydrosterculic acid must be considered. After a retrosynthetic analysis it was hypothesized that a 9- $d$ labelled dihydrosterculic acid could be prepared via Corey's protocol by using of $d_{1^{-}}$ ethyldiazoacetate and 10,10,10- $d_{3}$-decyne (Scheme 2.5). Conveniently, the preparation of $d_{1}$-diazo-carbonyls from $d_{2}$-diazomethane is also reported in this document (see Part $\mathbf{B}$ ). $d_{1}$-Ethyldiazoacetate could be readily prepared by the reaction of $d_{2}$-diazomethane and ethylchloroformate. Then with a similar approach to our synthesis of $(8,8,8)-d_{3^{-}}$ iodooctane (see Section 2.2), and subsequent Corey-Fuchs reaction, a remotely labelled terminal alkyne $\mathbf{8}$ could be furnished. However, strictly using the Corey cyclopropeneation approach, there is no viable pathway for obtaining the 10- $d$ labelled dihydrosterculic acid isomer since the stereocenter at position 10 is formed by a hydrogenation reaction. Also the biggest disadvantage of this synthesis is that it did not 
offer the opportunity to remove the unwanted minor enantiomer of $\mathbf{4}$ without the use of preparative chiral chromatography. Thus another approach must be used to properly synthesize deuterium-labelled dihydrosterculic acids $\mathbf{2}$ and $\mathbf{3}$ as single enantiomers.

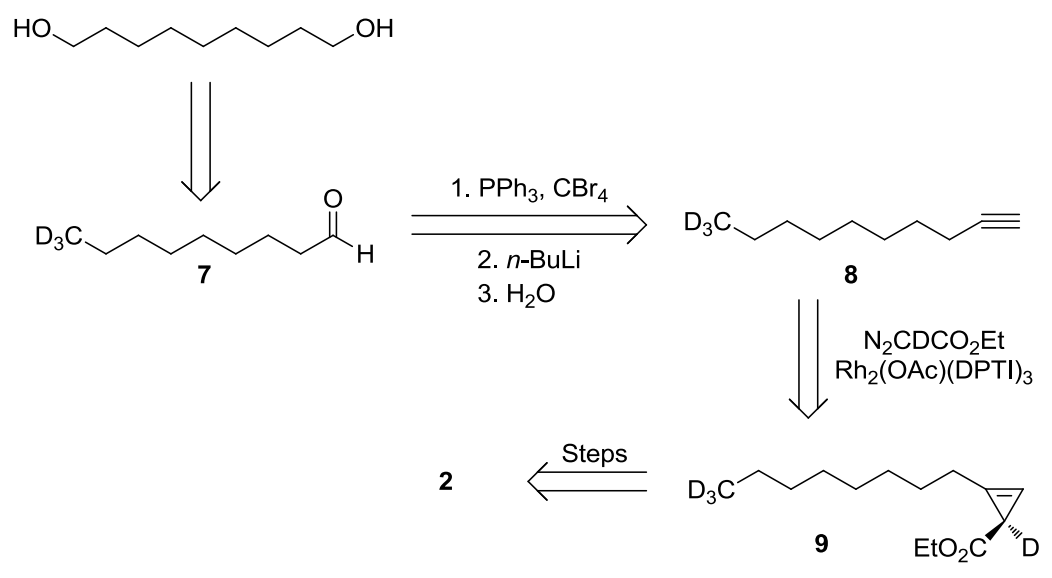

Scheme 2.5 Retrosynthetic analysis of (2) using Corey's catalytic cyclopropene formation

\subsubsection{Manthorpe enantioselective synthesis of 1 (2013)}

In 2013 Palko, Buist, and Manthorpe employed an diastereoselective route to dihydrosterculic acid by using a chiral bis(sulfoxide) auxiliary approach. ${ }^{27}$ This route encompasses the use of $p$-tolyl chiral sulfoxides as the stereochemical limiting factor, which began with the work of Anderson in $1962 . .^{37,38}$ The Manthorpe approach begins with a condensation of bis(sulfoxide) 12 with dec-9-enal to give a mixture of diastereomeric alcohols, followed by a carbodiimide-mediated dehydration to afford alkylidene 13 (Scheme 2.6). The key step in this synthesis was a Corey-Chaykovsky cyclopropanation to yield a cyclopropyl bis(sulfoxide) in good diastereomeric ratio (86:14) where the major product was the desired diastereomer. Two successive diastereoselective lithium-sulfoxide exchanges were preformed, with the most sterically hindered sulfoxide could be cleaved preferentially with $n$-butyllithium, and the second with $t$-butyllithium to yield alkene $\mathbf{1 5}$ in good yield. The final sequence utilized the 
Marshall ozonolysis protocol to afford methyl ester $\mathbf{1 6}$ and subsequent Gassman hydrolysis method to give $(9 R, 10 S)$-dihydrosterculic acid (1) in an overall yield of $14 \%$ over 7 steps from $\mathbf{1 0 .}$
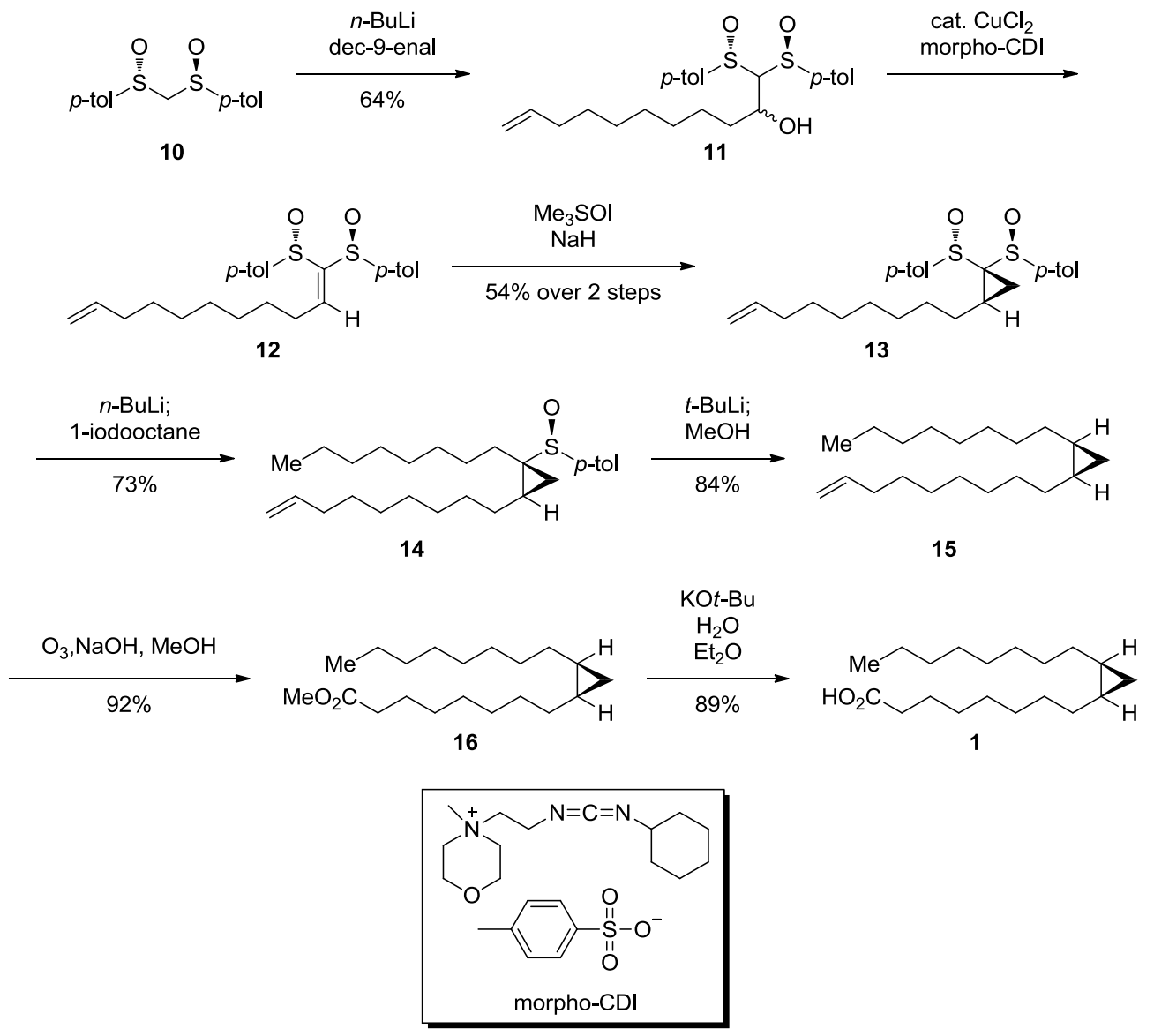

Scheme 2.6 Manthorpe diastereoselective synthesis of 1

The Manthorpe synthesis of $\mathbf{1}$ is highly modular and would allow the incorporation of the desired labels. The 9- $d$ isomer (2) could be readily accessed through the condensation of dec-9-en-1- $d$-al with bis(sulfoxide) 10. Moreover the 10- $d$ isomer (3) could be obtained via quenching the second lithium-sulfoxide exchange with MeOD. The remote mass label could be incorporated into 2 and 3 through preparation of 8,8,8- $d_{3-}$ iodooctane and using it in place of its unlabelled counterpart in the first lithium-sulfoxide 
exchange/alkylation step. Herein we will report the regiospecific and stereoselective synthesis of 9- $d$ dihydrosterculic acid (2), the regio- and stereospecific synthesis of 10- $d$ dihydrosterculic acid (3), labelled dihydrosterculic acids along with preparation of 1- $d$ dec-9-enal, and 8,8,8- $d_{3}$-iodooctane.

\subsection{Synthesis of 8,8,8- $d_{3}$-iodooctane}

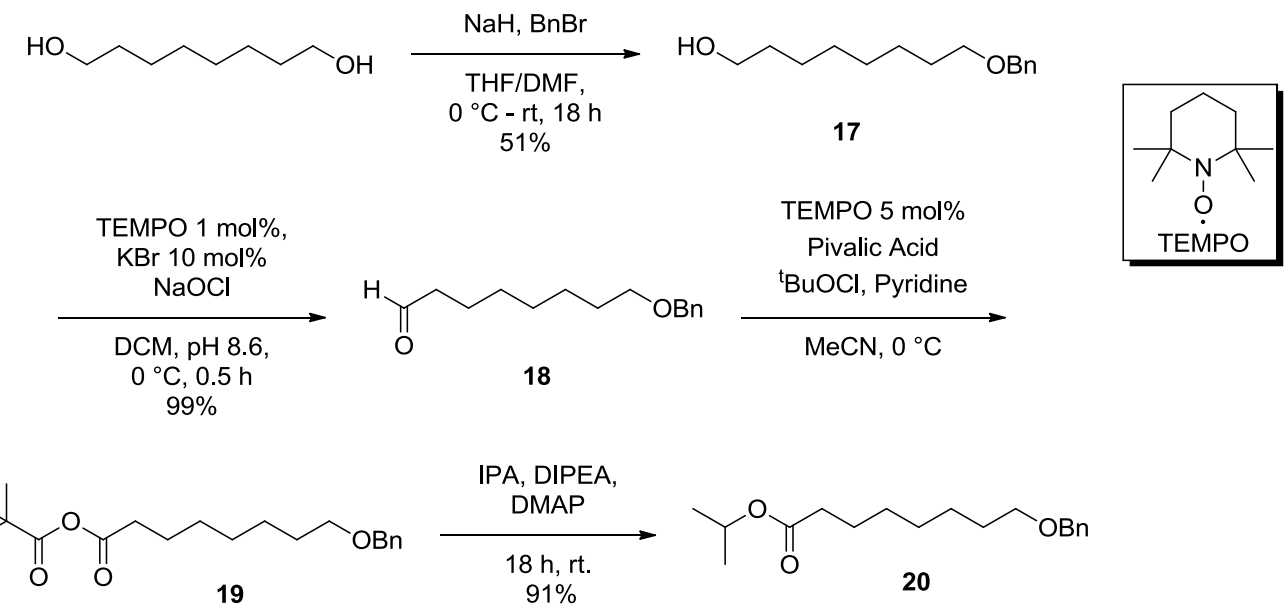

Scheme 2.7 Protection and oxidative sequence en route to labelled iodooctane

As mentioned in section 2.1.3 we required a remote mass tag to be incorporated into the labelled dihydrosterculic acids, so it would be possible to differentiate the products of the proposed KIE experiments. By using quite reliable redox chemistry it was possible to achieve such a goal. The synthesis commences with a simple monoprotection of 1,8-octanediol, where this desymmetrization step would facilitate the manipulations of one end of the molecule. The monoprotection of the $\mathrm{C}_{8}$ diol, as expected, gave a mixture of mono, di, and non-protected compounds, which were easily separable by flash column chromatography (FCC). The desired benzyl ether 17 could be cleanly converted to the corresponding aldehyde via a (tetramethylpiperidinyl)oxy radical (TEMPO) mediated oxidation. We then opted to use a novel 2-step 1-pot oxidation of the aldehyde to an 
isopropyl ester to suppress any possible transesterification. This 1-pot oxidation was first developed by Szpilman et al. in 2013 to avoid a 2-step reaction sequence and possible decomposition of an intermediate mixed anhydride. ${ }^{39}$ Although this oxidation sequence was quite laborious, toxic chromium species were avoided and high yields were achieved (90\% over 3 steps).
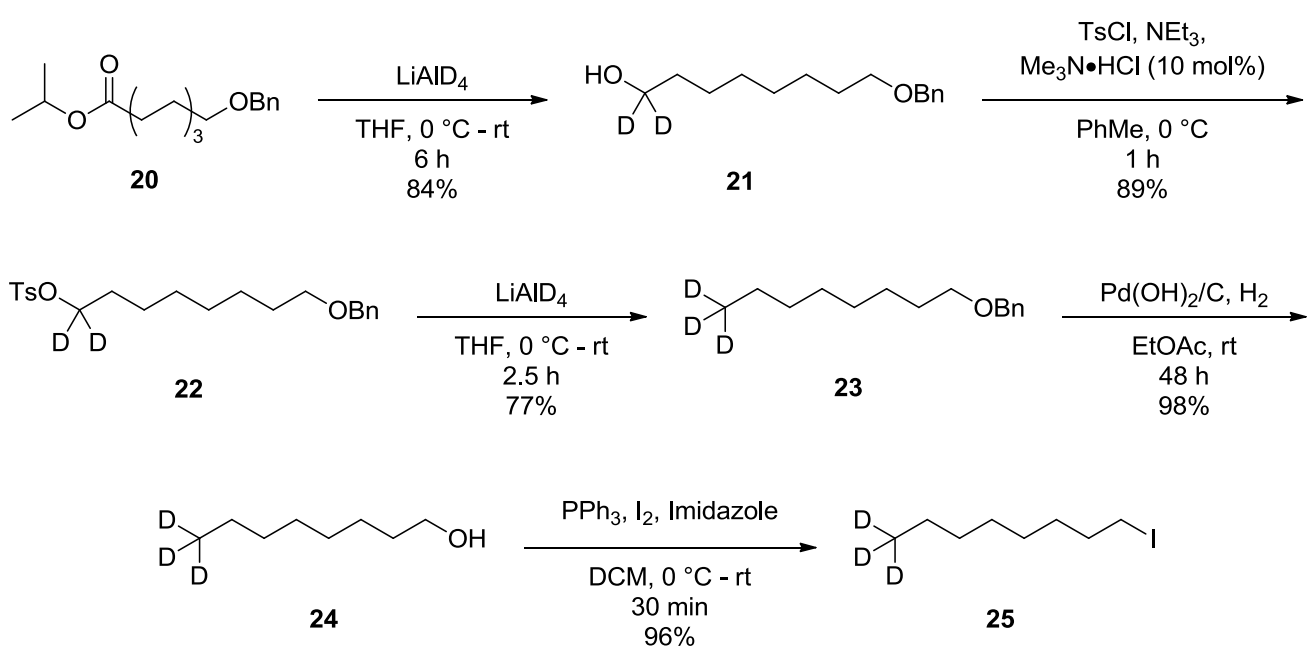

Scheme 2.8 Reductive sequence, deprotection and iodination steps toward remote mass label

With ester 20 in hand, it was promptly reduced to the $d_{2}$-alcohol in an $85 \%$ yield with no observed reductive cleavage of the benzyl ether using $\mathrm{LiAlD}_{4}$. There are many ways of quenching lithium aluminum hydride/deuteride reactions but in our hands the simplest by far is the use of solid sodium sulfate decahydrate as a proton source. Upon formation of deuterated alcohol $\mathbf{2 1}$ we explored two different tosylation procedures. The first was a standard procedure using $\mathrm{TsCl}$, diisopropylethylamine (DIPEA) as the stoichiometric base, and 4-( $N, N$-dimethylamino)pyridine (DMAP) as an activating agent. This procedure resulted in a poor yields (50-65\%), presumably due to formation of an unwanted alkyl chloride byproduct and unreacted starting material. We then turned our 
attention to the catalytic trimethylamine hydrochloride procedure reported by Tanabe in 1999. ${ }^{40}$ This protocol gave much higher yields $(89 \%)$ when compared to the above procedure, due to the novel activation of $\mathrm{TsCl}$ with $\mathrm{NMe}_{3}$ to yield a sterically unhindered potent tosylation agent $\mathrm{TsN}^{+} \mathrm{Me}_{3} \mathrm{Cl}^{-}$(Scheme 2.8). Also using toluene as the reaction solvent resulted in the removal of the byproduct chloride ion via precipitation of the $\mathrm{Et}_{3} \mathrm{~N} \cdot \mathrm{HCl}$ formed during reaction. This decreased the formation of alkyl chloride byproduct.

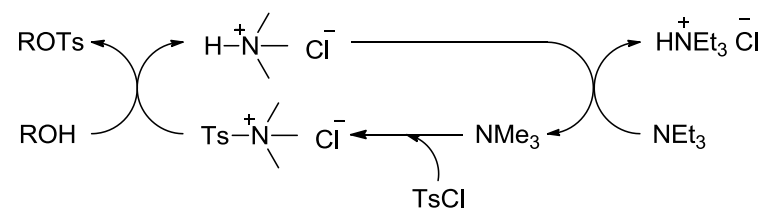

Scheme 2.9 Catalytic cycle of trimethyl amine in Tanabe's protocol

With tosylate 22 in hand a facile reduction with $\mathrm{LiAlD}_{4}$ furnished the desired tris(deuterio) methyl segment in useful yields. The next reaction was a debenzylation of the protected alcohol. There are many procedures for removing benzyl ethers, including hydrogenolysis, Lewis and Brønsted acid-promoted cleavage, and electron transfer reactions. Initially, using $\mathrm{Pd} / \mathrm{C}$ in varying amounts and various reaction solvents the debenzylation proved to be unfruitful and surprisingly challenging. It was hypothesized that a reduced sulfinate byproduct from the previous reaction could be poisoning the catalyst.

We turned our efforts toward an electron transfer process by using LiDBB as an electron source; however, this gave no positive results. Interestingly, when using classical Birch-type reaction conditions $\left(\mathrm{Li} / \mathrm{NH}_{3(1)}\right)$ the requisite alcohol was obtained in moderate to good yields $(70-80 \%)$. This procedure was very time consuming and labor intensive on 
larger scales, since the condensation of gaseous ammonia is required, as well as maintaining reaction temperatures at $-78{ }^{\circ} \mathrm{C}$ for long periods of time was quite inefficient. These factors combined to prompt us to return to hydrogenolysis conditions with a more powerful catalyst. Pearlman's catalyst $\left(\mathrm{Pd}(\mathrm{OH})_{2}\right)$ was used with higher catalyst loading, and longer reaction times to finally give tris(deuterio) alcohol $\mathbf{2 4}$ in $98 \%$. For a summary of the optimization of the deprotection step, see Table $\mathbf{1}$.

Table 1 Deprotection of benzyl ether (23)

\begin{tabular}{|c|c|c|c|c|c|c|}
\hline Entry & Reagent & $\begin{array}{c}\text { Catalyst } \\
\text { loading } \\
(\% w .)\end{array}$ & Solvent & Time & $\begin{array}{c}\text { Temperature } \\
\left({ }^{\circ} \mathrm{C}\right)\end{array}$ & Yield \\
\hline 1 & $10 \% \mathrm{Pd} / \mathrm{C}$ & 10 & EtOH & $1 \mathrm{~d}$ & rt. & no rxn. \\
\hline 2 & $10 \% \mathrm{Pd} / \mathrm{C}$ & 15 & EtOH & $1 \mathrm{~d}$ & rt. & no rxn. \\
\hline 3 & $10 \% \mathrm{Pd} / \mathrm{C}$ & 10 & DCM & $1 \mathrm{~d}$ & rt. & $>5 \%$ \\
\hline 4 & $\begin{array}{c}10 \% \\
\mathrm{Pd}(\mathrm{OH})_{2} / \mathrm{C}\end{array}$ & 10 & EtOAc & $1 \mathrm{~d}$ & rt. & $15 \%$ \\
\hline 5 & $\mathrm{LDBB}^{\mathrm{a}}$ & - & THF & $6 \mathrm{~h}$ & -78 & no rxn. \\
\hline 6 & $\mathrm{Li} / \mathrm{NH}_{3}$ & - & THF & $1 \mathrm{~h}$ & -78 & $72-80 \%$ \\
\hline 7 & $\begin{array}{c}10 \% \\
\mathrm{Pd}(\mathrm{OH})_{2} / \mathrm{C}\end{array}$ & 20 & EtOAc & $2 \mathrm{~d}$ & rt. & $98 \%$ \\
\hline
\end{tabular}

${ }^{\mathrm{a}} \mathrm{LDBB}=$ lithium 4,4'-di-tert-butylbiphenylide

Alkyl iodide $\mathbf{2 5}$ could be cleanly synthesized from $\mathbf{2 4}$ via an Appel reaction with triphenylphosphine. Due to the highly hydrophobic nature of the product, $\mathrm{PPh}_{3}$ and $\mathrm{P}(\mathrm{O}) \mathrm{Ph}_{3}$ could be triturated from solution with ice-cold hexanes. The overall yield of the preparation of $8,8,8-d_{3}$-iodooctane was $25 \%$ over 9 steps. 


\subsection{Synthesis of bis(sulfoxide) chiral auxiliary}
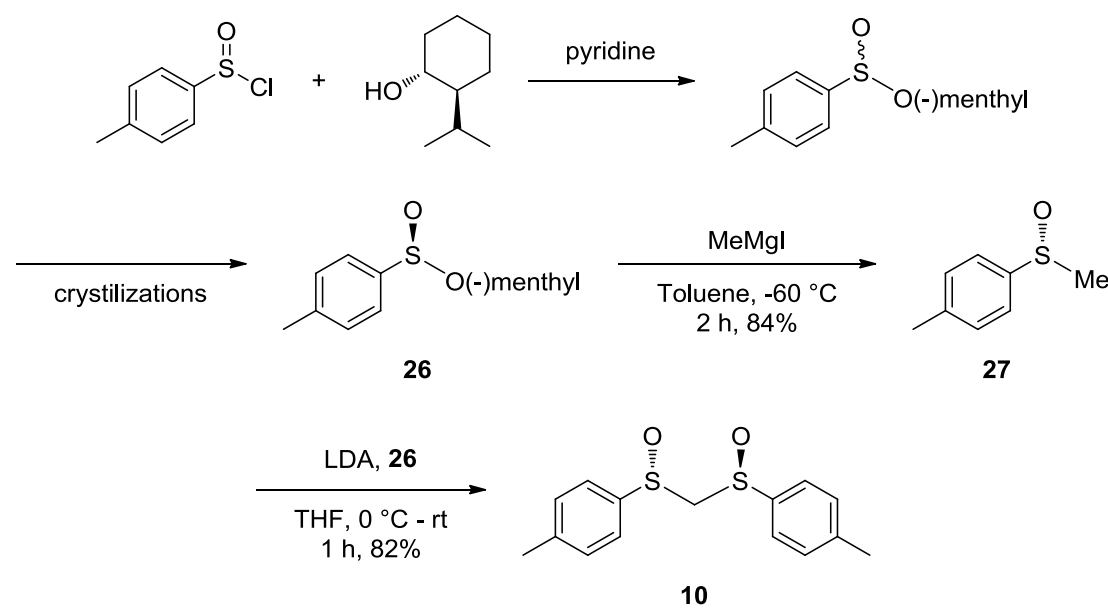

Scheme 2.10 Andersen-type preparation of chiral sulfoxide 27 and conversion to bis(sulfoxide) 10 .

For the synthesis of labelleed dihydrosterculic acids $\mathbf{2}$ and $\mathbf{3}$ we would require the production of the $\mathrm{C}_{2}$ symmetrical bis(sulfoxide) 10. There are a few different methods of producing chiral sulfoxides. Examples include resolution techniques (crystallization, kinetic), stereoselective oxidations and the derivation from chiral sulfinates. Andersen $e t$ al. developed a chiral sulfinate procedure in 1962, which would be the simplest and most cost effective method of producing $10.37,38$ This work involves a stereoselective addition of (-)-menthol to a sulfinyl chloride, selective crystallization, and inversion of stereochemistry at sulfur upon addition of a Grignard reagent.

Fortunately, the synthesis and laborious work of fabricating chiral sulfinate was part of another project in the Manthorpe lab. The procedure of purifying the diastereomeric mixture of (-)-menthyl sulfinate $\mathbf{2 6}$ includes the selective crystallization of the desired diastereomer $\left(S_{\mathrm{S}}\right)$ and epimerization of the remaining mother liquor with concentrated $\mathrm{HCl}$ (Scheme 2.11). The disadvantage to using these chiral sulfoxides is that they are extremely acid sensitive and great caution must be exercised to avoid epimerization. 


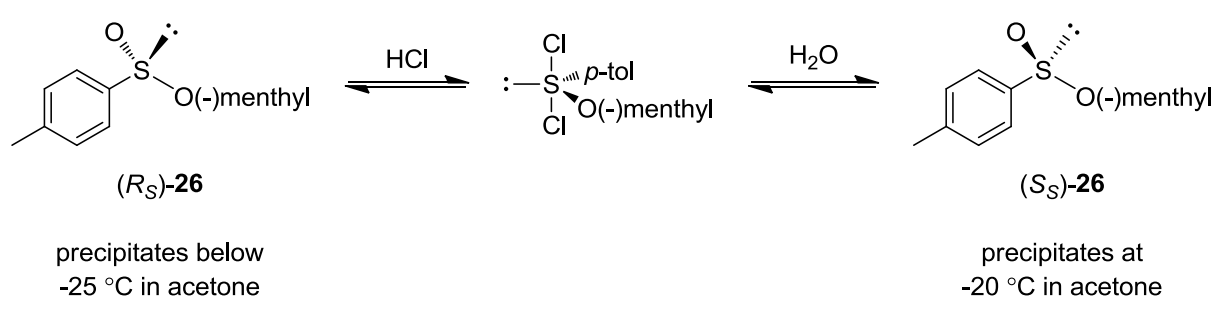

Scheme 2.11 Epimerization of chiral sulfinate with HCl

The sulfinate obtained from the previous project had to be purified, since upon standing, rapid decomposition would occur at room temperature and similarly, it would decompose slowly at $-20{ }^{\circ} \mathrm{C}$. Thus a facile purification by trituration with $45{ }^{\circ} \mathrm{C}$ hexanes:acetone (50:1) was preformed, with subsequent hot filtration, concentration and recrystalization from acetone gave pure $\mathbf{2 6}$ with a $75 \%$ recovery.

Sulfinate 26 was converted to $\left(R_{\mathrm{S}}\right)$-methyl sulfoxide 27 with methyl Grignard, where the stereochemistry was inverted, and the product was formed with an $84 \%$ yield. Bis(sulfoxide) $\mathbf{1 0}$ could now be furnished via deprotonation of methyl sulfoxide with lithium diisopropylamine (LDA). The use of two equivalents of methyl sulfoxide ylide is needed, and with more time, this reaction could be optimized to be more efficient on large scale. A facile purification was then performed by heating the crude solid to reflux in a mixture of hexanes and $\mathrm{Et}_{2} \mathrm{O}(1: 1)$ to remove excess 27 and give $\mathbf{1 0}$ in an $82 \%$ yield. 


\subsection{Synthesis of dec-9-en-1- $d$-al}

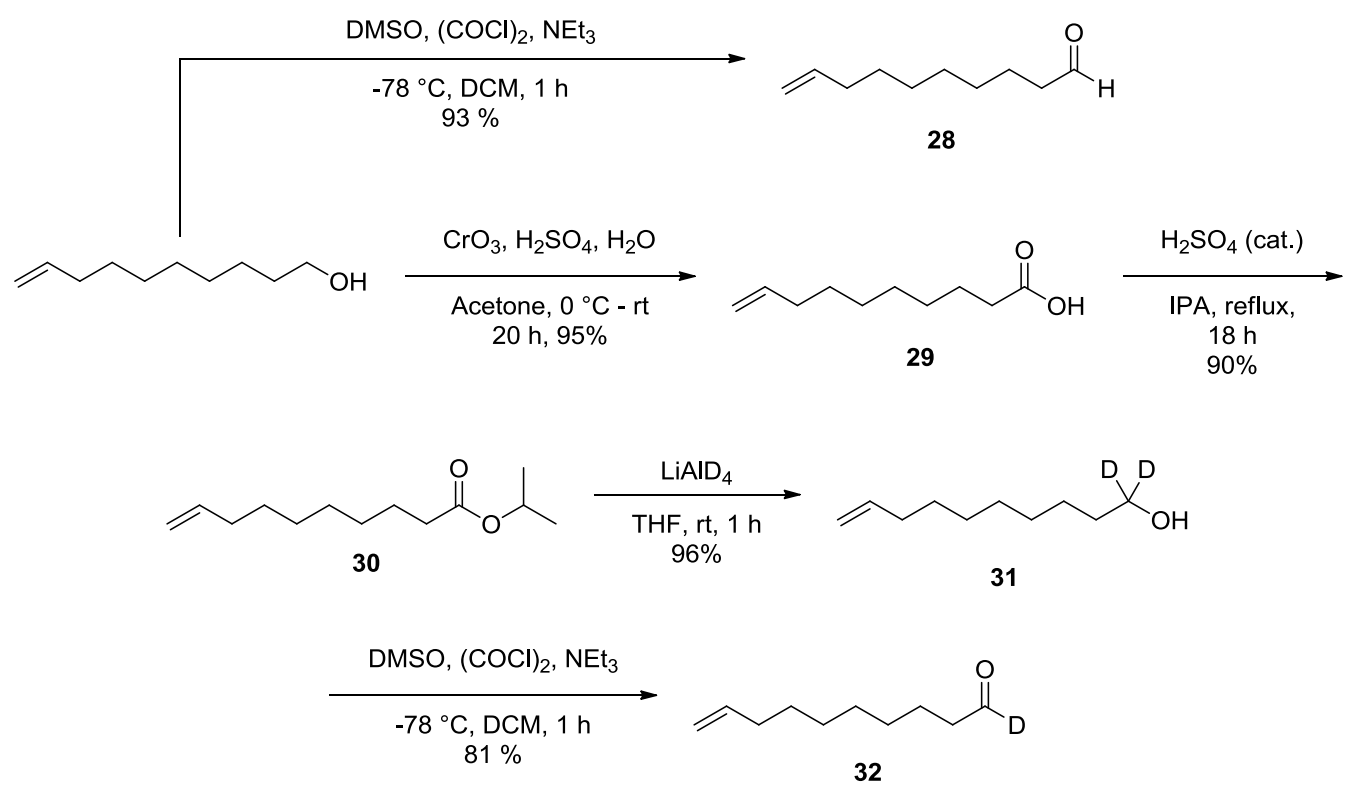

Scheme 2.12 Preparation of $d_{1}$ and $d_{0}$-aldehydes

We sought to prepare $d_{1}$ and $d_{0}$ aldehydes 28 and $\mathbf{3 2}$ from 9-decen-1-ol via a Swern oxidation. However, the $d_{1}$ material would require substantially more transformations than its $d_{0}$ analogue. Initially, a pyridinium chlorochromate (PCC) oxidation was attempted on a model substrate giving only modest yields $(70 \%)$ and required extensive purification. Thus, we turned our attention to the Swern oxidation which gave aldehyde $\mathbf{2 8}$ in a $93 \%$ yield.

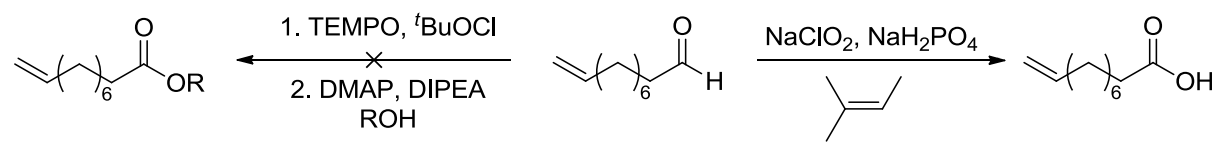

Scheme 2.13 Potential oxidations of aldehyde 28

Ideally, the preparation of aldehyde $\mathbf{3 2}$ could be prepared from its unlabelled analogue either by Szpilman's 2-step TEMPO-mediated esterification, or via a Pinnick 
oxidation and subsequent Fisher esterification. Unfortunately, an attempted reaction with Szpilman's conditions resulted in a complex mixture by NMR, where the alkene moiety was compromised. The proposed Pinnick oxidation was never attempted since the necessary hypochlorous acid scavenger - 2-methyl-2-butene - was unexpectedly expensive ( $\$ 80$ for $5 \mathrm{ml}$ ) and would be quite costly on large scale. These two methods were again an attempt to avoid toxic chromium oxidations; therefore we decided to resort to a Jones oxidation of 9-decen-1-ol since it is highly effective. With the resulting carboxylic acid $\mathbf{2 9}$ in hand, a simple Fisher esterification afforded isopropyl ester 30, and reduction with $\mathrm{LiAlD}_{4}$ gave 9-decen-1,1- $d_{2}$-ol in high yield. With access to the bis(deuterio) alcohol 31, a Swern oxidation was preformed to give aldehyde 32 with an overall yield of $66 \%$ over 4 steps.

\subsection{Synthesis of Dihydrosterculic acids (2) and (3)}

These syntheses are modeled after the diastereoselective synthesis of Palko, Buist, and Manthorpe in 2013. At the heart of this procedure is the diastereoselective preparation of cis-cyclopropyl alkanes using chemistry reported by Marek et al. in

$2008 .^{35}$ This report includes the use of a chiral bis(sulfoxide) auxiliary to control the Corey-Chaykovsky cyclopropanation, and selective lithium sulfoxide exchange to incorporate an alkyl moiety in the cis configuration. Here we will discuss our synthesis of the two deuterated dihydrosterculic acids $\mathbf{2}$ and $\mathbf{3}$. 


\subsubsection{Synthesis of Cyclopropyl fatty acid (2)}
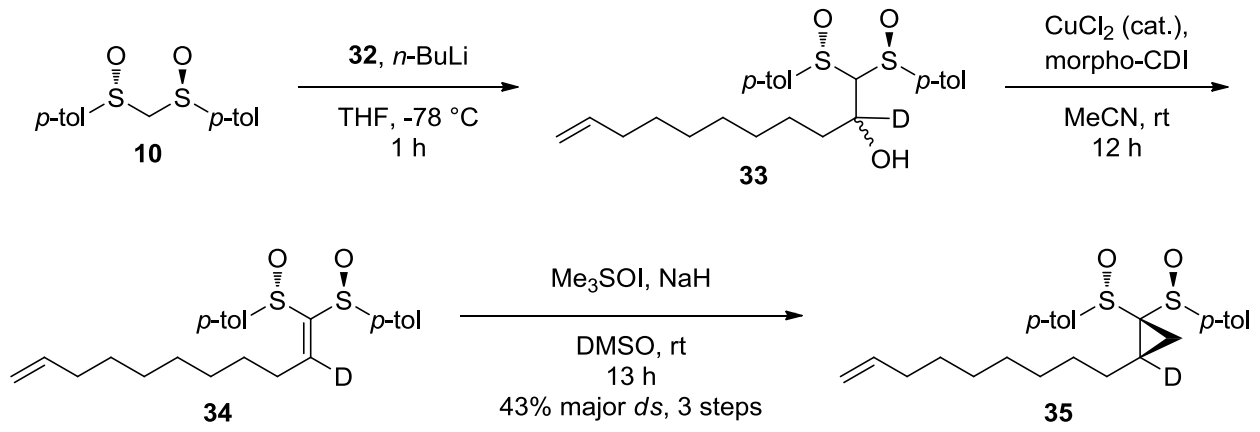

Scheme 2.14 Preparation of cyclopropyl bis(sulfoxide) (35)

The reaction sequence was initiated by the condensation of deuterated aldehyde 32 with chiral auxiliary $\mathbf{1 0}$ to produce a mixture of diastereomeric alcohols and minor amounts of dehydrated alkylidene 34. This crude mixture was semi-purified by FCC and immediately dehydrated via a carbodiimide-mediated reaction. Here by qualitative NMR analysis it could be determined that the labelling of alkenyl position of $\mathbf{3 4}$ with deuterium was achieved. Regrettably, due to the complexity of the spectra it was not possible to determine a quantitative $\% \mathrm{D}$ incorporation at this stage.

Alkylidene bis(sulfoxide) $\mathbf{3 4}$ was observed to be unstable to chromatography and thus crude mixture was filtered through Celite $^{\circledR}$ and a short pad of silica and then immediately submitted to the Corey-Chaykovsky cyclopropanation reaction as to reduce decomposition. The yields of the aldehyde addition and dehydration reactions were quite poor due to a proposed alkene migration/Evans-Mislow rearrangement (Scheme 2.15). ${ }^{27}$ This type of degradation pathway would affect $\alpha$-unbranched compounds like 33, since rearrangement is more likely to occur. 

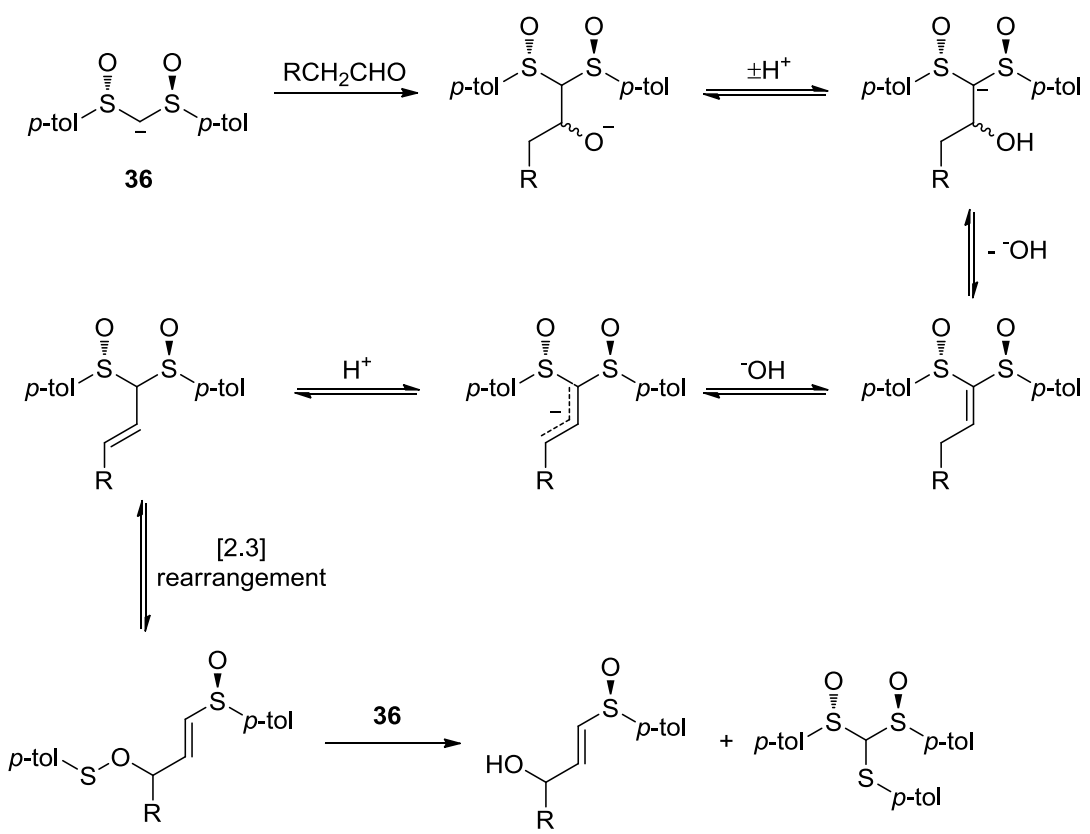

Scheme 2.15 Proposed degradation of bis(sulfoxide) (33) and (34)

Manthorpe and co-workers reported the use of a $20 \%$ EtOAc in toluene as their chromatographic elution solvent for the purification of the non-deuterated variant cyclopropyl bis(sulfoxide) $\mathbf{3 5}$ and its diastereomer and obtained a 35\% yield over three steps. We decided to undertake the task of optimizing the chromatographic separation of these two diastereomers. Initially it was determined that toluene and carbonyl-containing solvents were necessary, as absolutely no separation could be observed with solvents like $\mathrm{Et}_{2} \mathrm{O}$, DCM and $\mathrm{MeCN}$. Upon extensive TLC analysis we discovered that 3-methyl-2butanone in toluene had a large effect on separation and resolution of individual spots. With this knowledge we could tune the solvent system with non-polar components to keep the retention factors at desired magnitudes (0.25-0.30). As a second measure to assist the purification of these compounds we used finer mesh silica (see experimental section) to increase solid phase/mobile phase interactions. With the optimized 
purification protocol and iterative chromatography we were pleased to obtain diastereomerically pure 36 in a $43 \%$ yield over three steps.

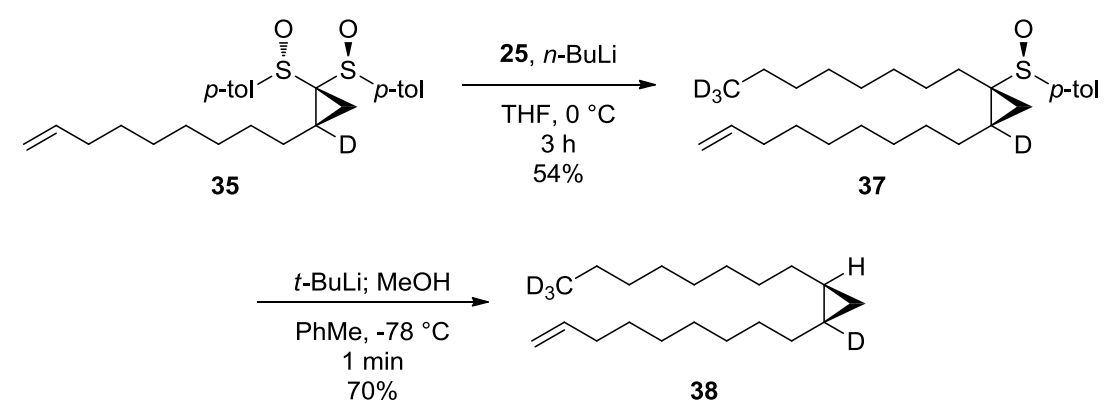

Scheme 2.16 Selective lithium sulfoxide cleavages of (35) and (37)

After purification of cyclopropyl bis(sulfoxide) 35 we needed to perform the regioselective lithium-sulfoxide exchange sequence to install the $\mathrm{C}_{8}$ branch containing the remote mass label. It has been proposed by Marek that the regioselectivity arises from release of steric strain surrounding the cyclopropane ring and steric bulk of the base that is used. Nevertheless the possibility of subtle electronic and orbital alignment factors could be at work here.

The initial procedure for the first sulfoxide procedure calls for the use of 10 equivalents of alkyl iodide. Preferring not to use more of our precious labelled alkyl iodide 25 than necessary, we implemented the use of only 5 equivalents. Sulfoxide 37 was furnished in a 54\% yield with recovery of $75 \%$ of initial alkyl iodide $\mathbf{2 5}$. The low reaction yield was most likely due to numerous sulfoxide byproducts observed in the crude NMR. To our delight, purification of sulfoxide $\mathbf{3 7}$ was achieved; however, multiple iterations of chromatographic purifications were necessary to ensure high purity. Furthermore, it was at this point that more spectroscopic evidence of a high $\% \mathrm{D}$ 
incorporation was achieved by virtue of the minimization of splitting from the only discernible cyclopropane peak in ${ }^{1} \mathrm{H}$ NMR spectra.

The final sulfoxide cleavage via ${ }^{t} \mathrm{BuLi}$ proceeded smoothly to furnish alkene $\mathbf{3 8}$ in a $70 \%$ yield. This modest yield was likely due to the slight volatility of this $\mathrm{C}_{20}$ alkene and perhaps some material was lost during concentration. Finally at this point we could clearly observed each cyclopropyl proton by ${ }^{1} \mathrm{H}$ NMR and quantitatively determine a 98\% D incorporation at C9.

For the completion of $\mathbf{2}$ we decided to explore the ozonolysis of alkene $\mathbf{3 8}$ directly to acid 2 by using an oxidative work-up. The first method that was attempted was ozonolysis, subsequent $\mathrm{H}_{2} \mathrm{O}_{2}$ /formic acid addition and reflux. This oxidative work-up resulted in a complex mixture of aldehyde, suspected ozonide product(s), and small amounts of carboxylic acid. The second oxidative work-up procedure that was attempted was the addition of Jones reagent after complete reaction with ozone (assessed by TLC). To our dismay, alkene $\mathbf{3 8}$ was not soluble in acetone at $-78{ }^{\circ} \mathrm{C}$, thus DCM was used as a co-solvent to obtain full ozonide formation. After the addition of Jones reagent and warming to room temperature no carboxylic acid formation had occurred, only the isolation of a suspected ozonide product. With the route directly to carboxylic acid 2 from alkene 38 proving unfruitful, we returned to the original Marshall ozonolysis procedure reported by Manthorpe. 


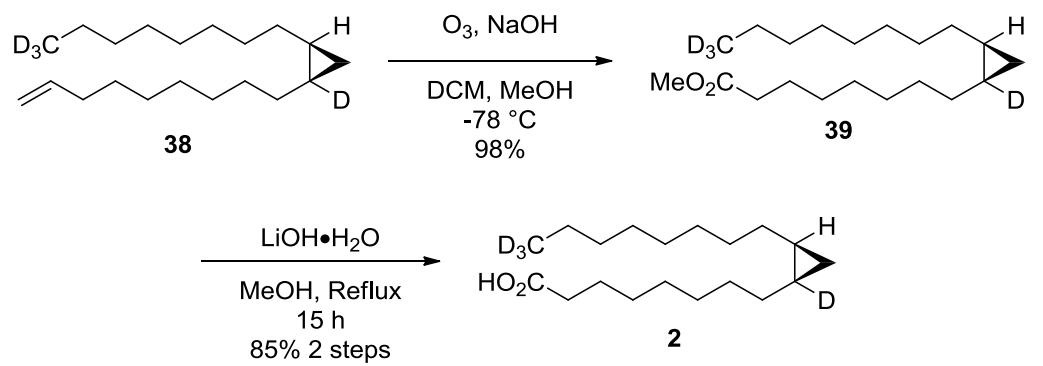

Scheme 2.17 Completion of (2) via Ozonolysis and Hydrolysis progression

Ozonolysis reaction mechanisms have been studied quite extensively by Criegee in 1975 and later validated thorough the years by ${ }^{17} \mathrm{O}$ NMR spectroscopy. ${ }^{41,42}$ Ozonolysis commences with the [1,3]-dipolar addition of ozone across the alkene give a 1,2,3trioxolane that decomposed to carbonyl oxides and aldehydes that can also undergo [1,3]dipolar additions to form a secondary 1,2,4-trioxolane product (Scheme 2.18). However, the Marshall ozonolysis conditions $(\mathrm{NaOH} / \mathrm{MeOH})$ act on intermediates 40 and $\mathbf{4 1}$ instead of directly on ozonide product like commonly employed reductive work-up procedures.

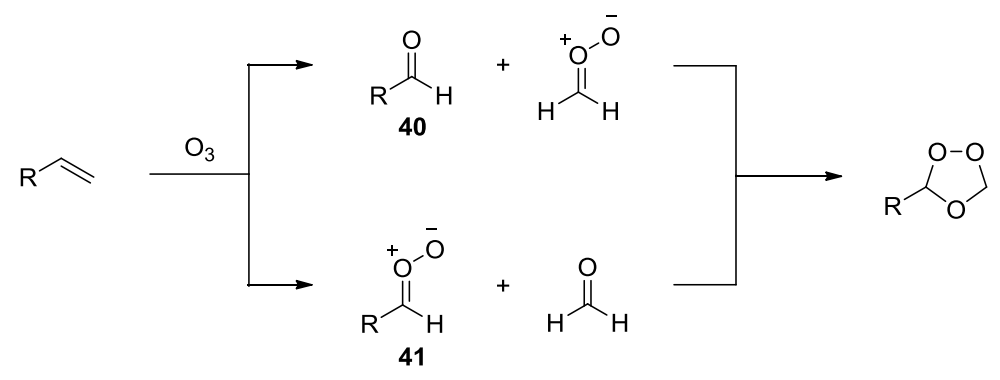

Scheme 2.18 Criegee mechanism of ozonide formation 


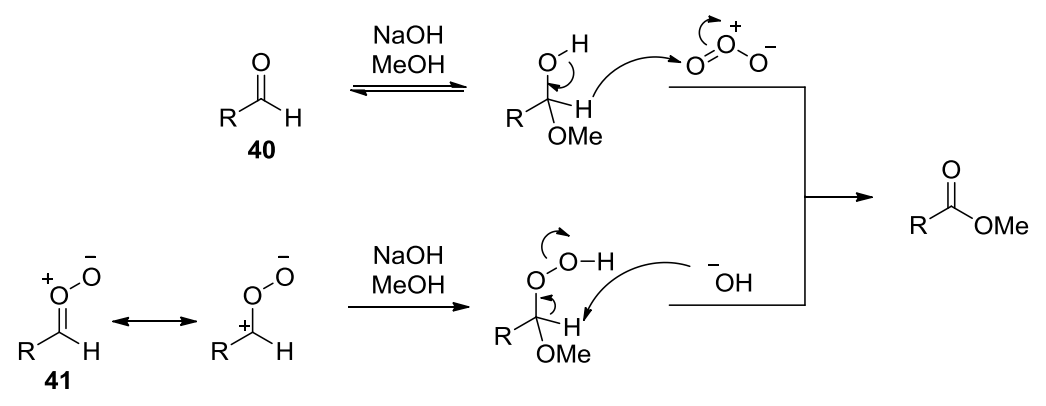

Scheme 2.19 Proposed Marshall ozonolysis mechanism.

The oxidative cleavage of alkene $\mathbf{3 8}$ proceeded smoothly giving methyl ester $\mathbf{3 9}$ in good yields, with a $10 \%$ suspected ozonide impurity. This impurity has yet to be corroborated as an ozonide, but the chemical shifts of 3 individual signals in ${ }^{1} \mathrm{H}$ NMR lend credence to such an idea. Nevertheless, we obtained moderate quantities of methyl ester 39 and perform small scale test reaction for the hydrolysis. The main limiting factor for hydrolysis on fatty methyl esters is solubility. From the report by Manthorpe et al. in 2013, Gassman amide hydrolysis procedure $\left(\mathrm{KO}^{t} \mathrm{Bu}, \mathrm{H}_{2} \mathrm{O}\right.$, THF) was used. Unfortunately, in our hands these results were not reproducible on small scale, thus we turned our efforts toward a $\mathrm{LiOH}$ facilitated hydrolysis in $\mathrm{MeOH}$. Again, small scale hydrolysis reactions were used to test the efficacy of this procedure. In doing so we observed that even crude methyl ester ( $10 \%$ impurity) could be converted to the desired carboxylic acid. It was also evident that under these conditions $(\mathrm{LiOH} / \mathrm{MeOH})$ that the contaminant (suspected ozonide) would be completely converted to an aldehyde, which was easily separable from desired acid 2 by chromatography. Upon repeating $\mathrm{LiOH} / \mathrm{MeOH}$ hydrolysis procedure with the remaining crude ester we obtained an $85 \%$ yield over 2 steps. We are pleased to report that the modification of the Manthorpe 
group's synthesis of dihydrosterculic acid afforded us our desired $(9 R, 10 S)-9-d_{1}$ dihydrosterculic acid 2 in 14\% yield over seven linear steps.

\subsubsection{Synthesis of Cyclopropyl fatty acid (3)}
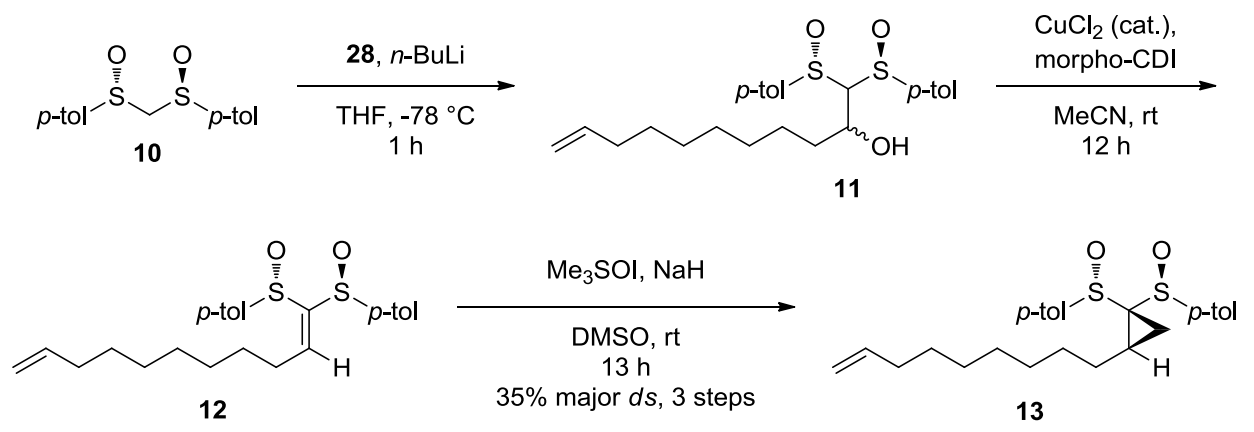

Scheme 2.20 Preparation of cyclopropyl bis(sulfoxide) (13) en route to (3)

To start the synthesis of $(9 R, 10 S)-10-d_{1}$-dihydrosterculic acid $\mathbf{3}$ was an exact replication of the above synthesis of cyclopropyl bis(sulfoxide) 35, but in this case the non-labelled aldehyde $\mathbf{2 8}$ would be used to incorporate hydrogen rather than a deuterium at position C9 (in the final product). Similarly, the condensation of bis(sulfoxide) $\mathbf{1 0}$ and aldehyde $\mathbf{2 8}$ yielded a mixture of diastereomeric alcohols and a minor unsaturated alkylidene 12. The crude mixture was once again semi-purified and submitted to dehydration conditions with morpho-CDI followed by Corey-Chaykovsky cyclopropanation. With the aforementioned chromatography conditions we obtained pure 13 in a $35 \%$ yield over the three steps. 


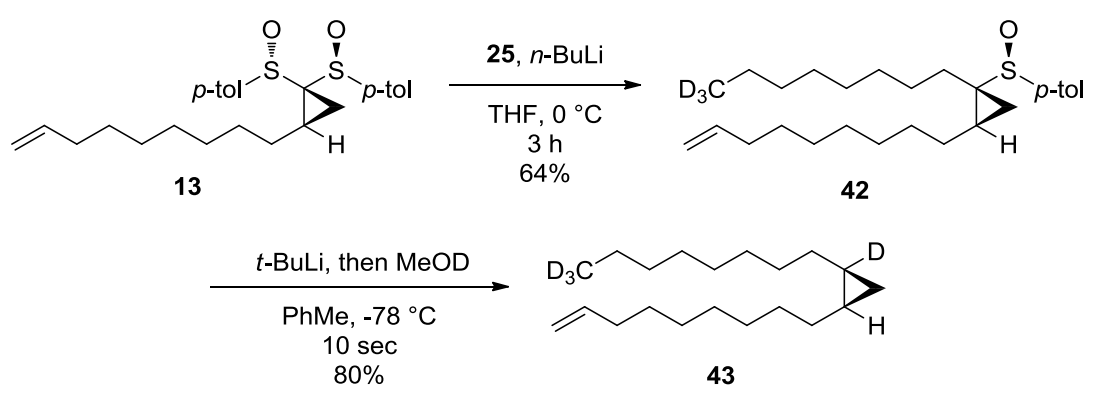

Scheme 2.21 Selective lithium sulfoxide exchanges of (13) and (42)

Continuing the preparation of dihydrosterculic acid $\mathbf{3}$, we again sought to perform the selective lithium-sulfoxide exchanges just as before. The first exchange and alkylation with mass labelled iodooctane $\mathbf{2 5}$ progressed as expected with a challenging purification and we obtained cyclopropyl sulfoxide in a $64 \%$ yield and $70 \%$ of 25 was recovered.

The second lithium-sulfoxide exchange and subsequent deuteration by $\mathrm{MeOD}$ was not as simple as we initially thought. Initially, without anticipation of problems the reaction was performed as reported and we obtained $<5 \%$ deuterium incorporation. The key observation during this procedure was a colour change from light yellow to a deep red colour upon dropwise addition of ${ }^{t} \mathrm{BuLi}$ (3 equivalents). The former yellow colouring is a typical colour observed for the formation of saturated alkyllithium compounds, whereas the red can be observed with metalated aromatic rings. Going back to the original paper by Marek, he reports unwanted protonation reaction during the first sulfoxide cleavage if less than 3 equivalents of $n$-butyllithium were used. He proposes that the ortho protons on the $n$-butyl $p$-tolyl sulfoxide are responsible for the unwanted protonation; however, deprotonation of the tolyl methyl group cannot be ruled out (Scheme 2.22). 


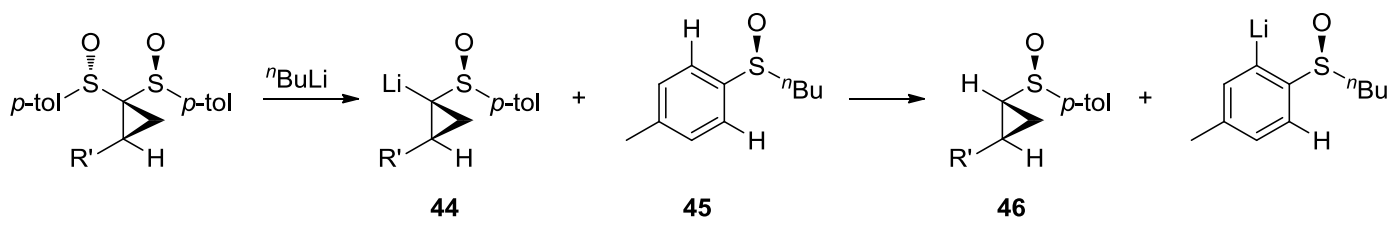

Scheme 2.22 Protonation of lithium cyclopropyl sulfoxide (46)

This very same protonation procedure would occur with the second sulfoxide cleavage, perhaps to an even greater extent, since cyclopropyllithium $\mathbf{4 7}$ does not benefit from $\alpha$-sulfoxide stabilization that $\mathbf{4 4}$ does. Scheme $\mathbf{2 . 2 3}$ depicts this protonation. We then strategized that a fast addition of base and very short reaction times would be necessary to achieve high deuterium incorporation. Indeed we could achieve an $84 \%$ deuterium incorporation when ${ }^{t} \mathrm{BuLi}$ was added in one portion and quenched with $\mathrm{MeOD}$ after only 10 seconds. Then on larger scale an $85 \%$ D incorporation with an $80 \%$ yield was achieved.

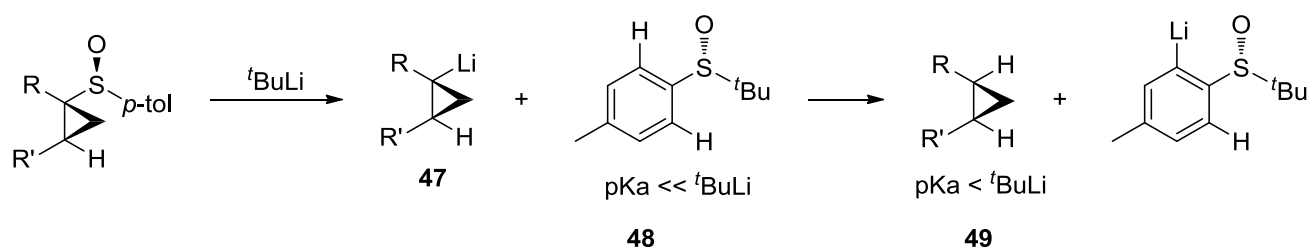

Scheme 2.23 Undesired protonation pathway of lithiated cyclopropane

With alkene $\mathbf{4 3}$ in hand, Marshall ozonolysis was used to produce methyl ester $\mathbf{5 0}$ in a $95 \%$ crude yield. Once again, submission of methyl dihydrosterculate $\mathbf{5 0}$ to $\mathrm{LiOH}$ mediated hydrolysis to yield cyclopropane fatty acid 3 in a $54 \%$ yield over the two steps. The preparation of $\mathbf{3}$ had a 10\% overall reaction yield over 7 linear steps, where $\mathbf{3}$ had a deuterium incorporation of $80 \%(\mathrm{C} 10)$. 


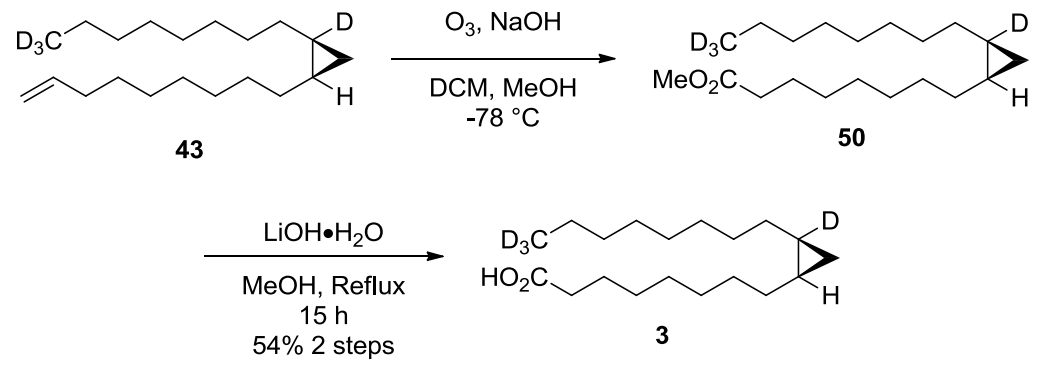

Scheme 2.24 Completion of cyclopropane fatty acid 3

\subsection{Conclusion and future work}

We report the first efforts toward regiospecifically and stereoselectively/stereospecifically labelled dihydrosterculic acids $\mathbf{2}$ and $\mathbf{3}$. These mechanistic probes will help determine the cryptoregiochemistry of cyclopropyl fatty acid desaturases through multiple KIE experiments. $\mathrm{A}_{8}$ alkyl iodide with an appended $\mathrm{CD}_{3}$ group was prepared in $25 \%$ yield over 9 steps using straightforward chemistry. The preparation of $d-1$ aldehyde was also performed using similar chemistry giving $66 \%$ over 4 steps.

In this study we successfully modified the diastereoselective synthesis of dihydrosterculic acid reported by Manthopre et al. During this synthesis the purification of the two diastereomeric cyclopropyl bis(sulfoxides) were optimized by use of a quaternary solvent system and higher grade silica. Oxidative cleavage of cyclopropyl alkene and subsequent hydrolysis was managed via a two step Marshall ozonolysis and $\mathrm{LiOH} / \mathrm{MeOH}$ mediated hydrolysis. Also By using the $d-1$ aldehyde 32 we obtained 9- $d$ - 
dihydrosterculic acid, with a remote mass label at $\mathrm{C} 18$, in a $14 \%$ yield and $98 \% \mathrm{D}$ incorporation over 7 linear steps.

Also we prepared a $d-10$ alkene which can be readily converted to $d-10$ dihydrosterculic acid 3. The deuterium label was installed via a selective lithium sulfoxide cleavage and subsequent quenching with MeOD. The installation of a deuterium atome at position 10 was optimized to increase $\% \mathrm{D}$ by using a fast addition and short reaction times. We managed to obtain alkene 42 in a $18 \%$ yield and $85 \% \mathrm{D}$ incorporation over 5 linear steps. We managed to obtain alkene 42 in an $80 \%$ yield and $85 \%$ D incorporation over 5 linear steps. Cyclopropne fatty acid $\mathbf{3}$ was then prepared via the same methodology as what was used with acid $\mathbf{2}$. These reactions resulted in a $10 \%$ yield over 7 linear steps of acid $\mathbf{3}$.

The long term goals of this project are to isolate the gene for cyclopropyl fatty acid desaturase and extrapolate it into a vector. Then perform KIE experiments using our labelled fatty acids to ascertain the cryptoregichemistry of this unique family of enzymes.

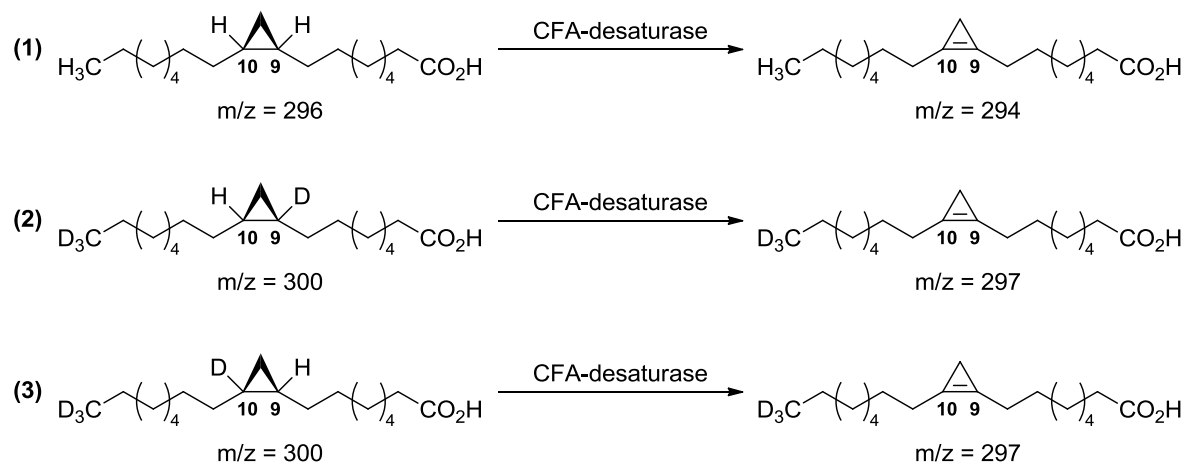

Scheme 2.25 KIE experiments with labelled and unlabelled dihydrosterculic acids 


\section{Chapter: Experimental (part A)}

\subsection{General Experimental}

All reagents were reagent grade and purchased from Sigma-Aldrich, Fluka, Analar, or Cambridge Isotope Laboratories Inc. and used as received, with the following exceptions: PhMe, DCM, DMSO, DIPA and $\mathrm{MeCN}$ were distilled from $\mathrm{CaH}_{2}, \mathrm{Et}_{2} \mathrm{O}$ and THF was distilled from $\mathrm{LiAlH}_{4}$ or sodium benzophenone ketyl, and all alkyl halides (commercial or prepared) were purified by elution through a short column of aluminum oxide (activated, basic, Brockman I) prior to use. All reactions involving air- or moisturesensitive reagents or intermediates were performed under an $\operatorname{Ar}$ or $\mathrm{N}_{2}$ atmosphere in glassware that was flame-dried or oven-dried. Reaction temperatures refer to the temperature of the cooling/heating bath. For the more unusual temperatures a Neslab Cryotrol cryobath was used with a liquid coolant composed of a mixture of acetone and methanol (1:1). Volatile solvents were removed under reduced pressure using a Heidolph rotary evaporator at $40^{\circ} \mathrm{C}$ (bath temperature). Thin layer chromatography was performed on glass-backed Extra Hard Layer (60 A) TLC plates purchased from Silicycle. Spots were visualized by fluorescence quenching under UV light $(254 \mathrm{~nm})$ and/or staining with aqueous ceric ammonium molybdate, iodine on silica gel, or $\mathrm{KMnO}_{4}$. Chromatography was performed using forced flow (flash chromatography, FCC) on Silia-P Flash silica gel (40-62 $\mu \mathrm{m})$ from Silicycle according to the method of Still, ${ }^{43}$ or adsorbed onto Celite 521 from Sigma-Aldrich and was performed using dry column vacuum chromatography $(\mathrm{DCVC})^{44}$ with SiliaFlash E60 silica gel $(15-40 \mu \mathrm{m})$ from Silicycle. Compounds that were dried under high vacuum refers to a reduced pressure of $\sim 20$ mTorr. FTIR spectra were recorded on a Varian 1000 Scimitar Series or an ABB Bomem MB Series 
spectrometer and were obtained as thin films on sodium chloride and are reported in wavenumbers $\left(\mathrm{cm}^{-1}\right) .{ }^{1} \mathrm{H}$ and ${ }^{13} \mathrm{C}$ NMR spectra were recorded on a Bruker Avance 300 or Bruker Avance III 400 spectrometer at 300 or $400 \mathrm{MHz}$ for ${ }^{1} \mathrm{H}$ and 75 or $100 \mathrm{MHz}$ for

${ }^{13} \mathrm{C}$, respectively, and were obtained at the indicated field as solutions in $\mathrm{CDCl}_{3}$ (stored over activated $4 \AA$ molecular sieves) unless otherwise indicated. Chemical shifts were referenced to tetramethylsilane ( $\delta=0.00 \mathrm{ppm})$ as an internal standard and are reported in parts per million (ppm, $\delta$ ) relative to TMS. Coupling constants $(J)$ are reported in $\mathrm{Hz}$ and the splitting abbreviations used are: $\mathrm{s}$, singlet; $\mathrm{d}$, doublet; $\mathrm{t}$, triplet; $\mathrm{q}$, quartet; $\mathrm{m}$, multiplet). Chemical purity of compounds that were used without purification was determined by ${ }^{1} \mathrm{H}$ NMR spectroscopy. Yields refer to purified compounds unless explicitly indicated as crude. Deuterium incorporation of deuterated compounds was determined by comparison of peak integrations of the labelled materials versus the integration of the same peak(s) in the ${ }^{1} \mathrm{H}$ NMR spectrum of the unlabelled compound. Ozone was generated by using a A2Z Systems INC, A2ZS-SGLAB ozonizer with a 0.5 $\mathrm{NL} / \mathrm{min} \mathrm{O}_{2}$ flow.

\subsection{Synthesis of $8,8,8,-d_{3}$-iodooctane}

\subsubsection{8-benzyloxy-1-ocatnol (17)}

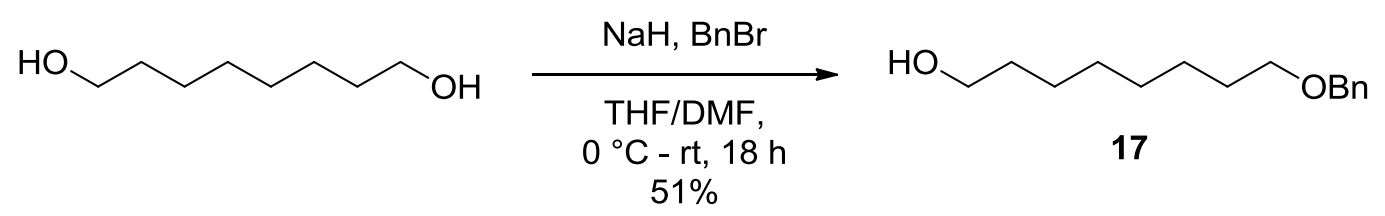

To a stirred suspension of sodium hydride $(95 \%, 4.11 \mathrm{~g}, 170 \mathrm{mmol})$ in DMF $(115 \mathrm{ml})$ a solution of 1,8-octanediol (22.67 g, $155 \mathrm{mmol})$ in THF/DMF (232.5 ml, 2:1) was added dropwise at $0{ }^{\circ} \mathrm{C}$. The mixture was stirred for $2 \mathrm{~h}$ before $\mathrm{BnBr}(19 \mathrm{ml}, 160 \mathrm{mmol})$ was 
added dropwise at $0{ }^{\circ} \mathrm{C}$. The reaction mixture was allowed to warm to ambient temperature and was stirred for $18 \mathrm{~h}$. The mixture was quenched with water $(250 \mathrm{ml})$ and extracted with ethyl acetate $(3 \times 250)$. Then the combined organic layers were washed with brine $(250 \mathrm{ml})$ dried over anhydrous $\mathrm{MgSO}_{4}$, filtered and concentrated under reduced pressure to give a crude yellow oil (53 g). This crude oil was purified by DCVC $(15-30 \%$ EtOAc/hexanes) to give a colourless oil (18.6 g, 51\%).

$\boldsymbol{R}_{\boldsymbol{f}} 0.32\left(30 \%\right.$ EtOAc/hexanes; UV) ${ }^{1} \mathbf{H}$ NMR $\left(\mathrm{CDCl}_{3}, 300 \mathrm{MHz}\right): \delta$ 7.37-7.25 (m, 5H), $4.49(\mathrm{~s}, 2 \mathrm{H}), 3.62\left(\mathrm{t},{ }^{3} J=6.6 \mathrm{~Hz}, 2 \mathrm{H}\right), 3.45\left(\mathrm{t},{ }^{3} J=6.6 \mathrm{~Hz}, 2 \mathrm{H}\right), 1.62-1.52(\mathrm{~m}, 4 \mathrm{H}), 1.32-$ $1.25(\mathrm{~m}, 8 \mathrm{H})$.

Spectroscopic data was in good agreement with literature. ${ }^{45}$

\subsubsection{8-benzyloxy-1-ocatanal (18)}

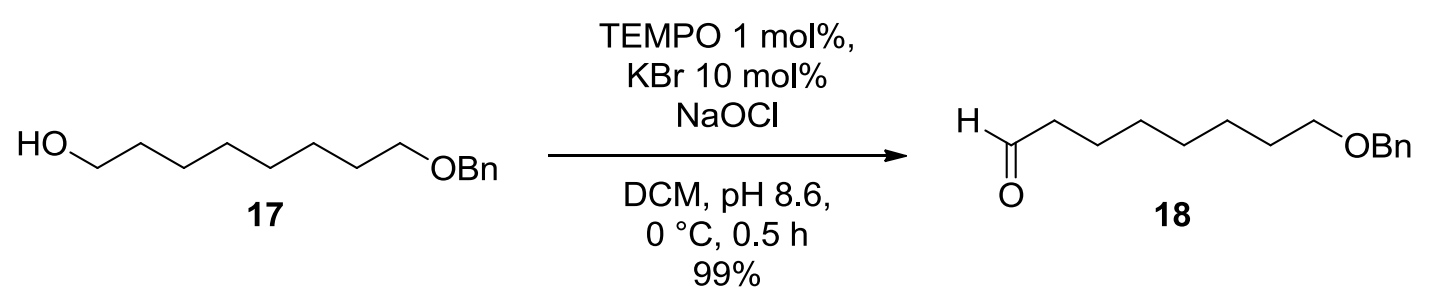

Alcohol 17 (7.98 g, $34 \mathrm{mmol})$ was dissolved in DCM $(97 \mathrm{ml})$ and cooled to $0{ }^{\circ} \mathrm{C}$. To the cooled solution TEMPO (53 mg, $0.33 \mathrm{mmol}), \mathrm{KBr}(0.41 \mathrm{~g}, 3.4 \mathrm{mmol})$ were added along with carbonate buffer (145 ml, pH 8.6). Ice-cold bleach (52.1 g, 7.8 wt.\%, 55 mmol) was then added in portions over 10 min until the reaction mixture was a persistent orange colour. The reaction was then quenched with saturated aqueous $\mathrm{Na}_{2} \mathrm{~S}_{2} \mathrm{O}_{3}(25 \mathrm{ml})$. The layers were separated and aqueous layer was extracted with EtOAc ( 2 x 150 ml). Organic layers were combined and washed with brine, dried over anhydrous $\mathrm{Na}_{2} \mathrm{SO}_{4}$, filtered and 
concentrated to afford a slightly pink liquid (7.81 g). This material was used without further purification.

$\boldsymbol{R}_{\boldsymbol{f}} 0.30\left(10 \%\right.$ EtOAc/hexanes; UV) ${ }^{1} \mathbf{H}$ NMR $\left(\mathrm{CDCl}_{3}, 300 \mathrm{MHz}\right): \delta 9.76\left(\mathrm{t},{ }^{3} \mathrm{~J}=1.8 \mathrm{~Hz}\right.$ $1 \mathrm{H}), 7.35-7.27(\mathrm{~m}, 5 \mathrm{H}), 4.50(\mathrm{~s}, 2 \mathrm{H}), 3.47\left(\mathrm{t},{ }^{3} J=6.3 \mathrm{~Hz}, 2 \mathrm{H}\right), 2.42\left(\mathrm{tt},{ }^{3} J=7.5 \mathrm{~Hz},{ }^{3} J=\right.$ $1.8 \mathrm{~Hz}, 2 \mathrm{H}), 1.51-1.74(\mathrm{~m}, 4 \mathrm{H}), 1.25-1.47(\mathrm{~m}, 6 \mathrm{H})$.

Spectroscopic data was in good agreement with literature. ${ }^{46}$

\subsection{3 isopropyl 8-(benzyloxy)octanoate (20)}

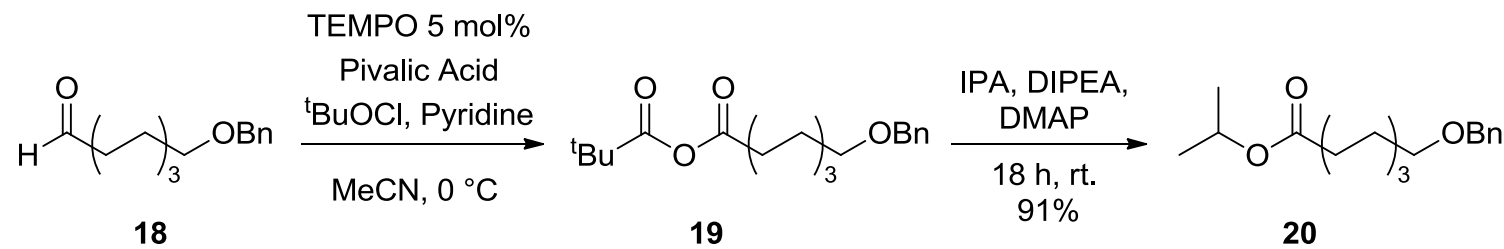

This procedure was adapted from the work of Szpilman et al. ${ }^{39}$ Aldehyde 18 (6.18 g, 26.4 mmol), pivalic acid (3.0 g, $29.4 \mathrm{mmol})$, TEMPO (207 mg, $1.3 \mathrm{mmol})$, and pyridine (4.3 $\mathrm{ml}, 53.2 \mathrm{mmol})$ were dissolved in $\mathrm{MeCN}(66 \mathrm{ml})$ and cooled to $0{ }^{\circ} \mathrm{C}$ and flushed with Argon. ${ }^{\mathrm{t}} \mathrm{BuOCl}(3.22 \mathrm{~g}, 29.7 \mathrm{mmol})$ was then added dropwise over $10 \mathrm{~min}$. The solution was allowed to warm to ambient temperature over $15 \mathrm{~min}$, and DIPA $(10.1 \mathrm{ml}, 58.0$ mmol), isopropanol (3.6 ml, $47 \mathrm{mmol})$ and DMAP (0.32 g, $2.6 \mathrm{mmol})$ were added sequentially. The reaction was allowed to stir overnight $(18 \mathrm{~h})$ at room temperature. The reaction was diluted with saturated aqueous $\mathrm{NaHCO}_{3}(1.3 \mathrm{~L})$, extracted with EtOAc $(3 \mathrm{x}$ $250 \mathrm{ml}$ ) and the organic layers were combined, washed with brine, dried over anhydrous $\mathrm{Na}_{2} \mathrm{SO}_{4}$, filtered and concentrated to yield a crude light pink oil $(7.67 \mathrm{~g})$. The crude oil was purified by FCC (20-30\% EtOAc/hexanes) to give a colourless liquid (7.04 g 91\%). 
$\boldsymbol{R}_{f} 0.77\left(30 \%\right.$ EtOAc/hexanes; UV) ${ }^{1} \mathbf{H}$ NMR $\left(\mathrm{CDCl}_{3}, 300 \mathrm{MHz}\right): \delta 7.35-7.16(\mathrm{~m}, 5 \mathrm{H})$, $5.00\left(\mathrm{sep},{ }^{3} J=6.3 \mathrm{~Hz}, 1 \mathrm{H}\right), 4.50(\mathrm{~s}, 2 \mathrm{H}), 3.46\left(\mathrm{t},{ }^{3} J=6.6 \mathrm{~Hz}, 2 \mathrm{H}\right), 2.25\left(\mathrm{t},{ }^{3} J=7.5 \mathrm{~Hz}\right.$, 2H), $1.66-1.56$ (m, 4H), $1.45-1.25(\mathrm{~m}, 6 \mathrm{H}), 1.22\left(\mathrm{~d},{ }^{3} \mathrm{~J}=6.3 \mathrm{~Hz}, 6 \mathrm{H}\right) .{ }^{13} \mathbf{C} \mathbf{~ N M R}\left(\mathrm{CDCl}_{3}\right.$, $75 \mathrm{MHz}$ ): $\delta 173.3,138.8,128.4,127.6,127.6,127.5,72.9,70.4,67.3,34.7,29.8,29.2$, 29.1, 26.1, 25.0, 21.9. FTIR ( $\mathrm{NaCl}$ plate, $\left.\mathrm{cm}^{-1}\right): 3064,3031,2979,2934,2857,1950$, $1730,1466,1373,1309,1253,1202,1179,1109,1028,963,901,823,736$.

\subsubsection{8-benzyloxy-1,1- $d_{2}$-ocatnol (21)}

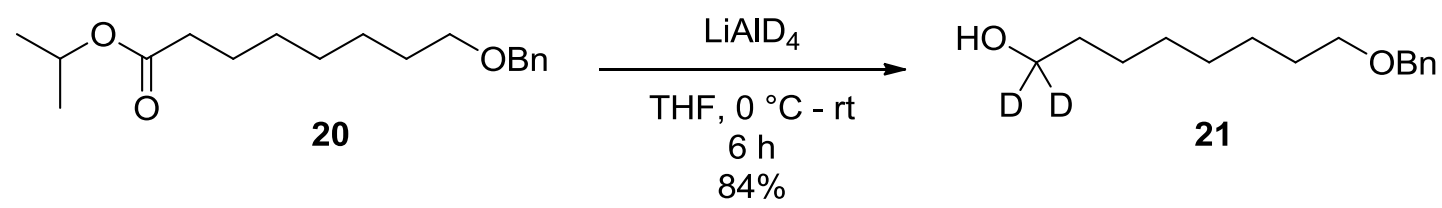

Ester $20(1.67 \mathrm{~g}, 5.7 \mathrm{mmol})$ was dissolved in THF $(5 \mathrm{ml})$ and added to a $0{ }^{\circ} \mathrm{C}$ suspension of $\operatorname{LiAlD}_{4}(0.20 \mathrm{~g}, 4.8 \mathrm{mmol})$ in THF $(25 \mathrm{ml})$. The reaction mixture was stirred at this temperature for $2 \mathrm{~h}$, and then was removed from the cooling bath and allowed to stir for 4 h. The reaction mixture was re-cooled in an ice/water bath for 10 min before slowly quenching via portionwise addition of solid $\mathrm{Na}_{2} \mathrm{SO}_{4} \bullet 10 \mathrm{H}_{2} \mathrm{O}(5 \mathrm{~g})$. Acetone $(10 \mathrm{ml})$ was added to ensure the consumption of any residual metal-deuteride species and the sludgy mixture was vigorously stirred for $2 \mathrm{~h}$ while warming to ambient temperature. The now white reaction mixture was filtered over Celite, washed with saturated aqueous Rochelle's salt $(2 \times 45 \mathrm{ml})$, dried over anhydrous $\mathrm{MgSO}_{4}$, filtered, and concentrated to give a light yellow liquid $(1.57 \mathrm{~g})$. The crude liquid was purified by FCC (15-30\% EtOAc/hexanes) to afford a clear liquid (1.15 g, 84\%). 
$\boldsymbol{R}_{\boldsymbol{f}} 0.35$ (30\% EtOAc/hexanes; UV) ${ }^{1} \mathbf{H}$ NMR $\left(\mathrm{CDCl}_{3}, 300 \mathrm{MHz}\right): \delta$ 7.35-7.24 (m, 5H), $4.50(\mathrm{~s}, 2 \mathrm{H}), 3.46\left(\mathrm{t},{ }^{3} J=6.6 \mathrm{~Hz}, 2 \mathrm{H}\right), 1.64-1.52(\mathrm{~m}, 4 \mathrm{H}), 1.45-1.25(\mathrm{~m}, 8 \mathrm{H}) .{ }^{13} \mathbf{C}$ NMR $\left(\mathrm{C}_{6} \mathrm{D}_{6}, 75 \mathrm{MHz}\right): \delta 139.3,127.8,127.5,127.4,72.7,70.3,61.7$ (quintet, ${ }^{1} J=21.0 \mathrm{~Hz}$ ), 32.7, 30.0, 29.6, 29.6, 26.4, 25.9. FTIR ( $\mathrm{NaCl}$ plate, $\left.\mathrm{cm}^{-1}\right): 3364,2928,2855,2194$, 2091, 1495, 1454, 1363, 1205, 1100, 1029, 967, 735, 697.

\subsubsection{8-(benzyloxy)octyl-1,1- $d_{2}$-p-toluenesulfonate (22)}

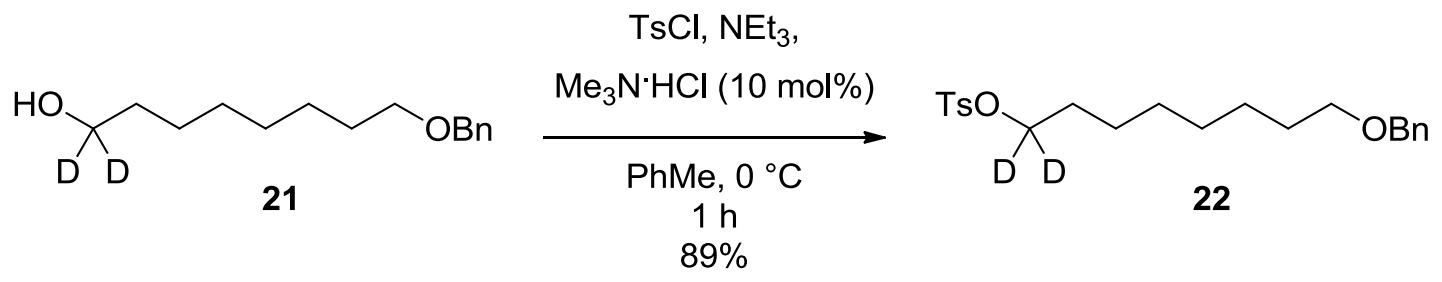

This protocol was adapted from the literature procedure reported by Tanabe. ${ }^{40}$ Trimethylamine hydrochloride $(92 \mathrm{mg}, 0.96 \mathrm{mmol})$ was suspended in toluene $(9 \mathrm{ml})$. Alcohol 21 (2.06 g, $8.7 \mathrm{mmol})$ and triethylamine $(2.5 \mathrm{ml}, 18.8 \mathrm{mmol})$ were added to the suspension and cooled in an ice bath. $p$-Toluenesulfonyl chloride (2.49 g, $13.1 \mathrm{mmol})$ was dissolved in toluene $(9 \mathrm{ml})$ and added in three $3 \mathrm{~mL}$ portions over 10 minutes to the cooled reaction mixture and stirred for $1 \mathrm{~h}$ at this temperature. Water $(50 \mathrm{ml})$ was added to dissolve amine salts, layers were separated, and aqueous layer was extracted with EtOAc ( 3 x $30 \mathrm{ml})$. Organic layers were combined washed with brine, dried over anhydrous $\mathrm{Na}_{2} \mathrm{SO}_{4}$, filtered and concentrated to give a brown liquid (3.47g). The crude liquid was purified by FCC (10\% EtOAc/hexanes) to give a colourless oil (3.02 g, 89\%).

$\boldsymbol{R}_{\boldsymbol{f}} 0.68$ (30\% EtOAc/hexanes; UV) ${ }^{1} \mathbf{H}$ NMR (CDCl $\left.3,300 \mathrm{MHz}\right): \delta 7.79\left(\mathrm{~d},{ }^{3} \mathrm{~J}=8.4 \mathrm{~Hz}\right.$, 2H), 7.37-7.24 (m, 7H), 4.49 (s, 2H), $3.45\left(\mathrm{t},{ }^{3} \mathrm{~J}=6.3 \mathrm{~Hz}, 2 \mathrm{H}\right), 2.44$ (s, 3H), 1.65-1.49 (m, 
4H), 1.43-1.12 (m, 8H). ${ }^{13}$ C NMR $\left(\mathrm{C}_{6} \mathrm{D}_{6}, 75 \mathrm{MHz}\right): \delta 144.0,139.3,134.3,129.6,127.9$, 127.8, 127.5, 127.4, 72.7, 70.3, 69.6 (quintet, ${ }^{1} J=24.0 \mathrm{~Hz}$ ), 29.9, 29.3, 28.9, 28.6, 26.2, 25.2, 20.9. FTIR (NaCl plate, $\left.\mathrm{cm}^{-1}\right): 3031,2932,2856,2240,2150,1810,1598,1495$, $1454,1362,1307,1275,1097,1028,957,815,771,662,554$.

\subsection{6 ((8,8,8- $d_{3}$-octyloxy)methyl)benzene (23)}

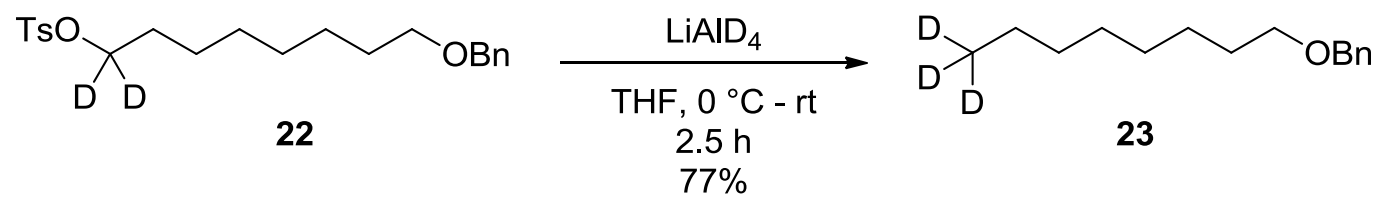

Tosylate $22(0.53 \mathrm{~g}, 1.4 \mathrm{mmol})$ was dissolved in THF $(2 \mathrm{ml})$ and added to a $0{ }^{\circ} \mathrm{C}$ suspension of $\mathrm{LiAlD}_{4}(77 \mathrm{mg}, 1.8 \mathrm{mmol})$ in THF $(2 \mathrm{ml})$. The reaction mixture was stirred at this temperature for $10 \mathrm{~min}$, then removed from the cooling bath and allowed to stir at ambient temperature for $2.5 \mathrm{~h}$. The reaction mixture was re-cooled in ice/water bath for 10 min before slowly quenching via portionwise addition of solid $\mathrm{Na}_{2} \mathrm{SO}_{4} \bullet 10 \mathrm{H}_{2} \mathrm{O}(1.5 \mathrm{~g})$. Acetone $(5 \mathrm{ml})$ was added to ensure the consumption of any residual metal-deuteride species and the sludgy mixture was vigorously stirred while warming to ambient temperature for $2 \mathrm{~h}$. The now white reaction mixture was filtered over Celite, washed with saturated aqueous Rochelle's salt ( 2 x $5 \mathrm{ml}$ ), dried over anhydrous $\mathrm{MgSO}_{4}$, filtered, and concentrated to give a light yellow liquid $(0.25 \mathrm{~g})$. The crude liquid was purified by FCC (5\% EtOAc/hexanes) to afford a clear liquid (0.23 g, 77\%).

$\boldsymbol{R}_{\boldsymbol{f}} 0.91\left(30 \%\right.$ EtOAc/hexanes; UV) ${ }^{\mathbf{1}} \mathbf{H}$ NMR $\left(\mathrm{CDCl}_{3}, 300 \mathrm{MHz}\right): \delta$ 7.34-7.24 (m, 5H), $4.50(\mathrm{~s}, 2 \mathrm{H}), 3.46\left(\mathrm{t},{ }^{3} \mathrm{~J}=6.6 \mathrm{~Hz}, 2 \mathrm{H}\right), 2.44(\mathrm{~s}, 3 \mathrm{H}), 1.66-1.57(\mathrm{~m}, 2 \mathrm{H}), 1.41-1.15(\mathrm{~m}$, 10H). ${ }^{13} \mathbf{C ~ N M R ~}\left(\mathrm{CDCl}_{3}, 75 \mathrm{MHz}\right): \delta 138.8,128.3,127.6,127.5,72.9,70.6,31.8,29.8$, 
29.5, 29.3, 26.2, 22.5, 22.4. FTIR ( $\mathrm{NaCl}$ plate, $\left.\mathrm{cm}^{-1}\right): 2926,2855,1454,1326,1101$, 1076, 1028, 733, 697.

\subsubsection{8,8,8- $d_{3}$-octan-1-ol (24)}

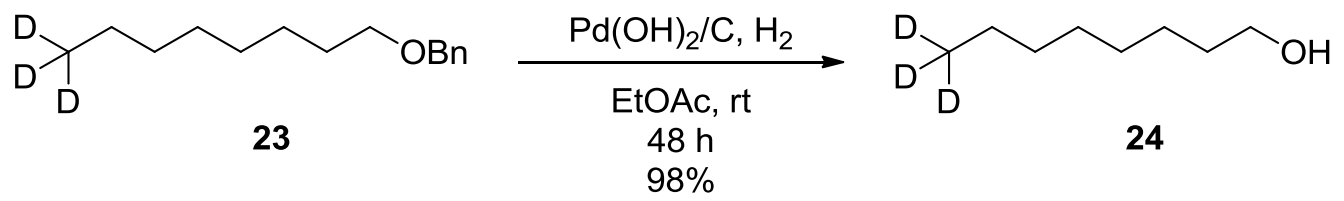

Benzyl ether $22(5.94 \mathrm{~g}, 26.5 \mathrm{mmol})$ was dissolved in EtOAc $(100 \mathrm{ml})$. To the stirred solution at ambient temperature, $\mathrm{Pd}(\mathrm{OH})_{2} / \mathrm{C}(20 \mathrm{wt} . \% \mathrm{Pd}, 0.62 \mathrm{~g}, 0.9 \mathrm{mmol})$ was added in one portion. The walls of the reaction flask were washed with additional EtOAc $(30 \mathrm{ml})$ to ensure all catalyst was in the suspension. The reaction vessel was purged with argon (x3), then $\mathrm{H}_{2}(\mathrm{x} 3)$. The reaction mixture was allowed to stir under $\mathrm{H}_{2}$ atmosphere for 48 h. The reaction mixture was filtered over Celite and concentrated to give a light yellow liquid (3.47 g, 98\%). This material was used without further purification.

$\boldsymbol{R}_{\boldsymbol{f}} 0.21\left(10 \%\right.$ EtOAc/hexanes; $\left.\mathrm{KMnO}_{4}, \mathrm{I}_{2}\right){ }^{1} \mathbf{H}$ NMR $\left(\mathrm{CDCl}_{3}, 300 \mathrm{MHz}\right): \delta 3.64\left(\mathrm{t},{ }^{3} J=\right.$ $6.6 \mathrm{~Hz}, 2 \mathrm{H}), 1.69-1.51(\mathrm{~m}, 2 \mathrm{H}), 1.41-1.19(\mathrm{~m}, 10 \mathrm{H}) .{ }^{13} \mathbf{C} \mathbf{N M R}\left(\mathrm{CDCl}_{3}, 100 \mathrm{MHz}\right): \delta$ $62.3,32.8,31.8,29.5,29.4,25.8,22.4,13.0$ (septet, $\left.{ }^{1} J=19.0 \mathrm{~Hz}\right)$. FTIR ( $\mathrm{NaCl}$ plate, $\left.\mathrm{cm}^{-1}\right): 3339,2926,2857,1465,1216,1057,758$.

\subsubsection{1-iodo-8,8,8- $d_{3}$-octane (25)}<smiles>[2H]C([2H])([2H])CCCCCCCO</smiles>

24

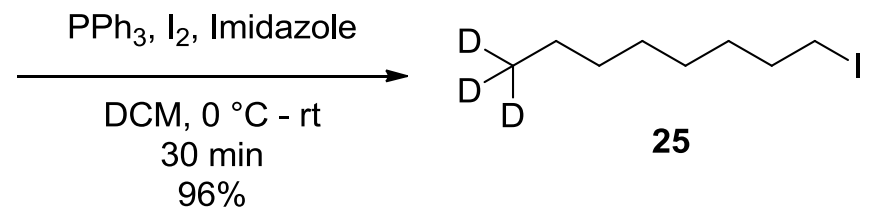


Alcohol 24 (0.61 g, $4.6 \mathrm{mmol}), \mathrm{PPh}_{3}(1.55 \mathrm{~g}, 5.9 \mathrm{mmol})$, imidazole (0.41 g, $\left.5.9 \mathrm{mmol}\right)$ were dissolved in DCM $(7.5 \mathrm{ml})$ at ambient temperature, before cooling to $0{ }^{\circ} \mathrm{C}$. $\mathrm{I}_{2}(1.57$ $\mathrm{g}, 5.9 \mathrm{mmol}$ ) was added slowly and a vigorous gas evolution was observed. The orange reaction mixture was warmed to ambient temperature and stirred for $30 \mathrm{~min}$. After the reaction was judged to be complete by TLC, saturated aqueous $\mathrm{Na}_{2} \mathrm{~S}_{2} \mathrm{O}_{3}(10 \mathrm{ml})$ was added, and the mixture was stirred for 5 min. The layers were separated and aqueous layer was extracted with DCM $(3 \times 10 \mathrm{ml})$. Organic layers were combined, dried over anhydrous $\mathrm{MgSO}_{4}$, and filtered over a short pad of silica. After thorough washing of the filter cake with hexanes $(30 \mathrm{ml})$, the solution was concentrated to give a slushy white solid. This solid was suspended in hexanes $(10 \mathrm{ml})$ and cooled to $0{ }^{\circ} \mathrm{C}$ without stirring. The suspension was filtered over a short pad of silica, and the filter cake was washed with cold hexanes $(50 \mathrm{ml})$, the filtrate was concentrated to give a colourless liquid (1.07 g, 96\%).

$\boldsymbol{R}_{f} 0.74\left(100 \%\right.$, hexanes; UV, $\left.\mathrm{KMnO}_{4}\right){ }^{1} \mathbf{H}$ NMR $\left(\mathrm{CDCl}_{3}, 400 \mathrm{MHz}\right): \delta 3.19\left(\mathrm{t},{ }^{3} J=6.8\right.$ Hz, 2H), 1.82 (quintet, $\left.{ }^{3} J=7.2 \mathrm{~Hz}, 2 \mathrm{H}\right), 1.45-1.35$ (m, 2H), 1.35-1.14 (m, 8H). ${ }^{13} \mathbf{C}$ NMR $\left(\mathrm{CDCl}_{3}, 100 \mathrm{MHz}\right.$ ): $\delta 33.6,31.7,30.5,29.1,28.5,13.2$ (quintet, ${ }^{1} J=19.0 \mathrm{~Hz}$ ), 7.21. FTIR $\left(\mathrm{NaCl}\right.$ plate, $\left.\mathrm{cm}^{-1}\right): 2923,2854,2212,2121,2075,1463,1196,1165,1055,720$. Spectroscopic data was in good agreement with literature. ${ }^{47}$ 


\subsection{Chiral bis(sulfoxide) synthesis}

\subsection{1 (R)-methyl $p$-tolyl sulfoxide (27)}

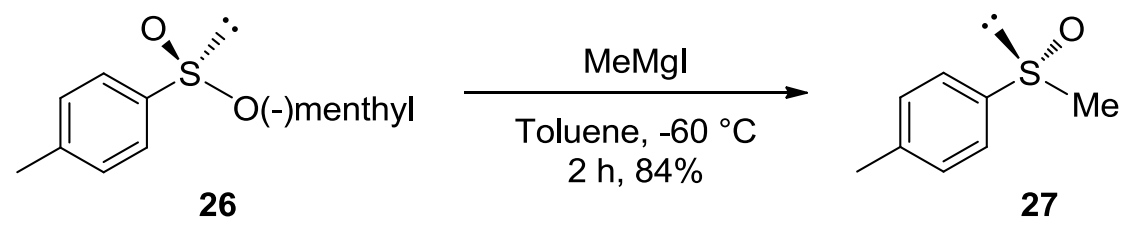

$\operatorname{MeMgI}(15 \mathrm{ml}, 3.0 \mathrm{M}, 45 \mathrm{mmol})$ was cooled to $0{ }^{\circ} \mathrm{C}$ in a $250 \mathrm{ml}$ Schlenk flask. The ether was removed slowly under reduced pressure; the resulting residue was suspended in toluene $(20 \mathrm{ml})$ and cooled to $-60{ }^{\circ} \mathrm{C}\left(\mathrm{IPA} / \mathrm{dry}\right.$ ice). Then a $0{ }^{\circ} \mathrm{C}$ solution of $(1 R, 2 S, 5 R)-(-$ )-menthyl $(S)$-p-toluenesulfinate ${ }^{\mathrm{i}}(5.95 \mathrm{~g}, 20 \mathrm{mmol})$ in toluene $(40 \mathrm{ml})$ was added dropwise to the Grignard reagent via cannula over $25 \mathrm{~min}$. The reaction mixture was allowed to warm to $-20^{\circ} \mathrm{C}$ before quenching with saturated aqueous $\mathrm{NH}_{4} \mathrm{Cl}(70 \mathrm{ml})$. The layers were separated and aqueous layer was extracted with $\mathrm{Et}_{2} \mathrm{O}(3 \times 50 \mathrm{ml})$. Then organic layers were combined, washed with brine $(100 \mathrm{ml})$, dried over anhydrous $\mathrm{Na}_{2} \mathrm{SO}_{4}$, filtered, and concentrated to give an off white solid (2.62 g, 84\%). This material was used without further purification.

$\boldsymbol{R}_{\boldsymbol{f}} 0.19\left(50 \%\right.$ EtOAc/hexanes; UV). ${ }^{1} \mathbf{H}$ NMR $\left(\mathrm{CDCl}_{3}, 300 \mathrm{MHz}\right): \delta 7.50\left(\mathrm{~d},{ }^{3} J=8.0 \mathrm{~Hz}\right.$ 2H), $7.28(\mathrm{~d}, \mathrm{~J}=8 \mathrm{~Hz}), 2.67(\mathrm{~s}, 3 \mathrm{H}), 2.36(\mathrm{~s}, 3 \mathrm{H})$.

Spectroscopic data was in good agreement with literature. ${ }^{48}$

i $(1 R, 2 S, 5 R)-(-)$-menthyl $(S)$-p-toluenesulfinate $(16.3 \mathrm{~g})$ was obtained from a previous research project and was purified by trituration from a mixture of warm hexanes $(300 \mathrm{ml})$ and acetone $(20 \mathrm{ml})$, and subsequent crystallization from warm acetone. The purified product decomposes at ambient temperature, thus it was stored a $-20{ }^{\circ} \mathrm{C}$. 


\subsection{2 $\quad(S, S)-p$-tolyl-bis $(p$-tolylsulfinyl)methane (10)}

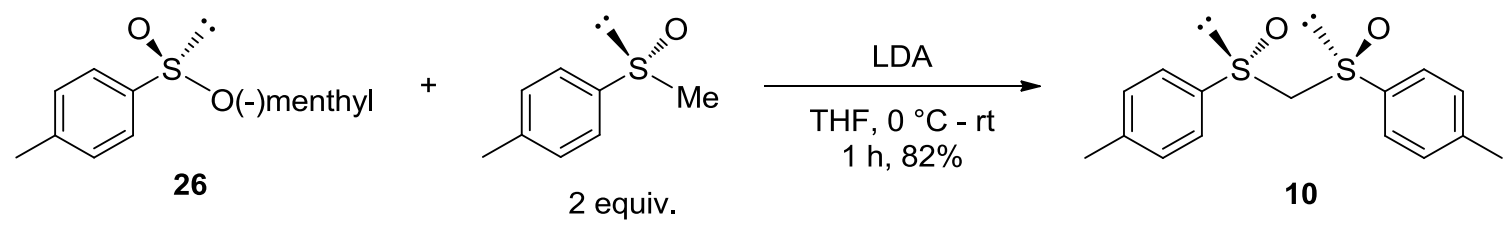

27

To a $0{ }^{\circ} \mathrm{C}$ solution of diisopropyl amine $(1.89 \mathrm{~g}, 14 \mathrm{mmol})$ in THF $(13 \mathrm{ml}), n$-BuLi (4.25 $\mathrm{ml}, 3.05 \mathrm{M}, 13 \mathrm{mmol}$ ) was added dropwise over $5 \mathrm{~min}$. After $15 \mathrm{~min}$ of stirring at this temperature, a $0{ }^{\circ} \mathrm{C}$ solution of sulfoxide $27(1.92 \mathrm{~g}, 12 \mathrm{mmol})$ in $\mathrm{THF}(12.5 \mathrm{ml})$ was added dropwise via cannula over $20 \mathrm{~min}$. The orange solution was warmed to ambient temperature and stirred for $45 \mathrm{~min}$. The solution was re-cooled to $0{ }^{\circ} \mathrm{C}$ and a $\sim 5{ }^{\circ} \mathrm{C}$ solution of $(1 R, 2 S, 5 R)-(-)-$ menthyl $(S)$-p-toluenesulfinate $(1.84 \mathrm{~g}, 6.2 \mathrm{mmol})$ in THF (13 ml) was added via cannula over $5 \mathrm{~min}$.) The reaction solution was stirred at this temperature for $1 \mathrm{~h}$ then warmed to ambient temperature and stirred for an additional 45 min. The layers were separated and aqueous layer was extracted with EtOAc $(3 \times 75 \mathrm{ml})$. Then organic layers were combined, washed with brine $(100 \mathrm{ml})$, dried over anhydrous $\mathrm{Na}_{2} \mathrm{SO}_{4}$, filtered, and concentrated to give a yellow amorphous solid (4.45 g). The crude solid was suspended in $\mathrm{Et}_{2} \mathrm{O} /$ hexanes $(1: 1,25 \mathrm{ml})$ and refluxed for $15 \mathrm{~min}$. The suspension was allowed to cool to room temperature without stirring. The white precipitate was washed with $\sim 0{ }^{\circ} \mathrm{C} \mathrm{Et}_{2} \mathrm{O} /$ hexanes $(50 \mathrm{ml})$. The white crystalline solid $(1.42 \mathrm{~g}, 82 \%)$ was used without further purification.

$\boldsymbol{R}_{\boldsymbol{f}} 0.22\left(50 \%\right.$ EtOAc in hexane; UV). ${ }^{1} \mathbf{H}$ NMR $\left(\mathrm{CDCl}_{3}, 400 \mathrm{MHz}\right): \delta 7.56\left(\mathrm{~d},{ }^{3} J=8.0\right.$ $\mathrm{Hz}, 4 \mathrm{H}), 7.33\left(\mathrm{~d},{ }^{3} J=8.0 \mathrm{~Hz}, 4 \mathrm{H}\right), 3.99(\mathrm{~s}, 2 \mathrm{H}), 2.42$ (s, 6H).

Spectroscopic data was in good agreement with literature. ${ }^{49}$ 


\subsection{Synthesis of $d_{0}$ and $d_{1}$ dec-9-enal}

\subsection{1 dec-9-enal (28)}

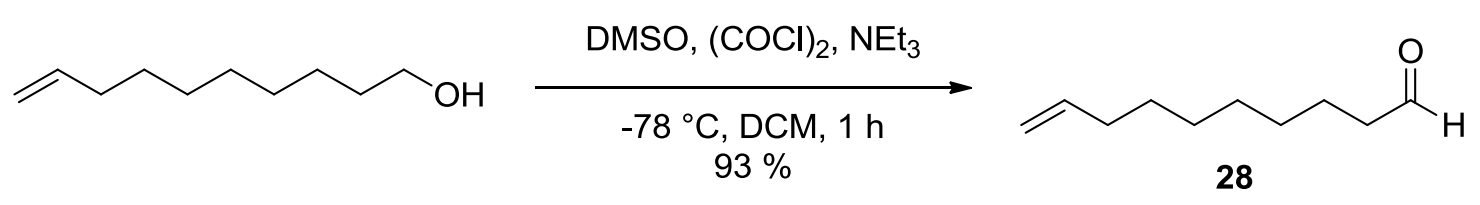

A $-40{ }^{\circ} \mathrm{C}$ solution of DMSO $(6.6 \mathrm{ml}, 93 \mathrm{mmol})$ in DCM $(25 \mathrm{ml})$, was added to a solution of $(\mathrm{COCl})_{2}(4.6 \mathrm{ml}, 54 \mathrm{mmol})$ in $\mathrm{DCM}(260 \mathrm{ml})$ at $-78{ }^{\circ} \mathrm{C}$ via cannula over $15 \mathrm{~min}$. The solution was stirred for $15 \mathrm{~min}$. A $0{ }^{\circ} \mathrm{C}$ solution of 9-decen-1-ol $(6.0 \mathrm{~g}, 38 \mathrm{mmol})$ in DCM $(75 \mathrm{ml})$ was then added via cannula over $15 \mathrm{~min}$ and the mixture was stirred for an additional $15 \mathrm{~min} . \mathrm{NEt}_{3}(21.5 \mathrm{ml}, 154 \mathrm{mmol})$ was then added, and the reaction mixture was allowed slowly to warm to $0{ }^{\circ} \mathrm{C}(4 \mathrm{~h})$. The reaction mixture was diluted in $\mathrm{H}_{2} \mathrm{O}(200$ $\mathrm{ml})$. The organic layer was washed with $1 \mathrm{M}$ aqueous $\mathrm{HCl}(3 \times 150 \mathrm{~mL})$ then saturated aqueous $\mathrm{NaCl}(1150 \mathrm{~mL})$. The organic layer was dried over anhydrous $\mathrm{Na}_{2} \mathrm{SO}_{4}$, filtered then concentrated in vacuo to afford a yellow oil $(6.10 \mathrm{~g})$. The crude oil was purified by FCC (5\% $\mathrm{Et}_{2} \mathrm{O} /$ hexanes) to afford a clear liquid (5.52 g, 93\%).

$\boldsymbol{R}_{f} 0.26\left(5 \% \mathrm{Et}_{2} \mathrm{O} /\right.$ hexanes, UV, $\left.\mathrm{KMnO}_{4}\right) .{ }^{1} \mathbf{H}$ NMR $\left(\mathrm{CDCl}_{3}, 300 \mathrm{MHz}\right): \delta 9.78\left(\mathrm{t},{ }^{3} \mathrm{~J}=\right.$ $1.8 \mathrm{~Hz}, 1 \mathrm{H}), 5.81\left(\mathrm{ddt},{ }^{3} J=17.4,10.2,6.6 \mathrm{~Hz}, 1 \mathrm{H}\right), 5.09-4.97$ (m, $\left.2 \mathrm{H}\right), 2.43\left(\mathrm{dt},{ }^{3} J=1.8\right.$, $7.2 \mathrm{~Hz}, 2 \mathrm{H}), 2.05\left(\mathrm{q},{ }^{3} J=7.2 \mathrm{~Hz}, 2 \mathrm{H}\right), 1.65$ (quintet, $\left.{ }^{3} J=7.5 \mathrm{~Hz}, 2 \mathrm{H}\right), 1.42-1.28(\mathrm{~m}, 8 \mathrm{H})$. Spectroscopic data was in good agreement with literature..$^{50}$ 


\subsection{2 dec-9-enoic acid (29)}

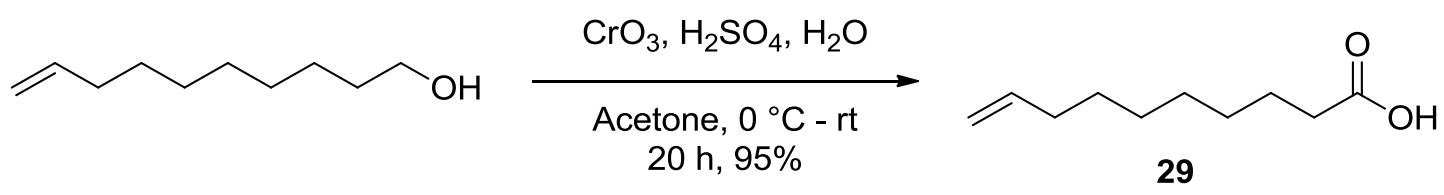

A solution of $\mathrm{CrO}_{3}(6.02 \mathrm{~g}, 60 \mathrm{mmol}), \mathrm{H}_{2} \mathrm{SO}_{4}(5.5 \mathrm{ml}, 98 \%)$, and water $(18 \mathrm{ml})$ was added dropwise to a stirred solution of 9-decen-1-ol (7.02 g, $45 \mathrm{mmol})$ in acetone (285 $\mathrm{ml}$ ) at $0{ }^{\circ} \mathrm{C}$. The reaction mixture was allowed to warm to ambient temperature and stir for 20 hours. The green reaction mixture was recooled to $0{ }^{\circ} \mathrm{C}$, and quenched with IPA (75 ml). Then the reaction mixture was filtered over Celite and concentrated. The blue/green residue was taken up in $\mathrm{H}_{2} \mathrm{O}(150 \mathrm{ml})$ and extracted with $\mathrm{Et}_{2} \mathrm{O}(3 \mathrm{x} 100 \mathrm{ml})$ washed with brine, dried over anhydrous $\mathrm{Na}_{2} \mathrm{SO}_{4}$, filtered and concentrated to give a light green oil (7.27 g, 95\%). This material was used without further purification.

$\boldsymbol{R}_{\boldsymbol{f}} 0.68\left(35 \%\right.$ EtOAc/hexanes, UV, $\left.\mathrm{KMnO}_{4}\right) .{ }^{1} \mathbf{H} \mathbf{N M R}\left(\mathrm{CDCl}_{3}, 300 \mathrm{MHz}\right): \delta 11.15$ (br s, 1H), $5.81\left(\mathrm{ddt},{ }^{3} J=17.1,10.2,6.6 \mathrm{~Hz}, 1 \mathrm{H}\right), 5.03-4.91(\mathrm{~m}, 2 \mathrm{H}), 2.35\left(\mathrm{t},{ }^{3} J=7.5 \mathrm{~Hz}, 2 \mathrm{H}\right)$, $2.04\left(\mathrm{q},{ }^{3} J=6.6 \mathrm{~Hz}, 2 \mathrm{H}\right), 1.69-1.57(\mathrm{~m}, 2 \mathrm{H}), 1.45-1.23(\mathrm{~m}, 8 \mathrm{H})$.

Spectroscopic data was in good agreement with literature. ${ }^{51}$

\subsection{3 isopropyl-dec-9-enoate (30)}

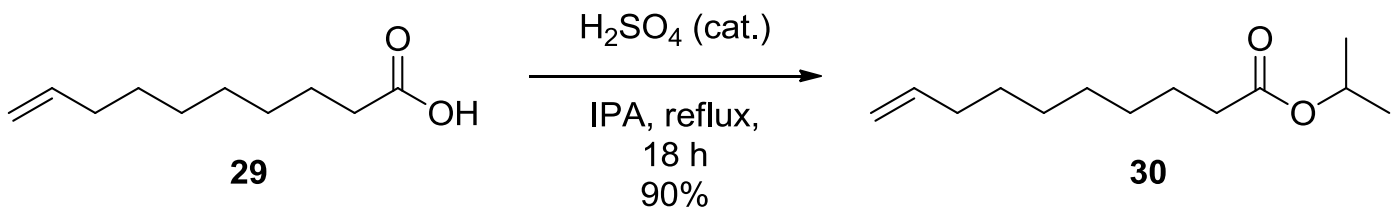

$\mathrm{H}_{2} \mathrm{SO}_{4}(1.01 \mathrm{~g}, 98 \%)$ was added to a stirred solution of carboxylic acid 29 (7.27 g, 43 mmol) in IPA $(430 \mathrm{ml})$. The solution was heated at reflux for $18 \mathrm{~h}$. The solution was 
concentrated under reduced pressure. The resultant oily residue was dissolved in $\mathrm{Et}_{2} \mathrm{O}$ $(400 \mathrm{ml})$ and washed with saturated aqueous $\mathrm{NaHCO}_{3}(2 \times 300 \mathrm{ml})$, brine $(300 \mathrm{ml})$, dried over anhydrous $\mathrm{MgSO}_{4}$, filtered, and concentrated to give a light yellow oil $(8.71 \mathrm{~g})$. The crude liquid was purified by FCC (2.5-5\% EtOAc/hexanes) to afford a clear oil ( $8.17 \mathrm{~g}$, $90 \%)$.

$\boldsymbol{R}_{\boldsymbol{f}} 0.32\left(5 \%\right.$ EtOAc/hexanes, UV, $\left.\mathrm{KMnO}_{4}\right) .{ }^{1} \mathbf{H}$ NMR $\left(\mathrm{CDCl}_{3}, 300 \mathrm{MHz}\right): \delta 5.80$ (ddt, ${ }^{3} J$ $=17.1,10.2,6.6 \mathrm{~Hz}, 1 \mathrm{H}), 5.07-4.91(\mathrm{~m}, 3 \mathrm{H}), 2.25\left(\mathrm{t},{ }^{3} J=7.5 \mathrm{~Hz}, 2 \mathrm{H}\right), 2.04\left(\mathrm{q},{ }^{3} J=6.9\right.$ Hz, 2H), 1.68-1.54 (m, 2H), 1.40- $1.25(\mathrm{~m}, 8 \mathrm{H}), 1.23\left(\mathrm{~d},{ }^{3} J=6.0 \mathrm{~Hz}, 6 \mathrm{H}\right) .{ }^{13} \mathbf{C}$ NMR $\left(\mathrm{CDCl}_{3}, 75 \mathrm{MHz}\right): \delta 173.4,139.1,114.2,67.3,34.7,33.8,29.1,29.1,29.0,28.9,25.0$ 21.9. FTIR ( $\mathrm{NaCl}$ plate, $\left.\mathrm{cm}^{-1}\right): 3078,2980,2929,2856,1734,1641,1467,1374,1248$, $1179,1111,994,909,824$.

\subsubsection{9-decen-1,1- $d_{2}$-ol (31)}

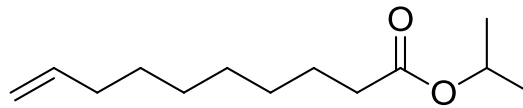

30

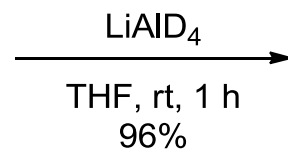
$96 \%$

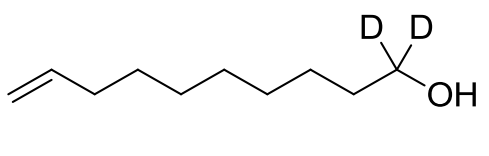

31

A solution of ester $\mathbf{3 0}(8.17 \mathrm{~g}, 38 \mathrm{mmol})$ in THF $(50 \mathrm{ml})$ was added to a suspension of $\mathrm{LiAlD}_{4}(1.30 \mathrm{~g}, 31 \mathrm{mmol})$ in $\mathrm{THF}(150 \mathrm{ml})$ at $0{ }^{\circ} \mathrm{C}$ via cannula over $10 \mathrm{~min}$. The mixture was warmed to ambient temperature and stirred for $1 \mathrm{~h}$. The reaction mixture was recooled in ice/water bath for 10 min before slowly quenching via portionwise addition of solid $\mathrm{Na}_{2} \mathrm{SO}_{4} \cdot 10 \mathrm{H}_{2} \mathrm{O}(10 \mathrm{~g})$. Acetone $(20 \mathrm{ml})$ was added to ensure the consumption of any residual metal-deuteride species and the sludgy mixture was vigorously stirred while warming to ambient temperature for $2 \mathrm{~h}$. The now white reaction mixture was filtered 
over Celite, washed with saturated aqueous Rochelle's salt $(2 \times 300 \mathrm{ml})$, dried over anhydrous $\mathrm{MgSO}_{4}$, filtered, and concentrated to give a light yellow liquid $(6.12 \mathrm{~g})$. The crude liquid was purified by DCVC (2.5-10\% EtOAc/hexanes) to afford a clear liquid (5.79 g, 96\%).

$\boldsymbol{R}_{f} 0.09\left(5 \%\right.$ EtOAc/hexanes, $\left.\mathrm{KMnO}_{4}\right) .{ }^{1} \mathbf{H}$ NMR $\left(\mathrm{CDCl}_{3}, 300 \mathrm{MHz}\right): \delta 5.81\left(\mathrm{ddt},{ }^{3} J=\right.$ 17.1, 10.2, 6.6 Hz, 1H), 5.03-4.92 (m, 2H), $2.04\left(\mathrm{q},{ }^{3} J=7.5 \mathrm{~Hz}, 2 \mathrm{H}\right), 1.57-1.53(\mathrm{~m}, 2 \mathrm{H})$, 1.40- $1.23(\mathrm{~m}, 10 \mathrm{H}), 1.18(\mathrm{~s}, 1 \mathrm{H}) .{ }^{13} \mathbf{C}$ NMR $\left(\mathrm{CDCl}_{3}, 75 \mathrm{MHz}\right): \delta$ 139.2, 114.2, 62.4 (quintet, $\left.{ }^{1} J=21.0 \mathrm{~Hz}\right), 33.8,32.6,29.4,29.5,29.1,28.9,25.7$. FTIR $\left(\mathrm{NaCl}\right.$ plate, $\left.\mathrm{cm}^{-1}\right)$ : 3334, 2926, 2855, 1641, 1465, 1367, 1134, 967, 909.

Spectroscopic data was in good agreement with literature. ${ }^{52}$

\subsection{5 dec-9-en-1- $d$-al (32)}

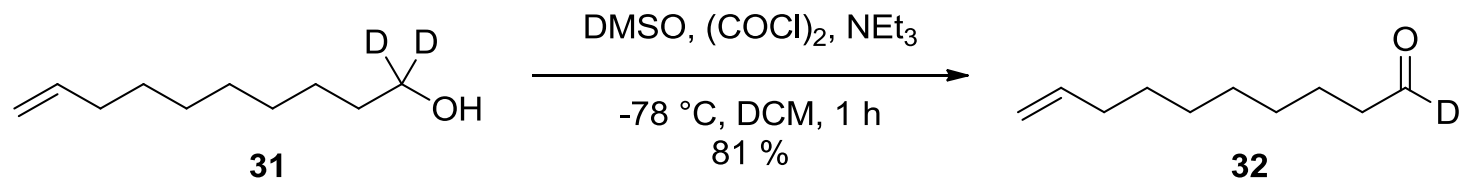

Prepared analogously to $\mathbf{2 8}$. Product was a clear oil (4.38 g, 81\%, 99\% D)

$\boldsymbol{R}_{\boldsymbol{f}} 0.26\left(5 \% \mathrm{Et}_{2} \mathrm{O} /\right.$ hexanes, $\left.\mathrm{KMnO}_{4}\right) .{ }^{1} \mathbf{H} \mathbf{N M R}\left(\mathrm{CDCl}_{3}, 300 \mathrm{MHz}\right): \delta 9.77\left(\mathrm{t},{ }^{3} J=1.8\right.$ $\mathrm{Hz}, 0.01 \mathrm{H}) 5.81\left(\mathrm{ddt},{ }^{3} J=17.1,10.2,6.6 \mathrm{~Hz}, 1 \mathrm{H}\right), 5.03-4.91(\mathrm{~m}, 2 \mathrm{H}), 2.42\left(\mathrm{t},{ }^{3} J=7.2\right.$ $\mathrm{Hz}, 2 \mathrm{H}$ ), 2.04 (q, $\left.{ }^{3} J=7.2 \mathrm{~Hz}, 2 \mathrm{H}\right), 1.63$ (quintet, ${ }^{3} J=7.2 \mathrm{~Hz}, 2 \mathrm{H}$ ), $1.41-1.23$ (m, 10H). ${ }^{13}$ C NMR $\left(\mathrm{C}_{6} \mathrm{D}_{6}, 100 \mathrm{MHz}\right): \delta 200.0\left(\mathrm{t},{ }^{1} J=26.0 \mathrm{~Hz}\right) 138.8,114.2,43.2\left(\mathrm{t},{ }^{2} J=3.7 \mathrm{~Hz}\right)$, 33.8, 29.1, 28.9, 28.8, 28.7, 21.8. FTIR ( $\mathrm{NaCl}$ plate, $\left.\mathrm{cm}^{-1}\right): 3077,2929,2856,2066$, 1716, 1641, 1465, 1406, 1095, 995, 910. 


\subsection{Synthesis of 9- $d_{1}$-hydrosterculic acid}

\subsection{1 $\left(S_{S}, S_{S},\right)$-1,1-bis $(p$-tolylsulfinyl)undec-10-en-2-d-2-ol (33)}

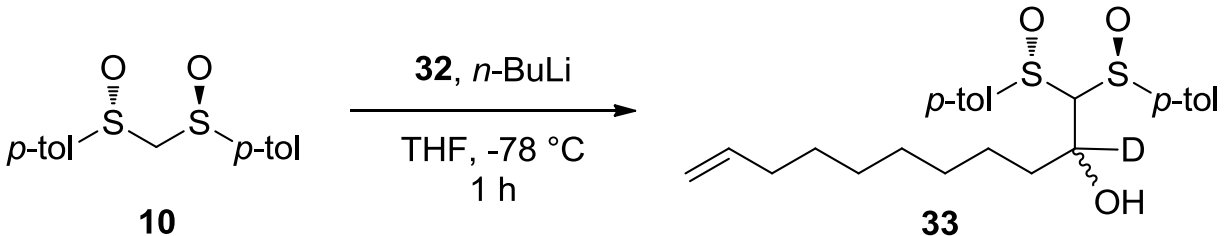

The protocol was adapted from the literature procedure reported by Malacria. ${ }^{53} \mathrm{~A}$ solution of $n$-BuLi in hexanes $(3.9 \mathrm{ml}, 2.91 \mathrm{M}, 11.3 \mathrm{mmol})$ was added dropwise to a solution of bis(sulfoxide) $\mathbf{1 0}{ }^{\mathrm{ii}}(2.99 \mathrm{~g}, 10.2 \mathrm{mmol})$ dissolved in THF $(43 \mathrm{ml})$ at $-50{ }^{\circ} \mathrm{C}$. The light yellow solution was allowed to warm to $-40{ }^{\circ} \mathrm{C}$ for $1 \mathrm{~h}$ to ensure complete formation of anion. Then the solution was re-cooled to $-78{ }^{\circ} \mathrm{C}$ in an acetone/dry ice bath for $15 \mathrm{~min}$. Aldehyde $32(6.51 \mathrm{~g}, 42 \mathrm{mmol})$ was chilled to $0{ }^{\circ} \mathrm{C}$ and added neat via cannula over $10 \mathrm{~min}$. The reaction was allowed to stir at this temperature for $30 \mathrm{~min}$ before quenching with saturated aqueous $\mathrm{NH}_{4} \mathrm{Cl}(60 \mathrm{ml})$ and subsequent warming to ambient temperature. The layers were separated and aqueous layer was extracted with DCM $(3 \times 50 \mathrm{ml})$. The combined organic layers were washed with brine, dried over anhydrous $\mathrm{Na}_{2} \mathrm{SO}_{4}$, filtered and concentrated to give a yellow oil $(9.5 \mathrm{~g})$. This material was semi-purified by FCC $(20-80 \%$ EtOAc/hexanes $)$ to afford a mixture of diastereomeric alcohols and dehydrated product $\mathbf{3 3}$ as a light yellow oil (4.06 g).

$\boldsymbol{R}_{\boldsymbol{f}} 0.42\left(50 \% \text { EtOAc/hexanes, UV, } \mathrm{KMnO}_{4}\right)^{\mathrm{iii}}$

ii best results were obtained if bis(sulfoxide) was dried under vacuum at $65^{\circ} \mathrm{C}$ for $18 \mathrm{~h}$.

iii product was not fully characterized due to its limited shelf life and complexity of spectra. 


\subsection{2 $\left(S_{S}, S_{S}\right)$-1,1-di-p-tolylsulfinyl-2-d-oct-1,10-diene (34)}

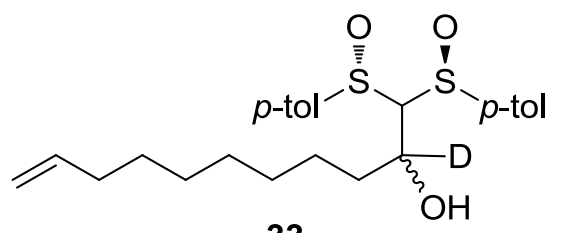

33

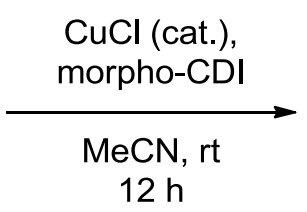

$12 \mathrm{~h}$

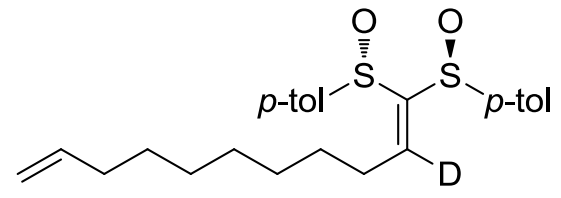

34

This protocol was adapted from the literature procedure reported by Malacria. ${ }^{53}$ A $500 \mathrm{ml}$ round-bottomed flask was charged with the mixture of diastereomeric alcohols and $\mathbf{3 4}$ prepared above (4.06 g, $9.10 \mathrm{mmol}), \mathrm{MeCN}$ (180 ml), and morpho-CDI (5.80 g, 13.7 mmol). To this solution, anhydrous $\mathrm{CuCl}_{2}(193 \mathrm{mg}, 1.43 \mathrm{mmol})$ was added and the mixture was stirred at room temperature for 12 hours. The reaction mixture was diluted in $\mathrm{CH}_{2} \mathrm{Cl}_{2}(160 \mathrm{ml})$ and filtered through a short pad of Celite and silica gel; the filter cake was washed with DCM $(200 \mathrm{ml})$ then EtOAc $(100 \mathrm{ml})$ and concentrated in vacuo to afford 34 as a yellow to blue-green oil (3.72 g). This oil was used without further purification because it was unstable to flash chromatography.

$\boldsymbol{R}_{\boldsymbol{f}} 0.56\left(40 \%\right.$ EtOAc, $\left.\mathrm{UV}, \mathrm{KMnO}_{4}\right)$.

\subsection{3 $\left(S_{S}, S_{S}, 2 R\right)$-1,1-bis-p-tolylsulfinyl-2-d-2-dec-10-enylcyclopropane (35)}

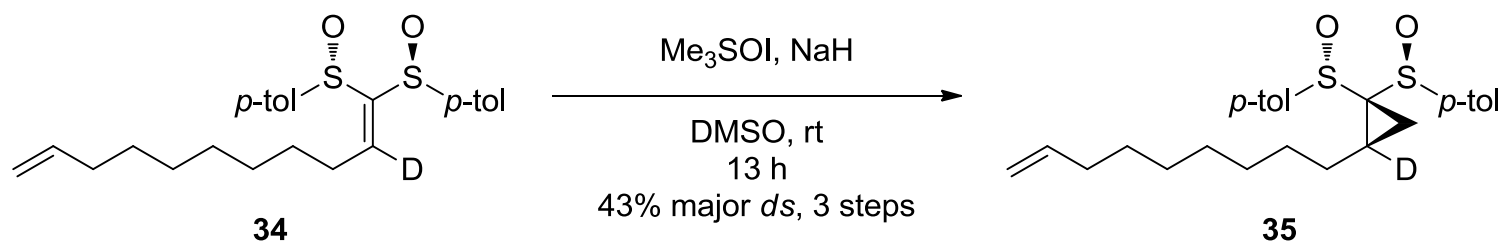

DMSO (68 ml) was cautiously added to a mixture of $\mathrm{NaH}(1.04 \mathrm{~g}, 95 \%, 41.2 \mathrm{mmol})$ and $\mathrm{Me}_{3} \mathrm{SOI}(9.55 \mathrm{~g}, 43.4 \mathrm{mmol})$ while stirring at room temperature until the mixture became 
homogeneous (30 min). To this solution was added alkylidene bis-sulfoxide 34 (3.72 g, $8.66 \mathrm{mmol}$ ) and the resultant mixture was stirred at room temperature for $12 \mathrm{~h}$, at which point the reaction was quenched with saturated aqueous $\mathrm{NH}_{4} \mathrm{Cl}(100 \mathrm{ml})$. The mixture was extracted with $\mathrm{Et}_{2} \mathrm{O}(3 \times 125 \mathrm{ml})$ and the combined organic layers were washed with brine $(200 \mathrm{ml})$, dried over anhydrous $\mathrm{Na}_{2} \mathrm{SO}_{4}$, filtered and concentrated to give a viscous yellow oil (3.38 g). The crude oil was exhaustively purified by FCC (Tol/Hex/EtOAc/3methyl-2-butanone 26:10:3:4) to afford major-35 as a colourless oil (1.97 g, 43\% yield over 3 steps).

$\boldsymbol{R}_{\boldsymbol{f}} 0.14\left(20 \%\right.$ EtOAc/PhMe, UV, $\left.\mathrm{KMnO}_{4}\right) \cdot[\alpha]^{26}{ }_{\mathrm{D}}=-114.08\left(c=0.233, \mathrm{CHCl}_{3}\right) .{ }^{1} \mathbf{H}$ NMR (CDCl, $300 \mathrm{MHz}): \delta 7.57\left(\mathrm{~d},{ }^{3} J=8.1 \mathrm{~Hz}, 2 \mathrm{H}\right), 7.36\left(\mathrm{~d},{ }^{3} J=7.8 \mathrm{~Hz}, 2 \mathrm{H}\right), 7.21(\mathrm{~d}$, $\left.{ }^{3} J=6.6 \mathrm{~Hz}, 2 \mathrm{H}\right), 7.05\left(\mathrm{~d},{ }^{3} J=8.4 \mathrm{~Hz}, 2 \mathrm{H}\right), 5.81\left(\mathrm{ddt},{ }^{3} J=17.1,10.2,6.6 \mathrm{~Hz}, 1 \mathrm{H}\right), 5.03-$ $4.92(\mathrm{~m}, 2 \mathrm{H}), 2.45$ (s, 3H), 2.39 (s, 3H), 2.04 (q, $\left.{ }^{3} \mathrm{~J}=7.5 \mathrm{~Hz}, 2 \mathrm{H}\right), 1.78-1.68(\mathrm{~m}, 2 \mathrm{H})$, 1.41-1.19 (m, 10H). ${ }^{13} \mathrm{C}$ NMR $\left(\mathrm{CDCl}_{3}, 75 \mathrm{MHz}\right): \delta 143.1,142.2,139.1,138.9,138.4$, $130.1,129.8,126.5,125.2,114.2,62.9,33.8,29.6,29.3,29.0,29.0,28.9,27.3,24.7\left(t,{ }^{1} J\right.$ $=23.0 \mathrm{~Hz}), 21.6,21.5,13.3$. FTIR $\left(\mathrm{NaCl}\right.$ plate, $\left.\mathrm{cm}^{-1}\right): 3058,2976,2926,2855,1640$, 1596, 1492, 1454, 1399, 1303, 1209, 1178, 1085, 1048, 1015, 994, 909, 809, 731, 635. 


\subsection{4 $\left(S_{S}\right)$-1-p-tolylsulfinyl-(1R,2R)-2-d-2-(non-8-en-1-yl)-1-(8,8,8- $d_{3^{-}}$}

\section{octyl)cyclopropane (37)}

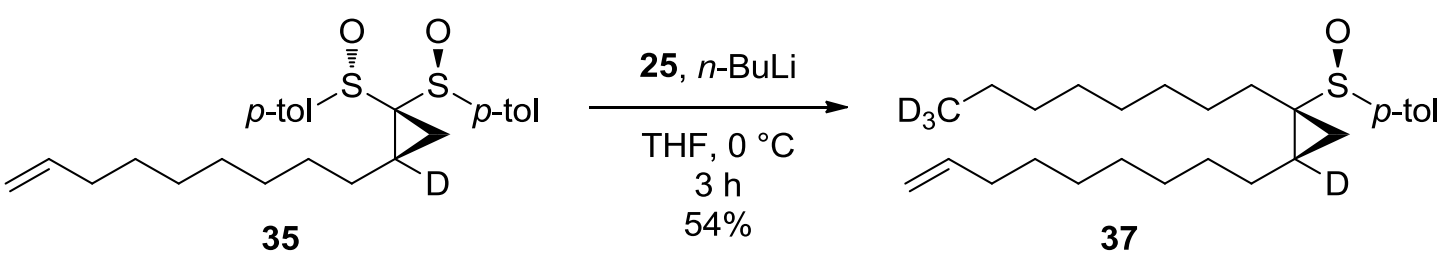

This protocol was adapted from the literature procedure reported by Marek and coworkers. ${ }^{35}$ A solution of $n$-BuLi in hexanes $(2.15 \mathrm{ml}, 2.50 \mathrm{M}, 4.7 \mathrm{mmol})$ was added dropwise to a solution of bis(sulfoxide) $\mathbf{3 5}(0.92 \mathrm{~g}, 2.1 \mathrm{mmol})$ in THF $(21 \mathrm{ml})$ at $-78{ }^{\circ} \mathrm{C}$. The solution was then warmed to $-40{ }^{\circ} \mathrm{C}$ and stirred for $1 \mathrm{~h}$. Labelled iodooctane 25 (3.01 $\mathrm{g}, 12.4 \mathrm{mmol}$ ) was added to the reaction mixture dropwise neat via cannula and stirred at $0{ }^{\circ} \mathrm{C}$ for $3 \mathrm{~h}$. The mixture was quenched with saturated aqueous $\mathrm{NH}_{4} \mathrm{Cl}(30 \mathrm{ml})$; the layers were separated and the aqueous layer was extracted with $\mathrm{Et}_{2} \mathrm{O}(3 \times 30 \mathrm{ml})$. The combined organic layers were combined and dried over anhydrous $\mathrm{Na}_{2} \mathrm{SO}_{4}$, filtered and concentrated to give a light yellow liquid ( $3.45 \mathrm{~g})$. The crude oil was purified by FCC (10-30\% $\mathrm{Et}_{2} \mathrm{O}$ in hexanes) to afford a colourless oil ( $\left.0.48 \mathrm{~g}, 60 \%\right)$.

$\boldsymbol{R}_{\boldsymbol{f}} 0.29\left(30 \% \mathrm{Et}_{2} \mathrm{O} / \mathrm{hexanes}, \mathrm{UV}, \mathrm{KMnO}_{4}\right) .[\alpha]^{25}=+62.13\left(c=0.235, \mathrm{CHCl}_{3}\right) .{ }^{1} \mathbf{H} \mathbf{N M R}$ $\left(\mathrm{CDCl}_{3}, 300 \mathrm{MHz}\right): \delta 7.50\left(\mathrm{~d},{ }^{3} J=8.1 \mathrm{~Hz}, 2 \mathrm{H}\right), 7.29\left(\mathrm{~d},{ }^{3} J=7.8 \mathrm{~Hz}, 2 \mathrm{H}\right), 5.81\left(\mathrm{ddt},{ }^{3} J=\right.$ 17.1, 10.2, 6.6 Hz, 1H), 5.03-4.91 (m, 2H), 2.41 (s, 3H), $2.03\left(\mathrm{q},{ }^{3} J=7.5 \mathrm{~Hz}, 2 \mathrm{H}\right), 1.65-$ $1.45(\mathrm{~m}, 2 \mathrm{H}), 1.44-1.05(\mathrm{~m}, 25 \mathrm{H}), 0.42\left(\mathrm{~d},{ }^{2} J=5.4 \mathrm{~Hz}, 1 \mathrm{H}\right) .{ }^{13} \mathbf{C}$ NMR $\left(\mathrm{CDCl}_{3}, 75\right.$ MHz): $\delta$ 141.4, 140.0, 139.2, 129.5, 125.1, 114.2, 44.2, 33.8, 31.8, 29.7, 29.4, 29.4, 29.3, $29.5,29.2,29.0,28.9,28.2,27.4,26.1,22.4,21.4,18.5\left(\mathrm{t},{ }^{1} J=25.0 \mathrm{~Hz}\right), 14.6,13.2$ 
(quintet, $\left.{ }^{1} J=19.0 \mathrm{~Hz}\right)$. FTIR $\left(\mathrm{NaCl}\right.$ plate, $\left.\mathrm{cm}^{-1}\right): 3075,2925,2855,1640,1463,1085$, $1053,908,807,722$.

\subsection{5 (1R,2S)-1-d-1-(non-8-en-1-yl)-2-(8,8,8- $d_{3}$-octyl)cyclopropane (38)}

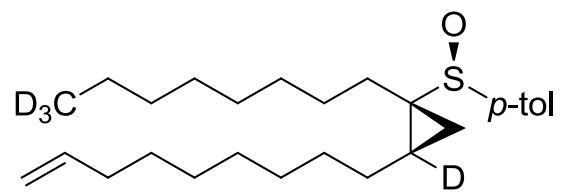

37

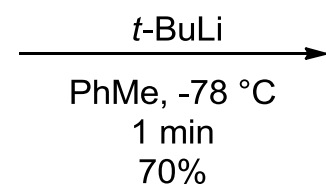

$70 \%$

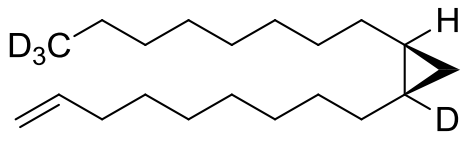

38

A $t$-BuLi solution in pentane $(2.15 \mathrm{ml}, 1.5 \mathrm{M}, 3.2 \mathrm{mmol})$ was added in one portion (as quickly and safely as possible) to a stirred solution of sulfoxide 37 (438 $\mathrm{mg}, 1.0 \mathrm{mmol}$ ) in toluene $(21 \mathrm{ml})$ at $-78{ }^{\circ} \mathrm{C}$. The reaction was stirred for $1 \mathrm{~min}$ before quenching with $\mathrm{MeOH}(3 \mathrm{ml})$ and allowing it to warm to $0{ }^{\circ} \mathrm{C}$ for $1 \mathrm{~h}$. Saturated $\mathrm{NH}_{4} \mathrm{Cl}(25 \mathrm{ml})$ was then added, the layers were separated and aqueous layer was extracted with $\mathrm{Et}_{2} \mathrm{O}(3 \times 20 \mathrm{ml})$. The combined organic layers were dried over anhydrous $\mathrm{MgSO}_{4}$, filtered, and concentrated to afford a crude oil $(0.65 \mathrm{~g})$. The oil was the purified by FCC (100\% HPLC grade hexanes) to afford $\mathbf{3 8}(202 \mathrm{mg}, 70 \%)$.

$\boldsymbol{R}_{\boldsymbol{f}} 0.88\left(100 \%\right.$ hexanes, $\left.\mathrm{I}_{2}, \mathrm{KMnO}_{4}\right) .[\alpha]^{25}{ }_{\mathrm{D}}=+2.012\left(c=0.400, \mathrm{CHCl}_{3}\right) .{ }^{1} \mathbf{H} \mathbf{~ N M R}$ $\left(\mathrm{CDCl}_{3}, 300 \mathrm{MHz}\right): \delta \quad 5.82\left(\mathrm{ddt},{ }^{3} J=17.1,10.2,6.6 \mathrm{~Hz}, 1 \mathrm{H}\right), 5.05-4.89(\mathrm{~m}, 2 \mathrm{H}), 2.04(\mathrm{q}$, $\left.{ }^{3} J=7.2 \mathrm{~Hz}, 2 \mathrm{H}\right), 1.45-1.22(\mathrm{~m}, 26 \mathrm{H}), 0.71-0.58(\mathrm{~m}, 1 \mathrm{H}), 0.58-0.51(\mathrm{~m}, 1 \mathrm{H}),-0.34(\mathrm{t}, J=$ $4.8 \mathrm{~Hz}, 1 \mathrm{H}) .{ }^{13} \mathbf{C}$ NMR $\left(\mathrm{CDCl}_{3}, 75 \mathrm{MHz}\right): \delta 139.2,114.1,33.8,31.9,30.2,30.2,29.7$, 29.6, 29.6, 29.4, 29.2, 29.0, 28.7, 28.6, 22.4, 15.7, 15.4 (t, $\left.{ }^{1} J=23.0 \mathrm{~Hz}\right), 13.2$ (quintet, ${ }^{1} J$ $=19.0 \mathrm{~Hz}), 10.8$. FTIR $\left(\mathrm{NaCl}\right.$ plate, $\left.\mathrm{cm}^{-1}\right):$ 3060, 2989, 2925, 2854, 1641, 1465, 909. 


\subsubsection{Methyl (9R,10S)-9-d-10-hydrosterculate (39)}

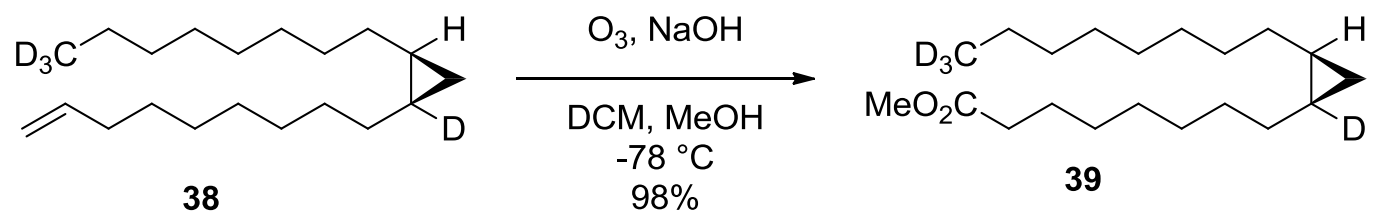

This protocol was adapted from the literature procedure reported by Marshall. ${ }^{54}$ A $100 \mathrm{ml}$ three-necked round-bottomed flask was charged with alkene 38 (112.9 mg, $0.40 \mathrm{mmol})$, DCM (15 ml), $\mathrm{MeOH}(4.4 \mathrm{ml})$, and $\mathrm{NaOH}(479.3 \mathrm{mg}, 12 \mathrm{mmol})$. The mixture was allowed to stir at ambient temperature until all $\mathrm{NaOH}$ was dissolved (10 min), and then cooled to $-78{ }^{\circ} \mathrm{C}$. Once cooled, $\mathrm{O}_{3}$ was bubbled through the resulting solution until it turned faintly blue $(1.5 \mathrm{~h})$. Argon was bubbled through the mixture for $10 \mathrm{~min}$ to remove any excess $\mathrm{O}_{3}$. The frothy mixture was allowed to warm to ambient temperature before dilution with $\mathrm{H}_{2} \mathrm{O}(30 \mathrm{ml})$ and $\mathrm{Et}_{2} \mathrm{O}(25 \mathrm{ml})$. The layers were separated and the aqueous layer was extracted with $\mathrm{Et}_{2} \mathrm{O}(3 \times 25 \mathrm{ml})$. Organic layers were combined and dried over anhydrous $\mathrm{Na}_{2} \mathrm{SO}_{4}$, filtered and concentrated to give a clear oil (137.8 mg, 90\% purity, $98 \%$ yield). The crude oil was used without further purification.

$\boldsymbol{R}_{\boldsymbol{f}} 0.51\left(10 \% \mathrm{Et}_{2} \mathrm{O} /\right.$ hexanes, $\left.\mathrm{KMnO}_{4}, \mathrm{UV}\right) .{ }^{1} \mathbf{H}$ NMR $\left(\mathrm{CDCl}_{3}, 300 \mathrm{MHz}\right): \delta 3.67(\mathrm{~s}, 3 \mathrm{H})$, $2.31\left(\mathrm{t},{ }^{3} J=7.5 \mathrm{~Hz}, 2 \mathrm{H}\right), 1.66-1.62(\mathrm{~m}, 2 \mathrm{H}), 1.39-1.20(\mathrm{~m}, 24 \mathrm{H}), 0.69-0.60(\mathrm{~m}, 1 \mathrm{H})$, 0.57-0.51 (m, 1H), $-0.34(\mathrm{t}, J=4.2 \mathrm{~Hz}, 1 \mathrm{H})$. 


\subsection{7 (9R,10S)-9-d-10-hydrosterculic acid (2)}

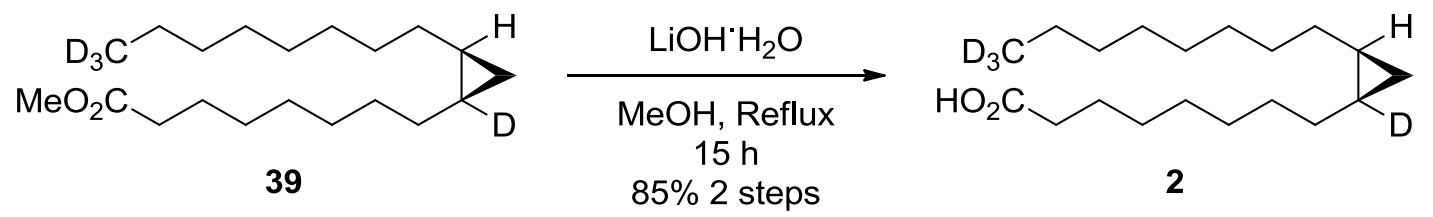

This protocol was adapted from the literature procedure reported by Kitahara. ${ }^{55}$ Crude ester 39 (137.8 mg, $0.44 \mathrm{mmol}$ if pure), $\mathrm{LiOH} \bullet \mathrm{H}_{2} \mathrm{O}(186.3 \mathrm{mg}, 4.4 \mathrm{mmol})$ were dissolved in $\mathrm{MeOH}(14.5 \mathrm{ml})$ and heated to reflux for $15 \mathrm{~h}$. The resulting reaction mixture was allowed to cool to ambient temperature before acidifying with $1 \mathrm{M} \mathrm{HCl}(5 \mathrm{ml})$ and concentrating under reduced pressure to remove the $\mathrm{MeOH}$. EtOAc $(15 \mathrm{ml})$ was added and the layers were separated. The aqueous layer was extracted with EtOAc $(3 \times 10 \mathrm{ml})$, and the combined organic layers were dried over anhydrous $\mathrm{Na}_{2} \mathrm{SO}_{4}$, filtered and concentrated to give a crude light brown oil $(120.5 \mathrm{mg})$. The crude oil was purified by FCC (9\% EtOAc/1\% AcOH/ hexanes) to afford acid 2 (102 mg, 85\% over two steps, $98 \% \mathrm{D}$ at $\left.\mathrm{C}_{9}\right)$

$\boldsymbol{R}_{f} 0.20\left(9 \% \mathrm{EtOAc} / 1 \% \mathrm{AcOH} /\right.$ hexanes, $\left.\mathrm{I}_{2}, \mathrm{KMnO}_{4}\right) .{ }^{1} \mathbf{H}$ NMR $\left(\mathrm{CDCl}_{3}, 300 \mathrm{MHz}\right): \delta$ 10.98 (br s, 1H), 2.35 (t, ${ }^{3} J=7.2 \mathrm{~Hz}, 2 \mathrm{H}$ ), 1.64 (quintet, ${ }^{3} J=7.2 \mathrm{~Hz}, 2 \mathrm{H}$ ), 1.45-1.21 (m, $22 \mathrm{H}), 1.19-1.05(\mathrm{~m}, 2 \mathrm{H}), 0.69-0.61(\mathrm{~m}, 1 \mathrm{H}), 0.57-0.53(\mathrm{~m}, 1 \mathrm{H}),-0.34\left(\mathrm{t},{ }^{3} J=4.5 \mathrm{~Hz}\right.$, 1H). ${ }^{13} \mathbf{C ~ N M R ~}\left(\mathrm{CDCl}_{3}, 75 \mathrm{MHz}\right): \delta 179.9,34.0,31.9,30.2,30.1,29.7,29.4,29.4,29.3$, 29.1, 28.7, 28.5, 24.7, 22.4, 15.7, $15.3\left(\mathrm{t},{ }^{1} J=23.6 \mathrm{~Hz}\right), 13.2\left(\mathrm{t},{ }^{1} J=19.0 \mathrm{~Hz}\right), 10.8$. FTIR ( NaCl plate, $\left.\mathrm{cm}^{-1}\right): 3057,2924,2854$, 2676, 2213, 1711, 1465, 1413, 1285, 936. 


\subsection{Synthesis of 10- $d_{1}$-dihydrosterculic acid}

\subsection{1 $\left(S_{S}, S_{S}, 2 R\right)-1,1-b i s-p$-tolylsulfinyl-2-dec-10-enylcyclopropane (13)}

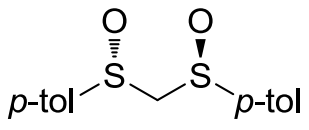

10

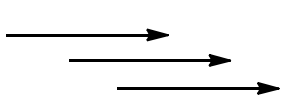

$35 \%$ major $d s, 3$ steps

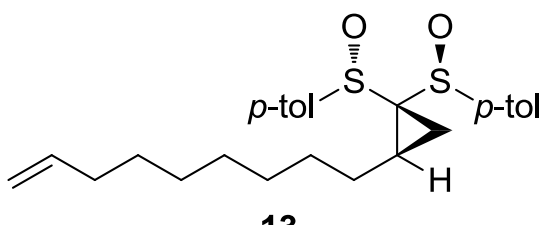

13

Prepared analogously to $\mathbf{3 5}$ except aldehyde $\mathbf{2 8}$ was used. Product was a clear oil $(1.61 \mathrm{~g}$, $35 \%$ over 3 steps)

$\boldsymbol{R}_{\boldsymbol{f}} 0.35\left(20 \%\right.$ EtOAc/PhMe, $\left.\mathrm{KMnO}_{4}, \mathrm{UV}\right) .{ }^{1} \mathbf{H}$ NMR $\left(\mathrm{CDCl}_{3}, 400 \mathrm{MHz}\right): \delta 7.58\left(\mathrm{~d},{ }^{3} J=\right.$ $8.0 \mathrm{~Hz}, 2 \mathrm{H}), 7.37\left(\mathrm{~d},{ }^{3} J=8 \mathrm{~Hz}, 2 \mathrm{H}\right), 7.23\left(\mathrm{~d},{ }^{3} J=8 \mathrm{~Hz}, 2 \mathrm{H}\right), 7.07\left(\mathrm{~d},{ }^{3} J=8.0 \mathrm{~Hz}, 2 \mathrm{H}\right)$, $5.81\left(\mathrm{ddt},{ }^{3} J=17.2,10.4,6.4 \mathrm{~Hz}, 1 \mathrm{H}\right), 5.03-4.92(\mathrm{~m}, 2 \mathrm{H}), 2.49(\mathrm{~s}, 3 \mathrm{H}), 2.41(\mathrm{~s}, 3 \mathrm{H}), 2.05$ $\left(\mathrm{q},{ }^{3} J=6.8 \mathrm{~Hz}, 2 \mathrm{H}\right), 1.80-1.62(\mathrm{~m}, 2 \mathrm{H}), 1.40-1.25(\mathrm{~m}, 11 \mathrm{H})$.

Spectroscopic data was in good agreement with literature. ${ }^{27}$

\subsection{2 $\left(S_{S}\right)-1-p-t o l y l s u l f i n y l-(1 R, 2 R)-2-d-2-\left(\right.$ non-8-en-1-yl)-1-(8,8,8- $d_{3}-$} octyl)cyclopropane (42)

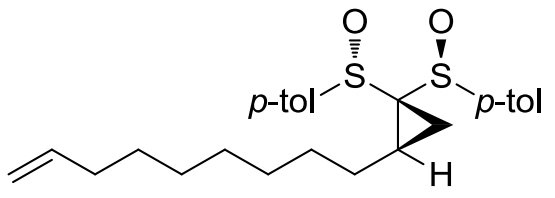

13

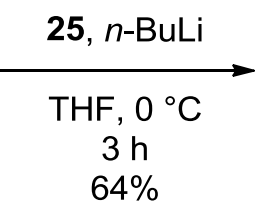
$64 \%$

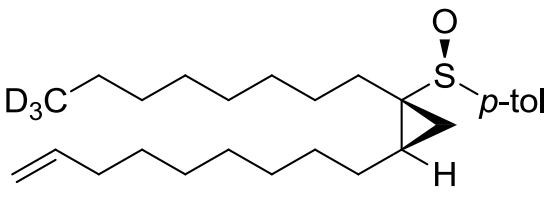

42

Prepared analogously to 37. Product was a clear oil (1.61 g, 64\%)

$\boldsymbol{R}_{\boldsymbol{f}} 0.29\left(30 \% \mathrm{Et}_{2} \mathrm{O} /\right.$ hexanes, UV, $\left.\mathrm{KMnO}_{4}\right) \cdot[\alpha]^{23}{ }_{\mathrm{D}}=+57.27\left(c=0.220, \mathrm{CHCl}_{3}\right) .{ }^{1} \mathbf{H} \mathbf{~ N M R}$ $\left(\mathrm{CDCl}_{3}, 400 \mathrm{MHz}\right): \delta 7.50\left(\mathrm{~d},{ }^{3} J=8.0 \mathrm{~Hz}, 2 \mathrm{H}\right), 7.29\left(\mathrm{~d},{ }^{3} J=8.0 \mathrm{~Hz}, 2 \mathrm{H}\right), 5.81\left(\mathrm{ddt},{ }^{3} J=\right.$ 
17.2, 10.4, 6.4 Hz, 1H), 5.04-4.87 (m, 2H), $2.41(\mathrm{~s}, 3 \mathrm{H}), 2.03\left(\mathrm{q},{ }^{3} J=7.6 \mathrm{~Hz}, 2 \mathrm{H}\right), 1.65-$ $1.45(\mathrm{~m}, 3 \mathrm{H}), 1.44-1.05(\mathrm{~m}, 25 \mathrm{H}), 0.42\left(\mathrm{t},{ }^{2} J=6.4 \mathrm{~Hz}, 1 \mathrm{H}\right) .{ }^{13} \mathbf{C}$ NMR $\left(\mathrm{CDCl}_{3}, 100\right.$ MHz): $\delta 141.4,139.8,139.1,129.5,125.1,114.2,44.4,33.8,31.8,29.8,29.4,29.4,29.3$, 29.3, 29.2, 29.0, 28.9, 28.3, 27.4, 26.2, 22.4, 21.4, 18.8, 14.7, 13.2 (quintet, ${ }^{1} J=18.0 \mathrm{~Hz}$ ). FTIR $\left(\mathrm{NaCl}\right.$ plate, $\left.\mathrm{cm}^{-1}\right):$ 2925, 2854, 2360, 1640, 1492, 1464.

\subsection{3 (1R,2S)-1-(non-8-en-1-yl)-2-2- $d-\left(8,8,8-d_{3}\right.$-octyl)cyclopropane (43)}

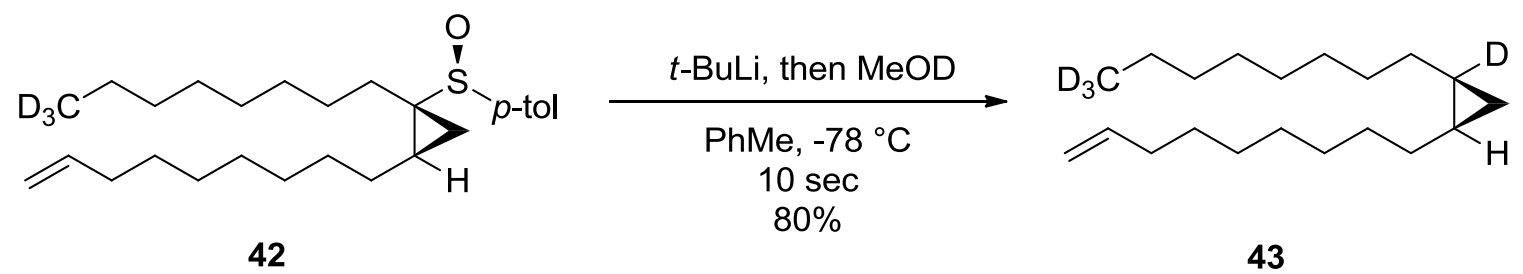

A $t$-BuLi solution in pentane $(0.75 \mathrm{ml}, 1.5 \mathrm{M}, 0.5 \mathrm{mmol})$ was added in one portion (as quickly and safely as possible) to a stirred solution of sulfoxide $\mathbf{4 2}(151.3 \mathrm{mg}, 0.36$ mmol) in toluene $(7.1 \mathrm{ml})$ at $-78{ }^{\circ} \mathrm{C}$. The reaction was stirred for 10 seconds before quenching with $\mathrm{MeOD}(1 \mathrm{ml})$ in one portion; the mixture was then warmed to $0{ }^{\circ} \mathrm{C}$ and stirred for $1 \mathrm{~h}$. Saturated $\mathrm{NH}_{4} \mathrm{Cl}(10 \mathrm{ml})$ was then added, the layers were separated and aqueous layer was extracted with $\mathrm{Et}_{2} \mathrm{O}(3 \times 10 \mathrm{ml})$. The combined organic layers were dried over anhydrous $\mathrm{MgSO}_{4}$, filtered, and concentrated to afford a crude oil (0.30 g). The oil was the purified by FCC (100\% HPLC grade hexanes) to afford $\mathbf{4 3}(93.1 \mathrm{mg}$, $80 \%, 84 \%$ D at $\left.\mathrm{C}_{10}\right)$.

$\boldsymbol{R}_{\boldsymbol{f}} 0.92\left(100 \%\right.$ hexanes, $\left.\mathrm{I}_{2}, \mathrm{KMnO}_{4}\right) \cdot[\alpha]_{\mathrm{D}}^{22}=+2.041\left(c=0.392, \mathrm{CHCl}_{3}\right) .{ }^{1} \mathbf{H}$ NMR $\left(\mathrm{CDCl}_{3}, 400 \mathrm{MHz}\right): \delta 5.82\left(\mathrm{ddt},{ }^{3} J=17.2,10.4,6.8 \mathrm{~Hz}, 1 \mathrm{H}\right), 5.05-4.90(\mathrm{~m}, 2 \mathrm{H}), 2.04(\mathrm{q}$, 
$\left.{ }^{3} J=7.6 \mathrm{~Hz}, 2 \mathrm{H}\right), 1.45-1.10(\mathrm{~m}, 26 \mathrm{H}), 0.71-0.58(\mathrm{~m}, 1 \mathrm{H}), 0.58-0.51(\mathrm{~m}, 1 \mathrm{H}),-0.34(\mathrm{t}, J=$ 4.4 Hz, 1H). ${ }^{13} \mathbf{C}$ NMR $\left(\mathrm{CDCl}_{3}, 100 \mathrm{MHz}\right): \delta$ 139.3, 114.1, 33.8, 31.8, 30.2, 29.7, 29.6, 29.5, 29.4, 29.2, 29.0, 28.7, 28.6, 22.4, 15.7, $15.4\left(\mathrm{t},{ }^{1} J=23.0 \mathrm{~Hz}\right), 13.2\left(\mathrm{t},{ }^{1} J=19.0 \mathrm{~Hz}\right)$, 10.8. FTIR (NaCl plate, $\left.\mathrm{cm}^{-1}\right)$ : 3076, 3060, 2989, 2912, 2856, 1641, 1464, 992, 909.

\subsubsection{Methyl $(9 R, 10 S)-10-d$-dihydrosterculate (50)}

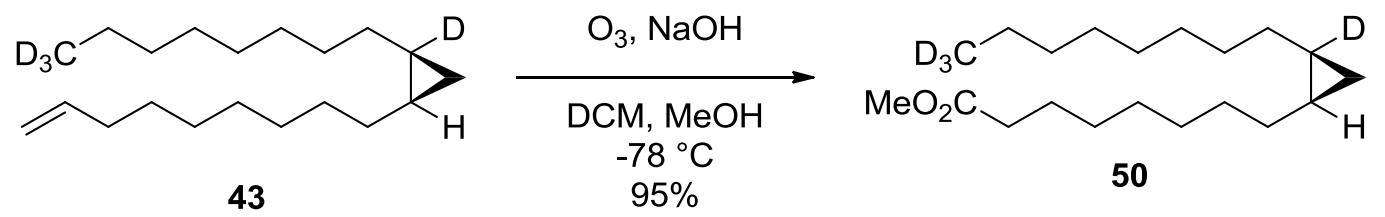

Prepared analogously to 39. Product was a clear oil (90 mg, 95\%)

$\boldsymbol{R}_{f} 0.49\left(10 \% \mathrm{Et}_{2} \mathrm{O} / \mathrm{hexanes}, \mathrm{KMnO}_{4}, \mathrm{UV}\right) .{ }^{1} \mathbf{H} \mathbf{N M R}\left(\mathrm{CDCl}_{3}, 300 \mathrm{MHz}\right): \delta 3.67(\mathrm{~s}, 3 \mathrm{H})$, $2.31\left(\mathrm{t},{ }^{3} J=7.5 \mathrm{~Hz}, 2 \mathrm{H}\right), 1.66-1.62(\mathrm{~m}, 2 \mathrm{H}), 1.39-1.20(\mathrm{~m}, 24 \mathrm{H}), 0.69-0.60(\mathrm{~m}, 1 \mathrm{H})$, $0.57-0.51(\mathrm{~m}, 1 \mathrm{H}),-0.34(\mathrm{t}, J=4.2 \mathrm{~Hz}, 1 \mathrm{H})$. 


\subsection{5 (9R,10S)-10-d-dihydrosterculic acid (3)}

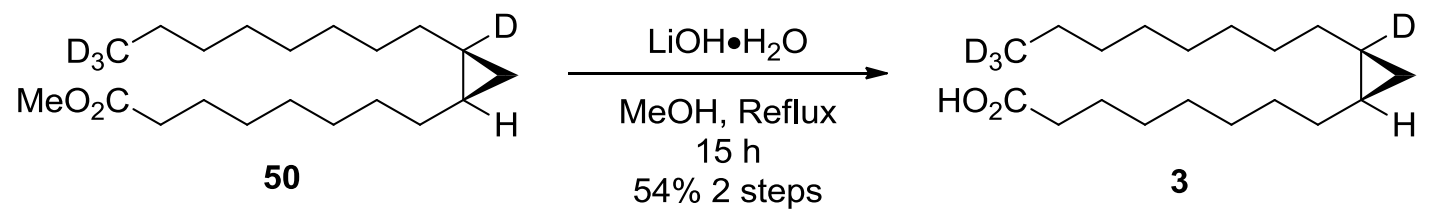

Prepared analogously to 3. Product was light yellow solid (43 mg, 54\%)

$\boldsymbol{R}_{\boldsymbol{f}} 0.20\left(9 \% \mathrm{EtOAc} / 1 \% \mathrm{AcOH} /\right.$ hexanes, $\left.\mathrm{I}_{2}, \mathrm{KMnO}_{4}\right) .{ }^{1} \mathbf{H} \mathbf{N M R}\left(\mathrm{CDCl}_{3}, 300 \mathrm{MHz}\right): \delta$ 10.98 (br s, 1H), 2.35 (t, $\left.{ }^{3} J=7.2 \mathrm{~Hz}, 2 \mathrm{H}\right), 1.64$ (quintet, $\left.{ }^{3} J=7.2 \mathrm{~Hz}, 2 \mathrm{H}\right), 1.45-1.21(\mathrm{~m}$, $22 \mathrm{H}), 1.19-1.05(\mathrm{~m}, 2 \mathrm{H}), 0.69-0.61(\mathrm{~m}, 1 \mathrm{H}), 0.57-0.53(\mathrm{~m}, 1 \mathrm{H}),-0.34\left(\mathrm{t},{ }^{3} J=4.5 \mathrm{~Hz}\right.$, 1H). ${ }^{13} \mathbf{C ~ N M R}\left(\mathrm{CDCl}_{3}, 75 \mathrm{MHz}\right): \delta 180.0,34.0,31.9,30.2,30.1,29.7,29.4,29.4,29.3$, 29.1, 28.7, 28.5, 24.7, 22.4, 15.62, $15.4\left(\mathrm{t},{ }^{1} J=23.6 \mathrm{~Hz}\right), 13.3\left(\mathrm{t},{ }^{1} J=19.0 \mathrm{~Hz}\right), 10.8$. FTIR ( $\mathrm{NaCl}$ plate, $\mathrm{cm}^{-1}$ ): 3057, 2924, 2854, 2676, 2213, 1711, 1465, 1413, 1285, 936. HRMS: $\left(\mathrm{C}_{19} \mathrm{H}_{31} \mathrm{D}_{4} \mathrm{O}_{2}{ }^{-}\right)$calculated 299.2894 found 299.2392 


\section{Part B: Efficient, and Scalable Preparation of bis(Deuterium)- and ${ }^{13} \mathrm{C}$-Labelled Diazomethane}




\section{Chapter: Introduction (part B)}

The deuterio and ${ }^{13} C$ labelled compounds are very useful to many different fields of chemistry. The prime example is in Chapter $\mathbf{1}$ where labelled compounds are used in KIE experiments to elucidate mechanistic aspects of enzymes, or as atomic tracers that whose fate can be determined when submitted to a biological system since labelled compounds can quite easily be quantified through the use of high resolution mass spectrometry (HRMS). However the incorporation of these labels are not always so straight forward, due to the fact deuterium $/{ }^{13} \mathrm{C}$ labelled substrates can be quite expensive. Also during the preparation of labelled compounds, the researcher must be concerned with isotopic dilution throughout the course of their synthesis. Thus a highly reactive isotope source should be used to construct more stable C-C bonds and C-heteroatom bonds. Herein we report the synthesis of bis(deuterio)- and ${ }^{13} \mathrm{C}$-labelled diazomethane as highly reactive reagents for the isotopic enrichment of many different molecular motifs.

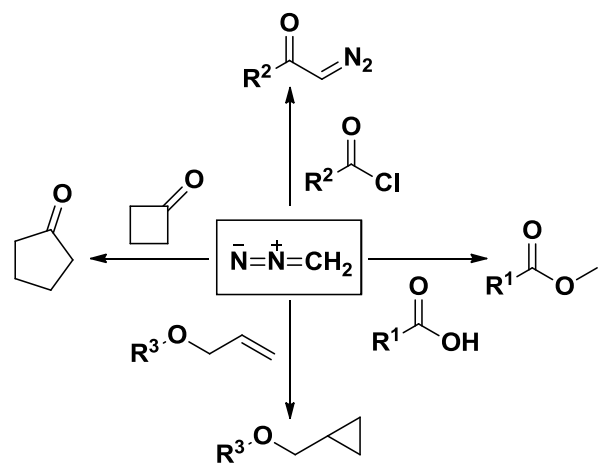

Scheme 4.1 Reactions of diazomethane

\subsection{Diazomethane precursors and preparation}

Diazomethane is a widely used reagent for rapid and efficient transformations like cyclopropanation, esterification, Arndt-Eistert homologation, alkylation of phenols, and 
cycloalkanone ring expansion. ${ }^{56}$ Some of the better known reactions are depicted in Figure 4.1. Diazomethane is a gas that is usually prepared in an ethereal solution that has been known to detonate upon exposure to, friction, mechanical shock, and heat. ${ }^{57}$ Particular caution must be used whilst preparing or using diazomethane since it is not only an explosive, but also a suspected carcinogen, toxin and a sensitizer. Three precursors are commonly used in the in the preparation of diazomethane such as $\mathrm{N}$ methyl- $N$ '-nitro- $N$-nitrosoguanidine 2 and $N$-methyl- $N$-nitrosourea 3 (see Figure 4.1). All three are $N$-methyl- $N$-nitroso derivatives, which upon contact with $\mathrm{KOH}$ decompose to diazomethane and an unwanted hydrophilic byproduct. The precursor most commonly used is $N$-methyl- $N$-nitroso- $p$-toluenesulfonamide (4), more commonly known as Diazald $^{\circledR}$.

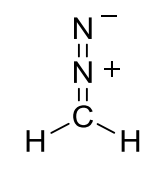

1

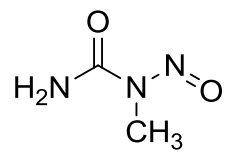

3
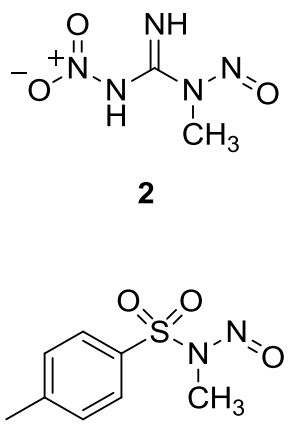

4

\section{Figure 4.1 Diazomethane and it most commonly used precursors}

Diazomethane can be prepared by a variety of different methods, but for lab scale purposes the use of specialized glassware with fire-polished joints is required (Figure 4.2). An ethereal solution of 4 is added dropwise to a heated solution of $\mathrm{KOH}$ in $\mathrm{H}_{2} \mathrm{O}$ and EtOH. Here in the reaction chamber diazomethane is formed diazomethane and co-distills with the ether; this then condenses on a cold finger on the other side of the apparatus. The ethereal solution generated by this method yields diazomethane solutions of $\sim 0.3 \mathrm{M}$. 


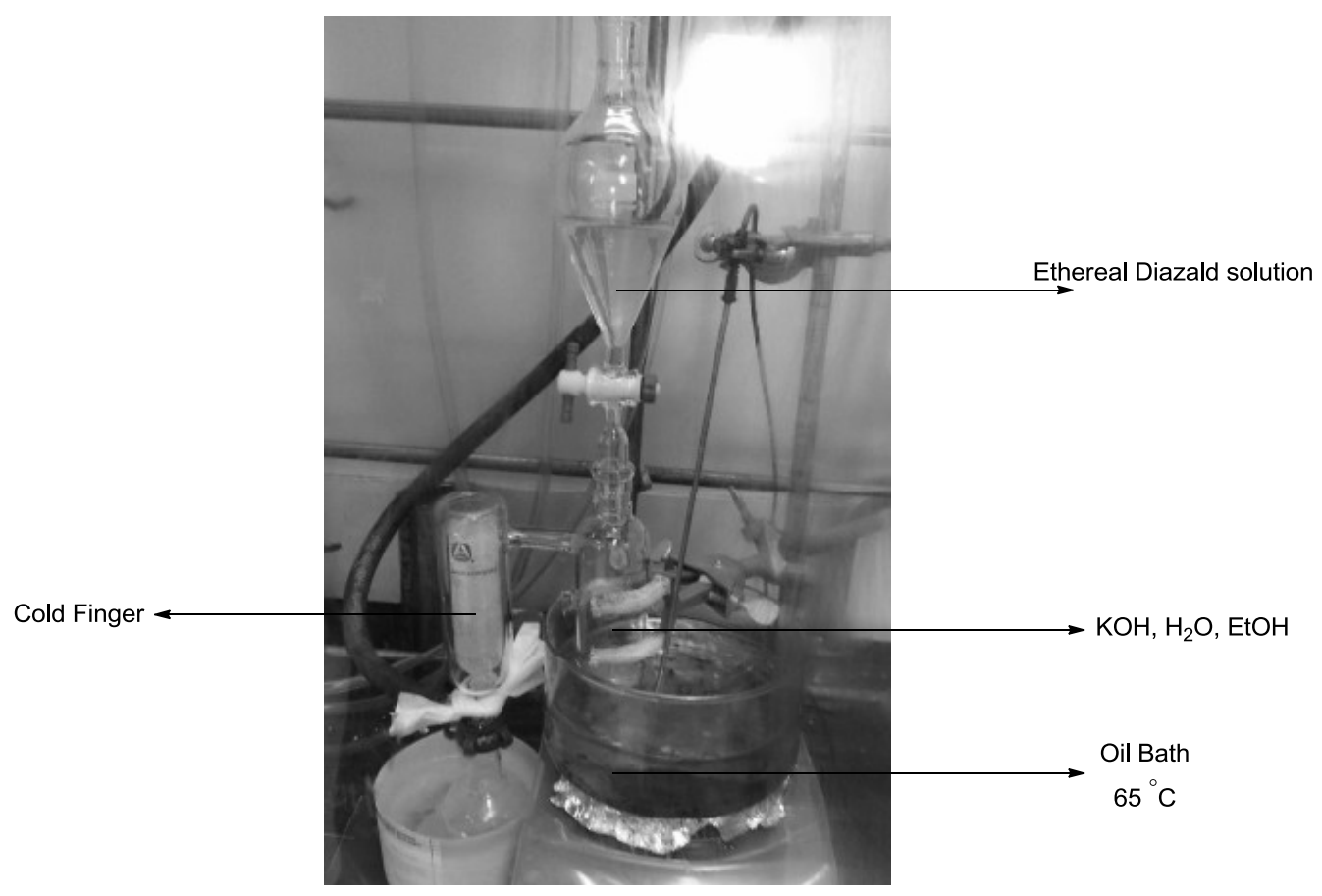

Figure 4.2 Aldrich mini-Diazald apparatus

\subsection{Labelled diazomethanes}

An ongoing research project necessitated access to isotopically labelled diazomethane, in particular bis(deuterio)diazomethane $\left(\mathrm{CD}_{2} \mathrm{~N}_{2}, \mathbf{1}-\boldsymbol{d}_{2}\right)$ and diazomethane${ }^{13} \mathrm{C}\left({ }^{13} \mathrm{CH}_{2} \mathrm{~N}_{2}, 1-{ }^{13} \mathrm{C}\right)$ for the labeling and MS analysis of biomolecules. A variety of methods have been used to prepare 1- $\boldsymbol{d}_{\mathbf{2}}$ including direct deuterium exchange on unlabelled material with $\mathrm{NaOD}$ and $\mathrm{D}_{2} \mathrm{O} .{ }^{58}$ Unfortunately, exchange procedures result in low chemical yield, moderate deuterium incorporation and extensive handling of hazardous materials. We decided that these methods were insufficient for our purposes and elected to prepare a labelled diazomethane precursor instead.

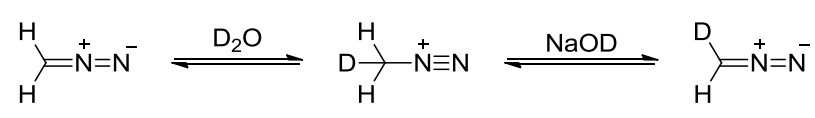

Scheme 4.2 Deuterium exchange on 1 


\subsection{Diazald and potential isotopic label sources}

Diazald can be prepared via a number of methods, but sulfonamide formation with methylamine, followed by nitrosolation with $\mathrm{NaNO}_{2}$ is by far the most common method. Regrettably, Diazald, labelled or otherwise, has been discontinued by a number of suppliers, or has been met with very strict shipping restrictions. Thus we decided to prepare our own labelled Diazald due to its stability, shelf life, and amenability of use, compared to the other precursors ( 2 and $\mathbf{3})$.

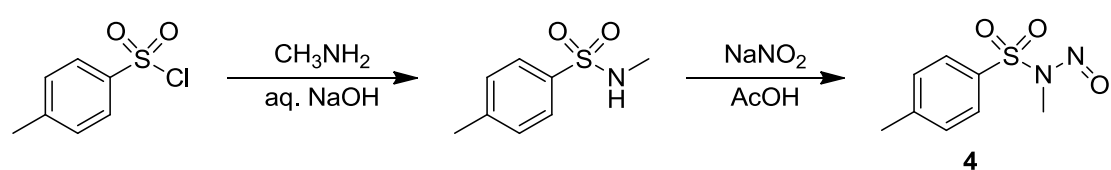

\section{Scheme 4.3 Standard preparation of 4}

Given that we required an efficient and cost effective synthesis of labelled $N$ methyl- $N$-nitroso- $p$-toluenesulfonamide we had to consider several different methyl sources. Iodomethane is a commonly used electrophilic methylating agent, and is available with many different isotopic labels $\left(d_{3},{ }^{13} C,{ }^{14} C\right)$. However it is a highly toxic, blister-inducing liquid and is often subject to exorbitant hazardous material shipping fees. Methylamine would be another potential candidate and would be the most direct option. Not only is it a low boiling gas, it is a highly controlled substance due to its association to the preparation of methamphetamine. After a comparison of potential labelled methyl sources (Table 2) methanol was flagged as the least expensive $(\$ / \mathrm{mol})$ than any other possible methyl sources. Additionally, methanol has low toxicity and is not subject to significant regulation. One major disadvantage to using methanol in our synthesis is it is 
neither an appropriate electrophile nor nucleophile. Methanol would therefore have to be activated in some way as to make it a feasible reagent in the preparation of labelled 4.

Table 2 Prices of labelled methyl sources

$\begin{array}{ccccc}\begin{array}{c}\text { Sigma-Aldrich (USA) } \\ \text { labelled precursor }\end{array} & \text { molecular mass } & \text { cost (US\$) } & \text { mass (g) } & \begin{array}{c}\text { cost (US\$) per } \\ \text { mole }\end{array} \\ \text { nitromethane- }{ }^{13} C & 62 & 526 & 1 & 32612 \\ \text { methyl iodide }-{ }^{13} C & 143 & 400.5 & 5 & 11454.3 \\ \text { methylamine- }{ }^{13} C & 32 & 682 & 0.5 & 43648 \\ \text { methylamine- }-{ }^{13} C \cdot \mathrm{HCl} & 68.5 & 657 & 1 & 45004.5 \\ \text { methanol- }{ }^{13} \boldsymbol{C} & \mathbf{3 3} & \mathbf{6 3 3} & \mathbf{5} & \mathbf{4 1 7 7 . 8} \\ & & & & \\ \text { nitromethane- } d_{3} & 64 & 206 & 25 & 527.36 \\ \text { methyl iodide- } d_{3} & 145 & 160.5 & 25 & 930.9 \\ \text { methylamine- } d_{5} & 36 & 966 & 10 & 3477.6 \\ \text { methanol- } \boldsymbol{d}_{\mathbf{4}} & \mathbf{3 5} & \mathbf{4 6 2} & \mathbf{5 0} & \mathbf{3 2 3 . 4}\end{array}$

\section{Chapter: Results and discussion (part B)}

\subsection{Preparation of labelled Diazalds}

By converting methanol to a shelf-stable and readily handled electrophile we could easily incorporate deuterium and ${ }^{13} \mathrm{C}$ labels into a Diazald motif. Among the most commonly used activation methods for alcohols are the corresponding tosylates and mesylates. Model studies with unlabelled $\mathrm{MeOH}$ demonstrated that methyl mesylate and methyl tosylate could be prepared with high yields using the Tanabe catalytic $\mathrm{Me}_{3} \mathrm{~N} \cdot \mathrm{HCl}$ procedure. $^{40}$ But the preparation of methyl mesylate presented challenges in the isolation since it was moderately water-soluble. Even with exhaustive extraction resulted in lower yields than those of $\mathbf{5}$.

Initially, a direct methylation of $\mathbf{6}$ with $\mathbf{5}$ was attempted and to our dismay, but not our surprise, resulted in a 3:10:2 mixture of starting material, monomethylated, and 
dimethylated products. However, when the methylation was attempted on $\mathrm{N}$-Boc protected sulfonamide 7 , this led to the required methylated product $\mathbf{8}$ with a $90 \%$ yield. A straight forward chromatographic purification was performed at this step.
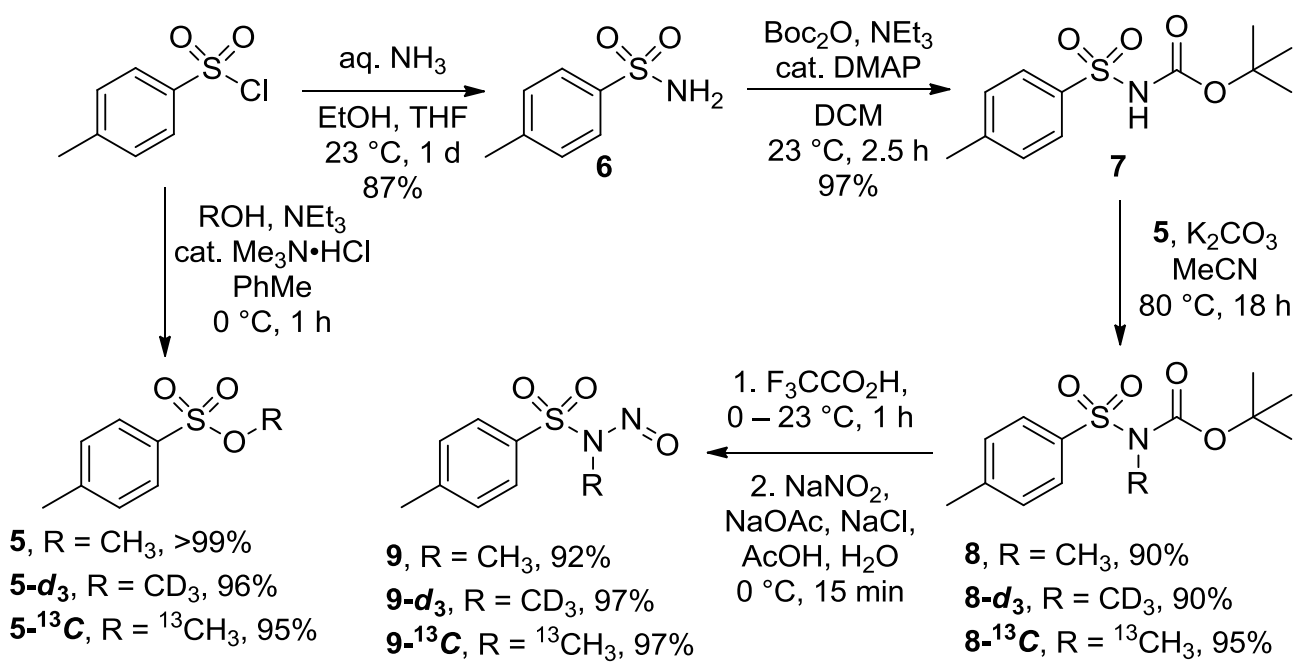

Scheme 5.1 Synthesis of deuterium and ${ }^{13} C$ labelled Diazalds

Since deprotection of Boc groups and nitrosolation procedures are both performed in acidic conditions we hypothesized a one-pot approach could be feasible. $N$-Boc- $N$ nitroso- $p$-toluenesulfonamide 8 was dissolved in neat trifluoroacetic acid (TFA); ;after $1 \mathrm{~h}$ an aqueous solution of $\mathrm{NaNO}_{2}, \mathrm{NaOAc}$, and $\mathrm{NaCl}$ was added to yield $86 \%$ of the desired nitroso compound 9. However this procedure proved to inferior to a two-step, one-pot procedure, which resulted in yielding $92 \%$ of desired product 9 . These two approaches were performed side by side for the same amount of time to ensure accuracy.

Now having established highly efficient and scaleable methodology for the production of unlabelled Diazald we prepared the labelled compounds $9-\boldsymbol{d}_{3}$ and $9-{ }^{13} \boldsymbol{C}$. The four-step procedure (Scheme 5.1) gave ${ }^{9-d_{3}}$ and $\mathbf{9 -}^{13} \boldsymbol{C}$ in overall yields of $74 \%$ and 
$78 \%$ respectively. At this stage we could now produce labelled diazomethane and use it in multiple reactions.

\subsection{Preparation and use of diazomethane $-{ }^{13} C$}

$1-{ }^{13} \mathrm{C}$ was readily prepared by the addition of an ethereal solution of $9-{ }^{13} \mathrm{C}$ to a heated solution $\mathrm{KOH}, \mathrm{EtOH}$, and $\mathrm{H}_{2} \mathrm{O}$. Benzoic acid was then immediately esterified with the ethereal $1-{ }^{13} \boldsymbol{C}$ to cleanly give methyl ${ }^{13} C$ benzoate in a $93 \%$ yield. As expected, ${ }^{1} \mathrm{H}$ NMR showed a methyl doublet (for $J=147 \mathrm{~Hz}\left[\mathrm{H}^{13} \mathrm{C}\right]$ ) and a smaller methyl singlet at $3.88 \mathrm{ppm}$ in a ratio of 99:1 respectively. We then decided to use $1-{ }^{13} \boldsymbol{C}$ in the alkylation of 2,4-dibromophenol and the cyclopropanation of allyl phenyl ether (Scheme 5.2). Both 11 and $13-{ }^{13} \mathrm{C}$ displayed a ${ }^{13} \mathrm{C}$ content of $99 \%$.

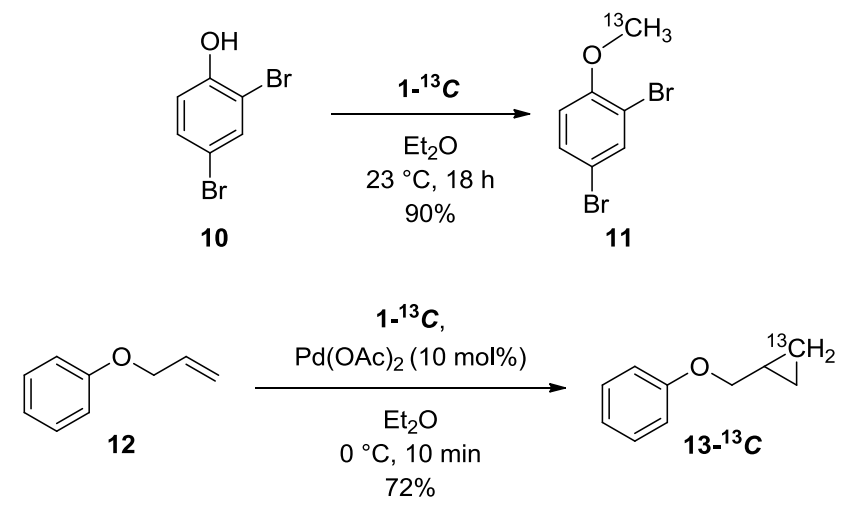

Scheme 5.2 Phenol alkylation and alkene cyclopropanation with $1-{ }^{13} \mathrm{C}$

\subsection{Preparation and use of $d_{2}$-diazomethane}

The conversion of 9- $\boldsymbol{d}_{3}$ to $\mathrm{CD}_{2} \mathrm{~N}_{2}$ had greater risks due to the rapid $\mathrm{H} / \mathrm{D}$ exchange that diazomethane is known to undergo. ${ }^{58}$ In order to minimize this exchange, the preparation of 1- $\boldsymbol{d}_{\mathbf{2}}$ was performed with dry solvents and a basic solution prepared by adding $\mathrm{NaH}$ to $\mathrm{D}_{2} \mathrm{O}$ and EtOD. The requisite ethereal solution was used to methylate 
benzoic acid- $d_{1}(87 \% \mathrm{D})$ afforded methyl $-d_{3}$ benzoate. Upon analysis of the ${ }^{1} \mathrm{H}$ NMR spectra, it revealed only a minor quintet corresponding to a minor $\mathrm{CD}_{2} \mathrm{H}$ group. Integration of the methyl peak showed a deuterium incorporation of $96 \%$ (given $87 \% \mathrm{D}$ of benzoic acid- $d_{1}$ ). Despite the rapid H/D exchange process of $\mathbf{1}-\boldsymbol{d}_{\mathbf{2}}$, it remains a highly versatile reagent in the preparation of many labelled compounds. Scheme $\mathbf{5 . 3}$ depicts the utility of diazomethane- $d_{2}$ in the cyclopropanation of allyl phenyl ether, diazoketone formation and subsequent transformation to the dideuterated $\alpha$-chloro ketone 15 . Cyclopropyl ether $\mathbf{1 3 -} \boldsymbol{d}_{\mathbf{2}}$ displayed a deuterium incorporation of $98 \%$ whilst $\mathbf{1 4}$ and $\mathbf{1 5}$ showed 91 and 93\% D incorporation, respectively.
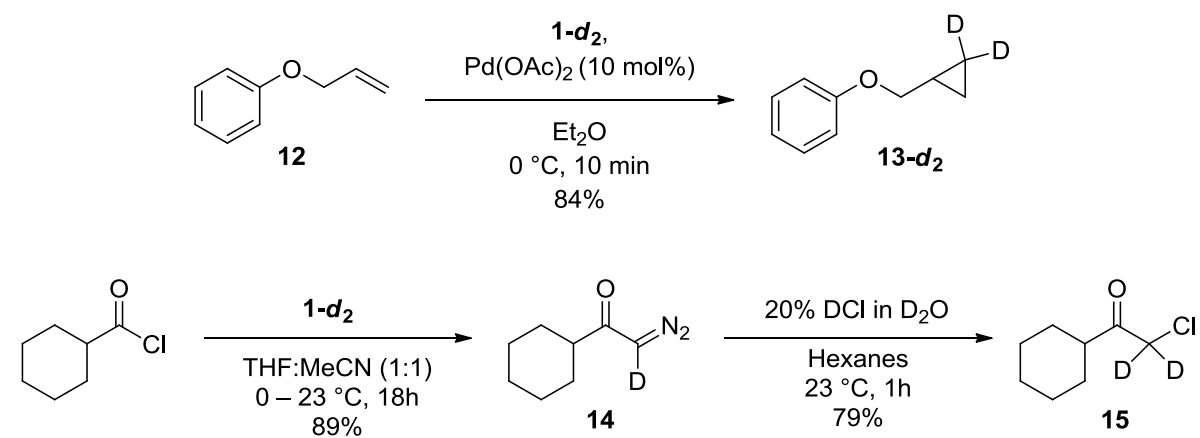

Scheme 5.3 Additional reactions involving diazomethane- $d_{2}$

\subsection{Conclusion}

We have developed an efficient, scalable and robust method for the synthesis of bis(deuterio)diazomethane and ${ }^{13} \mathrm{C}$-labelled diazomethane, and the corresponding precursors $9-\boldsymbol{d}_{3}$ and $9-{ }^{13} \boldsymbol{C}$. These compounds were derived from readily available, costeffective labelled methanols. The utility of these labelled diazomethanes has been demonstrated by a variety of transformations leading to products with high label incorporations. These protocols are anticipated to be highly useful to researchers who 
require isotopically labelled diazomethane but do not have access to suitable labelled precursors.

\section{Chapter: Experimental (part B)}

\subsection{General experimental}

All reagents were reagent grade and purchased from Sigma-Aldrich, Fluka, Analar, or Cambridge Isotope Laboratories Inc. and used as received, with the following exceptions: PhMe, DCM, DMSO, DIPA and MeCN were distilled from $\mathrm{CaH}_{2}, \mathrm{Et}_{2} \mathrm{O}$ and THF was distilled from $\mathrm{LiAlH}_{4}$ or $\mathrm{Na}^{0}$ /benzophenone, and all alkyl halides (commercial or prepared) were purified by elution through a short column of aluminum oxide (activated, basic, Brockman I) prior to use. All reactions involving air- or moisturesensitive reagents or intermediates were performed under an $\operatorname{Ar}$ or $\mathrm{N}_{2}$ atmosphere in glassware that was flame-dried or oven-dried. Reaction temperatures refer to the temperature of the cooling/heating bath. For the more unusual temperatures a Neslab Cryotrol cryobath was used with the cooling liquid composing of a mixture of acetone and methanol (1:1). Volatile solvents were removed under reduced pressure using a Heidolph rotary evaporator at $40{ }^{\circ} \mathrm{C}$ (bath temperature). Thin layer chromatography was run on glass-backed Extra Hard Layer (60 A) TLC plates purchased from Silicycle. Spots were visualized by fluorescence quenching under UV light $(254 \mathrm{~nm})$ and/or staining with aqueous ceric ammonium molybdate, Iodine or $\mathrm{KMnO}_{4}$. Chromatography was performed using forced flow (flash chromatography, FCC) on Silia-P Flash silica gel (40-62 $\mu \mathrm{m})$ from Silicycle according to the method of Still, ${ }^{43}$ or adsorbed onto Celite 521 from Sigma-Aldrich and was performed using dry column vacuum chromatography (DCVC) ${ }^{44}$ 
with SiliaFlash E60 silica gel $(15-40 \mu \mathrm{m})$ from Silicycle. Compounds that were dried under high vacuum refers to a reduced pressure of $\sim 20$ mTorr. Diazomethane and isotopically labelled diazomethanes were prepared using an Aldrich Mini Diazald apparatus according to the procedure outlined in the Sigma-Aldrich technical bulletin. ${ }^{59}$ FTIR spectra were recorded on a Varian 1000 Scimitar Series or an ABB Bomem MB Series spectrometer and were obtained as thin films on sodium chloride and are reported in wavenumbers $\left(\mathrm{cm}^{-1}\right) .{ }^{1} \mathrm{H}$ and ${ }^{13} \mathrm{C}$ NMR spectra were recorded on a Bruker Avance 300 or Bruker Avance III 400 spectrometer at 300 or $400 \mathrm{MHz}$ for ${ }^{1} \mathrm{H}$ and 75 or $100 \mathrm{MHz}$ for ${ }^{13} \mathrm{C}$, respectively, and were obtained at the indicated field as solutions in $\mathrm{CDCl}_{3}$ (stored over activated $4 \AA$ molecular sieves) unless otherwise indicated. Chemical shifts were referenced to tetramethylsilane $(\delta=0.00 \mathrm{ppm})$ as an internal standard and are reported in parts per million (ppm, $\delta$ ) relative to TMS. Coupling constants $(J)$ are reported in $\mathrm{Hz}$ and the splitting abbreviations used are: $\mathrm{s}$, singlet; $\mathrm{d}$, doublet; $\mathrm{t}$, triplet; $\mathrm{q}$, quartet; $\mathrm{m}$, multiplet). Chemical purity of compounds that were used without purification was determined by ${ }^{1} \mathrm{H}$ NMR spectroscopy. Yields refer to purified compounds unless explicitly indicated as crude. Deuterium incorporation of deuterated compounds was determined by comparison of peak integrations of the labelled materials versus the integration of the same peak(s) in the ${ }^{1} \mathrm{H}$ NMR spectrum of the unlabelled compound. ${ }^{13} \mathrm{C}$ content of ${ }^{13} \mathrm{C}$-labelled compounds was determined by integration of the methyl doublet resulting from ${ }^{1} J^{13} \mathrm{C}-{ }^{1} \mathrm{H}$ coupling versus the singlet of the unlabelled methyl group in the same spectrum. 


\subsection{Preparation of labelled Diazalds and their conversion to isotopically enriched}

\section{diazomethanes. $^{60}$}

\subsection{1 p-Toluenesulfonamide (6)}

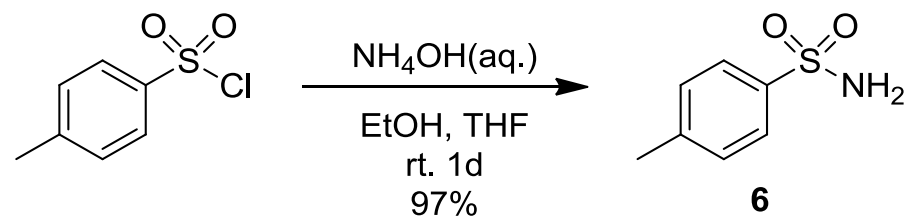

Aqueous ammonium hydroxide $(28 \% \mathrm{w} / \mathrm{w}, 82.0 \mathrm{~g}, 1.35 \mathrm{~mol})$ was combined with absolute ethanol $(250 \mathrm{~mL})$ and added via a dropping funnel over 5 minutes to a solution of $p$-toluenesulfonyl chloride $(50.0 \mathrm{~g}, 262 \mathrm{mmol})$ in THF $(150 \mathrm{~mL})$. The resulting mixture was stirred for 1 day at room temperature. Solvents were removed under reduced pressure and the off-white solid was washed with $200 \mathrm{~mL}$ of cold distilled water and dried under high vacuum to give 6 as a white solid (43.5 g, 97\%, 90\% purity). This material was used without further purification.

mp $126-127{ }^{\circ} \mathrm{C} . \boldsymbol{R}_{\boldsymbol{f}} 0.21(30 \%$ EtOAc in hexanes; UV, $) .{ }^{1} \mathbf{H}$ NMR $\left(\mathrm{CDCl}_{3}, 300 \mathrm{MHz}\right): \delta$ $7.82\left(\mathrm{~d},{ }^{3} J=8.1 \mathrm{~Hz}, 2 \mathrm{H}\right), 7.32\left(\mathrm{~d},{ }^{3} J=8.1 \mathrm{~Hz}, 2 \mathrm{H}\right), 4.81$ (br s, 2H), 2.44 (s, 3H). Spectroscopic data was in good agreement with reported data. ${ }^{61}$

\subsection{2 tert-Butyl p-toluenesulfonylcarbamate (7)}<smiles>Cc1ccc(S(N)(=O)=O)cc1</smiles>

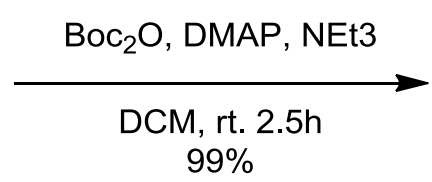<smiles>Cc1ccc(S(=O)(=O)NC(=O)OC(C)(C)C)cc1</smiles>

$N, N$-Dimethylaminopyridine $(3.14 \mathrm{~g}, 25.7 \mathrm{mmol})$, triethylamine $(39 \mathrm{~mL}, 280 \mathrm{mmol}), p$ toluenesulfonamide $6(43.5 \mathrm{~g}, 254 \mathrm{mmol})$ were combined in DCM (300 mL) to give a 
suspension. Di-tert-butyl dicarbonate $(66.68 \mathrm{~g}, 305 \mathrm{mmol})$ was separately dissolved in DCM $(510 \mathrm{~mL})$ and added via dropping funnel to the suspension of $p$-toluenesulfonamide (6) over $25 \mathrm{~min}$ and the mixture was stirred for $2 \mathrm{~h}$ at room temperature. Solvent was removed under reduced pressure and residue was dissolved in ethyl acetate $(500 \mathrm{~mL})$. The organic layer was washed with $1 \mathrm{M}$ aqueous $\mathrm{HCl}(2 \times 500 \mathrm{~mL}), \mathrm{H}_{2} \mathrm{O}(500 \mathrm{~mL})$, and brine $(500 \mathrm{~mL})$, then dried over $\mathrm{MgSO}_{4}$, filtered, and concentrated to give 7 as an offwhite solid (68.5 g, 99\%, 97\% purity). This material was used without further purification.

mp 102.0-103.7 ${ }^{\circ} \mathrm{C} . \quad \boldsymbol{R}_{\boldsymbol{f}} 0.49$ (30\% EtOAc in hexanes; UV,). ${ }^{1} \mathbf{H}$ NMR $\left(\mathrm{CDCl}_{3}, 300\right.$ MHz): $\delta 7.90$ (d, $\left.{ }^{3} J=8.3 \mathrm{~Hz}, 2 \mathrm{H}\right), 7.34\left(\mathrm{~d},{ }^{3} J=8.3 \mathrm{~Hz}, 2 \mathrm{H}\right), 2.45$ (s, 3H), 1.39 (s, 9H). Spectroscopic data was in good agreement with reported data. ${ }^{62}$

\subsubsection{Methyl- $d_{3} p$-toluenesulfonate $\left(5-d_{3}\right)$}

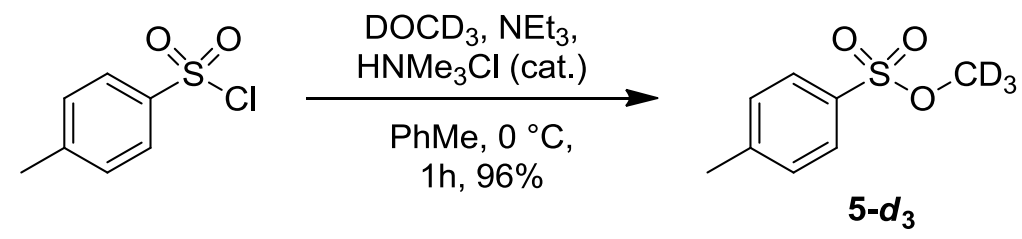

This protocol was adapted from the literature procedure reported by Tanabe. ${ }^{40}$ Trimethylamine hydrochloride $(1.18 \mathrm{~g}, 12.3 \mathrm{mmol})$ was suspended in toluene $(123 \mathrm{~mL})$. Methanol- $d_{4}(5 \mathrm{~mL}, 123 \mathrm{mmol}, 99.8 \% \mathrm{D})$ and triethylamine $(19 \mathrm{~mL}, 136 \mathrm{mmol})$ were added to the suspension and cooled in an ice bath. $p$-Toluenesulfonyl chloride (25.82 g, $135 \mathrm{mmol}$ ) was dissolved in toluene $(90 \mathrm{~mL})$ and added in three $30 \mathrm{~mL}$ portions over 10 minutes to the cooled reaction mixture. The mixture was allowed to stir for $1 \mathrm{~h}$ at $0{ }^{\circ} \mathrm{C}$ 
and filtered over Celite. The filter cake was washed with ice-cold toluene $(200 \mathrm{~mL})$. Solvent was removed under reduced pressure to give $\mathbf{5 - d _ { 3 }}$ as an amber liquid $(24.63 \mathrm{~g}$, $106 \%, 91 \%$ purity) that was used without further purification.

$\boldsymbol{R}_{\boldsymbol{f}} 0.23\left(10 \%\right.$ EtOAc in hexanes; UV). ${ }^{1} \mathbf{H}$ NMR $\left(\mathrm{CDCl}_{3}, 400 \mathrm{MHz}\right): \delta 7.79\left(\mathrm{~d},{ }^{3} J=8.0\right.$ $\mathrm{Hz}, 2 \mathrm{H}), 7.36\left(\mathrm{~d},{ }^{3} J=8.0 \mathrm{~Hz}, 2 \mathrm{H}\right), 2.45(\mathrm{~s}, 3 \mathrm{H}) .{ }^{13} \mathbf{C} \mathbf{N M R}\left(\mathrm{CDCl}_{3}, 100 \mathrm{MHz}\right): \delta 145.0$, 132.2, 129.9, 128.0, 55.5 (septet, $\left.{ }^{1} J=23 \mathrm{~Hz}\right), 21.6$. IR $\left(\mathrm{NaCl}\right.$ plate, $\left.\mathrm{cm}^{-1}\right): 3068,2927$, $2875,2592,2264,2129,2087,1925,1736,1598,1495,1453,1361,1308,1180,1104$, $1080,996,934,817,741,704$.

\subsection{4 $N$-Methyl- $d_{3}$ tert-butyl $p$-toluenesulfonylcarbamate $\left(8-d_{3}\right)$}

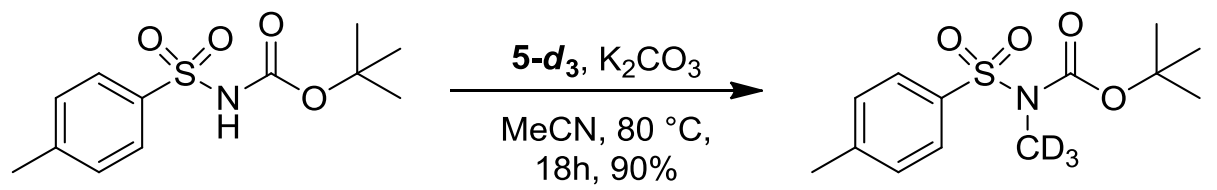

8- $d_{3}$

Finely ground tert-butyl $p$-toluenesulfonylcarbamate 7 (15.64 g, $57.6 \mathrm{mmol})$, methyl- $d_{3}$ p-toluenesulfonate 5- $\boldsymbol{d}_{\mathbf{3}}$ [9.82 g (crude material, 91\% purity), $47.2 \mathrm{mmol}$ ] was dissolved in $\mathrm{MeCN}(230 \mathrm{~mL})$. While reaction solution was stirring vigorously, powdered $\mathrm{K}_{2} \mathrm{CO}_{3}$ (13.23 g, $695.7 \mathrm{mmol}$ ) was added in one portion (caution: if carbonate was added too slowly the mixture would gel and stirring became very difficult). The flask was fitted with a reflux condenser and heated to $80{ }^{\circ} \mathrm{C}$ for $18 \mathrm{~h}$. After stirring at this temperature overnight, the mixture was allowed to cool before adding $\mathrm{H}_{2} \mathrm{O}(100 \mathrm{~mL})$ to dissolve the salts. The reaction mixture was transferred to a separatory funnel and the layers were separated. The aqueous layer was washed ethyl acetate $(3 \times 75 \mathrm{~mL})$. The combined 
organic layers were dried over $\mathrm{MgSO}_{4}$, filtered, and concentrated to afford a sludgy solid (19 g). The crude yellow solid was adsorbed onto Celite and purified by dry column vacuum chromatography (0-16\% EtOAc in hexanes) to afford $N$-methyl- $d_{3}$ tert-butyl $p$ toluenesulfonylcarbamate 8- $\boldsymbol{d}_{\mathbf{3}}$ as a white solid (11.96 g, 90\%).

mp 63.1-64.5 ${ }^{\circ} \mathrm{C} \boldsymbol{R}_{\boldsymbol{f}} 0.20$ (10\% EtOAc in hexanes, UV). ${ }^{1} \mathbf{H}$ NMR $\left(\mathrm{CDCl}_{3}, 300 \mathrm{MHz}\right): \delta$ $7.78\left(\mathrm{~d},{ }^{3} J=8.4 \mathrm{~Hz}, 2 \mathrm{H}\right), 7.31\left(\mathrm{~d},{ }^{3} J=8.4 \mathrm{~Hz}, 2 \mathrm{H}\right), 2.44(\mathrm{~s}, 3 \mathrm{H}), 1.35(\mathrm{~s}, 9 \mathrm{H}) .{ }^{13} \mathbf{C}$ NMR $\left(\mathrm{CDCl}_{3}, 75 \mathrm{MHz}\right): \delta 151.2,144.2,137.2,129.3,127.7,84.1,32.7$ (septet, ${ }^{1} J=21.7 \mathrm{~Hz}$ ), 27.9, 21.6. IR (KBr pellet, $\left.\mathrm{cm}^{-1}\right): 3405,3058,2983,2931,2447,2402,2257,2124,2076$, $1712,1599,1457,1365,1311,1256,1178,1106,870,849,817,769,734$.

\subsection{5 $N$-Methyl- $d_{3}-N$-nitroso-p-toluenesulfonamide $\left(9-d_{3}\right)$}

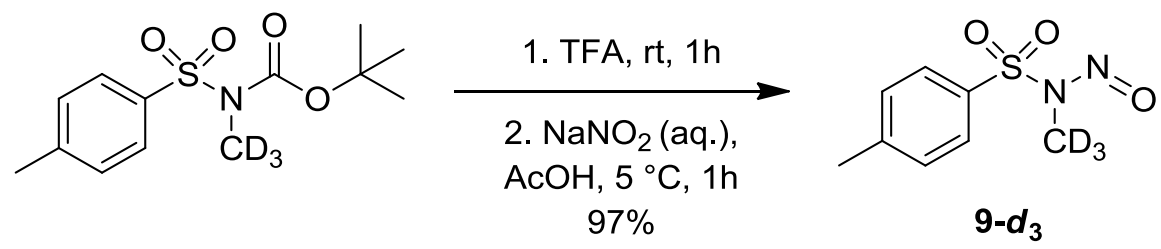

This protocol was adapted from the literature procedure reported by de Boer and Backer. ${ }^{57}$ Trifluoroacetic acid $(45 \mathrm{~mL})$ was cooled to $0{ }^{\circ} \mathrm{C}$ before adding $d_{3}$-methyl $p$ toluenesulfonylcarbamate $\mathbf{8}-\boldsymbol{d}_{\mathbf{3}}(11.58 \mathrm{~g}, 40.2 \mathrm{mmol})$ slowly. The solution was warmed to room temperature and stirred for $1 \mathrm{~h}$. The TFA was removed under reduced pressure and the resulting residue was dissolved in acetic acid $(42 \mathrm{~mL})$ and cooled to $5^{\circ} \mathrm{C}$ (internal temp) in an ice/water bath. A solution of $\mathrm{NaCl}$ (2.36 g, $40.4 \mathrm{mmol}), \mathrm{NaOAc}(0.14 \mathrm{~g}, 1.7$ mmol), and $\mathrm{NaNO}_{2}(3.03 \mathrm{~g}, 44.0 \mathrm{mmol})$ in $\mathrm{H}_{2} \mathrm{O}(13 \mathrm{~mL})$ was then added such that the internal temperature was kept below $7{ }^{\circ} \mathrm{C}$. After the addition was complete, the reaction 
mixture was stirred for a further 15 minutes, ice-cold $\mathrm{H}_{2} \mathrm{O}(40 \mathrm{~mL})$ was added and stirring was continued for a further $5 \mathrm{~min}$. The mixture was allowed to stand without stirring for 20 minutes, filtered, washed with ice-cold $\mathrm{H}_{2} \mathrm{O}(300 \mathrm{~mL})$ and dried under high vacuum overnight to afford $\mathbf{9}-\boldsymbol{d}_{\mathbf{3}}$ as a light yellow solid $(8.51 \mathrm{~g}, 97 \%, 99 \% \mathrm{D})$

mp 49.1-50.0 ${ }^{\circ} \mathrm{C} . \boldsymbol{R}_{\boldsymbol{f}} 0.57\left(30 \%\right.$ EtOAc in hexanes, UV). ${ }^{1} \mathbf{H} \mathbf{N M R}\left(\mathrm{CDCl}_{3}, 300 \mathrm{MHz}\right): \delta$ $7.87\left(\mathrm{~d},{ }^{3} J=8.4 \mathrm{~Hz}, 2 \mathrm{H}\right), 7.38\left(\mathrm{~d},{ }^{3} J=8.4,2 \mathrm{H}\right), 2.46(\mathrm{~s}, 3 \mathrm{H}) \cdot{ }^{13} \mathbf{C} \mathbf{N M R}\left(\mathrm{CDCl}_{3}, 75\right.$ MHz): $\delta 146.2,134.1,130.4,128.0,28.4$ (septet, $\left.{ }^{1} J=21.8 \mathrm{~Hz}\right), 21.7$. IR (NaCl plate, $\mathrm{cm}^{-}$ $\left.{ }^{1}\right): 3075,2973,2925,2867,2591,2405,2291,2255,2185,2108,1922,1803,1595,1493$, $1381,1330,1302,1258,1192,1163,1119,1088,1046,910,879,812$.

\subsubsection{Diazomethane- $d_{2}\left(1-d_{2}\right)$}

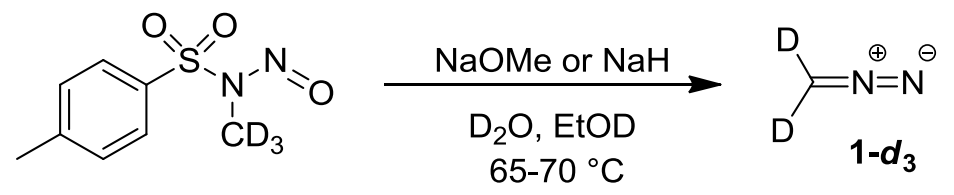

Sodium methoxide protocol: This procedure was adapted from the literature procedure given by Sigma-Aldrich. ${ }^{59}$ A basic solution was prepared by dissolving $\mathrm{NaOMe}(95 \%$, $6.37 \mathrm{~g}, 118 \mathrm{mmol})$ in $\mathrm{D}_{2} \mathrm{O}(10 \mathrm{~mL}) .4 .5 \mathrm{~mL}$ of the alkaline solution and EtOD $(95 \%, 5.4$ $\mathrm{mL}$ ) was added to an Aldrich mini Diazald apparatus which was heated to $65^{\circ} \mathrm{C}$ in an oil bath. Then a solution of $N$-methyl- $d_{3}-N$-nitroso- $p$-toluenesulfonamide $\mathbf{9 - d _ { 3 }}(2.01 \mathrm{~g}, 9.27$ mmol) in ether $(18 \mathrm{~mL})$ was added dropwise to the heated alkaline solution. Diazomethane- $d_{2} \mathbf{1 -} \boldsymbol{d}_{\mathbf{2}}$ was collected in a new $50 \mathrm{~mL}$ Erlenmeyer flask that was cooled in an isopropanol/dry ice bath. After addition of the ethereal $N$-methyl- $d_{3}-N$-nitroso- $p$ toluenesulfonamide $\mathbf{9}-\boldsymbol{d}_{\mathbf{3}}$ solution was complete, a further $2 \mathrm{~mL}$ of ether was added to the 
dropping funnel and added dropwise to the heated alkaline solution. $20 \mathrm{~mL}$ of a translucent yellow solution of $\mathbf{1}-\boldsymbol{d}_{\mathbf{2}}$ was collected, adequately insulated and stored in a freezer $\left(\sim-15{ }^{\circ} \mathrm{C}\right)$ under inert atmosphere. Deuterium incorporation of 1-d $\mathbf{2}$ was determined by ${ }^{1} \mathrm{H}$ NMR analysis of methyl- $d_{3}$ benzoate $\mathbf{1 0}-\boldsymbol{d}_{3}$ below.

Sodium hydride protocol: A basic solution was prepared by reacting $\mathrm{NaH}(95 \%, 2.67 \mathrm{~g}$, $106 \mathrm{mmol})$ with a chilled solution of $\mathrm{D}_{2} \mathrm{O}(10 \mathrm{~mL})$ and $\mathrm{EtOD}(95 \%, 12.5 \mathrm{~mL})$ and stirred for $10 \mathrm{~min}$. This alkaline solution $(18 \mathrm{~mL})$ was added to the Aldrich mini Diazald ${ }^{\circledR}$ apparatus and heated to $65{ }^{\circ} \mathrm{C}$. Then a solution of $N$-methyl- $d_{3}-N$-nitroso-ptoluenesulfonamide $9-\boldsymbol{d}_{3}(5.0 \mathrm{~g}, 24.6 \mathrm{mmol})$ in ether $(45 \mathrm{~mL})$ was added dropwise to heated alkaline solution. Diazomethane- $d_{2} \mathbf{1}-\boldsymbol{d}_{2}$ was collected in Clear-Seal ${ }^{\circledR} 100 \mathrm{~mL}$ flask that was cooled in an isopropanol/dry ice bath. After addition of ethereal nitrososulfonamide a further $5 \mathrm{~mL}$ of ether was used to rinse dropping funnel. $50 \mathrm{~mL}$ of a translucent yellow solution of $\mathbf{1}-\boldsymbol{d}_{\mathbf{2}}$ was collected and adequately insulated and stored in the freezer $\left(\sim-15^{\circ} \mathrm{C}\right)$.

\subsubsection{Benzoic acid- $d_{1}$}

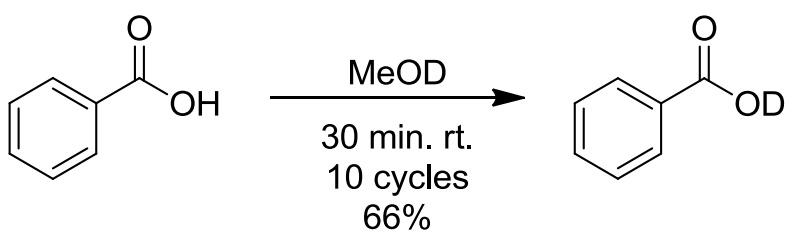

Benzoic acid (275 mg, $2.25 \mathrm{mmol})$ was dissolved in methanol- $d_{1}(2 \mathrm{~mL}, 99.6 \% \mathrm{D})$, and stirred for $30 \mathrm{~min}$ at room temperature. The methanol was removed under reduced pressure. This cycle was repeated 10 times to give an off white solid $(182 \mathrm{mg}, 66 \%, 87$ $\% \mathrm{D})$ 
${ }^{1}$ H NMR $\left(\mathrm{C}_{6} \mathrm{D}_{6}, 300 \mathrm{MHz}\right): \delta 12.22$ (broad s, 0.117H), $8.10(\mathrm{~m}, 2 \mathrm{H}), 7.05(\mathrm{~m}, 3 \mathrm{H})$.

\subsubsection{Methyl- $d_{3}$ benzoate}

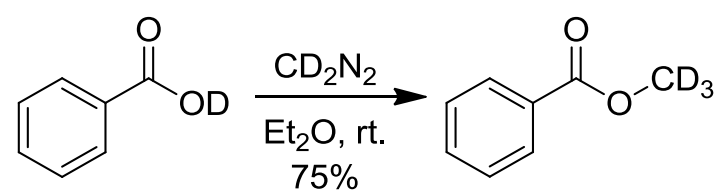

Benzoic acid- $d_{1}(74.6 \mathrm{mg}, 0.61 \mathrm{mmol})$ was dissolved in ether $(10 \mathrm{~mL})$. Using a firepolished pipet, cold diazomethane- $d_{2}\left(\mathbf{1}-\boldsymbol{d}_{\mathbf{2}}\right)$ solution $(\sim 4 \mathrm{~mL})$ was added dropwise until the solution had a persistent light yellow colour. Ar was bubbled into reaction for $20 \mathrm{~min}$ to remove residual $\mathbf{1}-\boldsymbol{d}_{\mathbf{2}}$. Solvent was removed under reduced pressure to yield a brown oil. The crude material was purified using flash column chromatography $\left(3 \% \mathrm{Et}_{2} \mathrm{O}\right.$ in hexanes) to afford methyl- $d_{3}$ benzoate as a clear liquid $(63.0 \mathrm{mg}, 75 \%, 96 \% \mathrm{D}$ incorporation given $87 \% \mathrm{D}$ incorporation in benzoic acid). Spectroscopic data was in good agreement with literature. ${ }^{63}$

$\boldsymbol{R}_{\boldsymbol{f}} 0.22\left(3 \% \mathrm{Et}_{2} \mathrm{O}\right.$ in hexanes, UV). ${ }^{1} \mathbf{H}$ NMR $\left(\mathrm{CDCl}_{3}, 300 \mathrm{MHz}\right): \delta 8.05(\mathrm{~m}, 2 \mathrm{H}), 7.50$ $(\mathrm{m}, 3 \mathrm{H}), 3.90(\mathrm{~m}, 0.204 \mathrm{H})$

\subsubsection{Methyl $p$-toluenesulfonate- ${ }^{13} C\left(5-{ }^{13} C\right)$}

Prepared analogously to compound $\mathbf{5}-\boldsymbol{d}_{3}$ using methanol- ${ }^{13} \mathrm{C}\left(5 \mathrm{~mL}, 99 \%{ }^{13} \mathrm{C}\right)$ above to afford $5-{ }^{13} \boldsymbol{C}\left(30.15 \mathrm{~g}, 106 \%, 90 \%\right.$ purity, $\left.99 \%{ }^{13} \mathrm{C}\right)$

$\boldsymbol{R}_{\boldsymbol{f}} 0.21\left(10 \%\right.$ EtOAc in hexanes; UV). ${ }^{1} \mathbf{H}$ NMR $\left(\mathrm{CDCl}_{3}, 300 \mathrm{MHz}\right): \delta 7.80\left(\mathrm{~d},{ }^{3} J=8.1\right.$ Hz, 2H), $7.36\left(\mathrm{~d},{ }^{3} J=8.1 \mathrm{~Hz}, 2 \mathrm{H}\right), 3.74\left(\mathrm{~d},{ }^{1} J=149 \mathrm{~Hz}, 3 \mathrm{H}\right), 2.46(\mathrm{~s}, 3 \mathrm{H}) .{ }^{13} \mathbf{C}$ NMR $\left(\mathrm{CDCl}_{3}, 75 \mathrm{MHz}\right): \delta 145.0,132.2,129.9,128.1,56.2,21.6 . \mathrm{IR}\left(\mathrm{NaCl}\right.$ plate, $\left.\mathrm{cm}^{-1}\right): 2952$, 1926, 1744, 1599, 1455, 1360, 1293, 1178, 1096, 1019, 979, 818, 765. 


\subsubsection{0 $\mathrm{N}$-Methyl- ${ }^{13} \mathrm{C}$ tert-butyl $p$-toluenesulfonylcarbamate $\left(8-{ }^{13} \mathrm{C}\right)$}

Prepared analogously to compound $\mathbf{8}-\boldsymbol{d}_{\mathbf{3}}$ above to afford $\mathbf{8 -}{ }^{\mathbf{1 3}} \boldsymbol{C}\left(14.11 \mathrm{~g}, 95 \%, 99 \%{ }^{13} \mathrm{C}\right)$ mp 61.1-62.0 ${ }^{\circ} \mathrm{C} \boldsymbol{R}_{\boldsymbol{f}} 0.27$ (10\% EtOAc in hexanes, UV). ${ }^{1} \mathbf{H} \mathbf{N M R}\left(\mathrm{CDCl}_{3}, 300 \mathrm{MHz}\right): \delta$ $7.78\left(\mathrm{~d},{ }^{3} J=8.1 \mathrm{~Hz}, 2 \mathrm{H}\right), 7.31\left(\mathrm{~d},{ }^{3} J=8.1,2 \mathrm{H}\right), 3.35\left(\mathrm{~d},{ }^{1} J=143 \mathrm{~Hz}, 3 \mathrm{H}\right), 2.44(\mathrm{~s}, 3 \mathrm{H})$, 1.35 (s, 9H). ${ }^{13} \mathbf{C ~ N M R}\left(\mathrm{CDCl}_{3}, 75 \mathrm{MHz}\right): \delta 151.2,144.2,137.2,129.3,127.7,84.2,33.3$, 27.9, 21.6. IR ( $\mathrm{NaCl}$ plate, $\left.\mathrm{cm}^{-1}\right): 2982,1731,1598,1456,1417,1359,1296,1258,1157$, $1087,967,849,804,770,723$.

\subsubsection{N-Methyl- ${ }^{13} C-N$-nitroso-p-toluenesulfonamide $\left(9-{ }^{13} C\right)$}

Prepared analogously to compound $\mathbf{9 - d _ { 3 }}$ above to afford $\mathbf{9 -}{ }^{\mathbf{1 3}} \boldsymbol{C}\left(10.03 \mathrm{~g}, \mathbf{9 7 \%}, \mathbf{9 9 \%}{ }^{13} \mathrm{C}\right)$

mp 46.2-47.0 ${ }^{\circ} \mathrm{C} . \boldsymbol{R}_{\boldsymbol{f}} 0.23\left(10 \%\right.$ EtOAc in hexanes, UV). ${ }^{1} \mathbf{H} \mathbf{N M R}\left(\mathrm{CDCl}_{3}, 300 \mathrm{MHz}\right): \delta$ $7.87\left(\mathrm{~d},{ }^{3} J=8.4 \mathrm{~Hz}, 2 \mathrm{H}\right), 7.38\left(\mathrm{~d},{ }^{3} J=8.4,2 \mathrm{H}\right), 3.12\left(\mathrm{~d},{ }^{1} J=144 \mathrm{~Hz}, 3 \mathrm{H}\right), 2.46(\mathrm{~s}, 3 \mathrm{H})$. ${ }^{13} \mathrm{C}$ NMR $\left(\mathrm{CDCl}_{3}, 75 \mathrm{MHz}\right): \delta 146.2,134.1,130.4,128.0,28.9,21.7$. IR $(\mathrm{NaCl}$ plate, $\left.\mathrm{cm}^{-1}\right): 3075,2980,2925,1922,1801,1594,1496,1402,1381,1301,1216,1174,1135$ $1085,860,812$. 


\subsubsection{Diazomethane- ${ }^{13} C\left(1-{ }^{13} C\right)$}

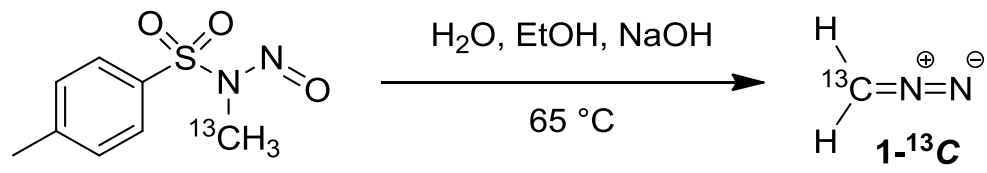

This procedure was adapted from the analogous Sigma-Aldrich literature procedure for a mini-Diazald apparatus.Error! Bookmark not defined. Sodium hydroxide $(1.51 \mathrm{~g}, 37.8$ mmol) was dissolved in $\mathrm{H}_{2} \mathrm{O}(3.4 \mathrm{~mL})$ and $\mathrm{EtOH}(99 \%, 4.2 \mathrm{~mL})$ and warmed to $65^{\circ} \mathrm{C}$. A solution of $N$-methyl- ${ }^{13} C$ - $N$-nitroso-p-toluenesulfonamide $9-{ }^{13} C(2.00 \mathrm{~g}, 9.29 \mathrm{mmol})$ in ether $(17 \mathrm{~mL})$ was then added dropwise to the heated alkaline solution. $\mathbf{1 -}^{13} \boldsymbol{C}$ was collected in a pristine $50 \mathrm{~mL}$ Erlenmeyer flask that was cooled in an isopropanol/dry ice bath. After addition of ethereal solution of $9-{ }^{13} \boldsymbol{C}$ was complete, the dropping funnel was rinsed with a further $2 \mathrm{~mL}$ of ether, which was then added dropwise into the reaction mixture. Upon completion of the distillation $20 \mathrm{~mL}$ of a translucent yellow solution of diazomethane- ${ }^{13} \mathrm{C}$ had been collected, and was adequately insulated and stored under inert atmosphere in a freezer $\left(\sim-15^{\circ} \mathrm{C}\right)$.

\subsubsection{Methyl- ${ }^{13} C$ benzoate}

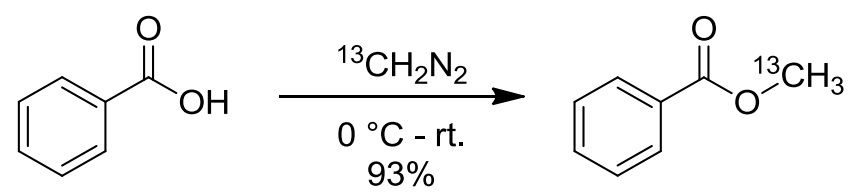

Benzoic acid (255 mg, $2.10 \mathrm{mmol})$ was dissolved in $\mathrm{Et}_{2} \mathrm{O}$ and cooled in an ice bath. Then cold diazomethane solution $(\sim 4 \mathrm{~mL})$ was added dropwise until solution had a persistent light yellow colour. The solution was warmed to room temperature and Ar was bubbled into reaction for $20 \mathrm{~min}$. Solvent was removed under reduced pressure to give $1 \mathbf{1 0}^{\mathbf{1 3}} \boldsymbol{C}$ as a clear liquid (267 mg, 93\%, $\left.99 \%{ }^{13} \mathrm{C}\right)$. 
$\boldsymbol{R}_{f} 0.49\left(10 \%\right.$ EtOAc in hexanes, UV). ${ }^{1} \mathbf{H}$ NMR $\left(\mathrm{CDCl}_{3}, 300 \mathrm{MHz}\right): \delta 8.0(\mathrm{~m}, 2 \mathrm{H}), 7.52$ (m, 1H), $7.4(\mathrm{~m}, 2 \mathrm{H}), 3.87\left(\mathrm{~d},{ }^{1} J=147 \mathrm{~Hz}, 3 \mathrm{H}\right) .{ }^{13} \mathbf{C}$ NMR (CDCl, $\left.75 \mathrm{MHz}\right): \delta 167.0(\mathrm{~d}$, $\left.{ }^{2} J=2.4 \mathrm{~Hz}\right), 132.9,130.2\left(\mathrm{~d},{ }^{3} J=1.2 \mathrm{~Hz}\right), 129.5,128.3,52.0$. IR $\left(\mathrm{NaCl}\right.$ plate, $\left.\mathrm{cm}^{-1}\right)$ : $3065,2948,2839,1723,1601,1493,1453,1432,1277,1178,1108,1071,1027,954$, $823,710$.

\subsubsection{2,4-Dibromoanisole-methyl- ${ }^{13} C(11)$}

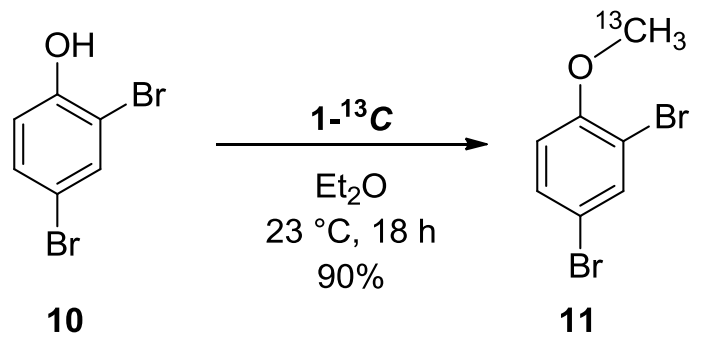

Diazomethane- ${ }^{13} C(4.5 \mathrm{~mL})$ was added to a solution of 2,4-dibromophenol $(0.95 \mathrm{~g}, 97 \%$, $0.38 \mathrm{mmol})$ in $\mathrm{Et}_{2} \mathrm{O}(0.5 \mathrm{~mL})$ and stirred for $18 \mathrm{~h}$ at room temperature. Argon was bubbled through solution to remove excess diazomethane- ${ }^{13} C$. Solvent was removed under reduced pressure to yield a light yellow solid $(0.93 \mathrm{~g})$. The crude material was purified by forced flow column chromatography ( $2.5 \%$ EtOAc in hexanes) to afford 2,4dibromoanisole- ${ }^{13} \mathrm{C}$ as a white solid $\left(0.09 \mathrm{~g}, 90 \%, 99 \%{ }^{13} \mathrm{C}\right)$.

mp 44.5-45.4 ${ }^{\circ}$ C. $\boldsymbol{R}_{f} 0.22\left(2.5 \%\right.$ EtOAc in hexanes, UV). ${ }^{1} \mathbf{H}$ NMR $\left(\mathrm{CDCl}_{3}, 300 \mathrm{MHz}\right): \delta$ $7.66\left(\mathrm{~d},{ }^{4} J=2.4 \mathrm{~Hz}, 1 \mathrm{H}\right), 7.37\left(\mathrm{dd},{ }^{3} J=9.0,{ }^{4} J=2.4,1 \mathrm{H}\right), 6.77\left(\mathrm{~d},{ }^{3} J=9.0 \mathrm{~Hz}, 1 \mathrm{H}\right), 3.87$ $\left(\mathrm{d},{ }^{1} J=144.9 \mathrm{~Hz}, 3 \mathrm{H}\right) .{ }^{13} \mathrm{C}$ NMR $\left(\mathrm{CDCl}_{3}, 75 \mathrm{MHz}\right): \delta 155.2\left(\mathrm{~d},{ }^{4} J=2.0 \mathrm{~Hz}\right), 135.5$, 131.2, 113,1 (d, $\left.{ }^{3} J=5.0 \mathrm{~Hz}\right), 112.9,112.6\left(\mathrm{~d},{ }^{4} J=3.2 \mathrm{~Hz}\right), 56.4$. IR $\left(\mathrm{NaCl}\right.$ plate, $\left.\mathrm{cm}^{-1}\right)$ : 
$3082,2962,2930,2830,1861,1578,1557,1476,1410,1378,1287,1172,1083,1048$, $1010,876,806$.

\subsubsection{5 ((cyclopropyl-2,2- $\left.d_{2}\right)$ methoxy)benzene (13- $\left.d_{2}\right)$}

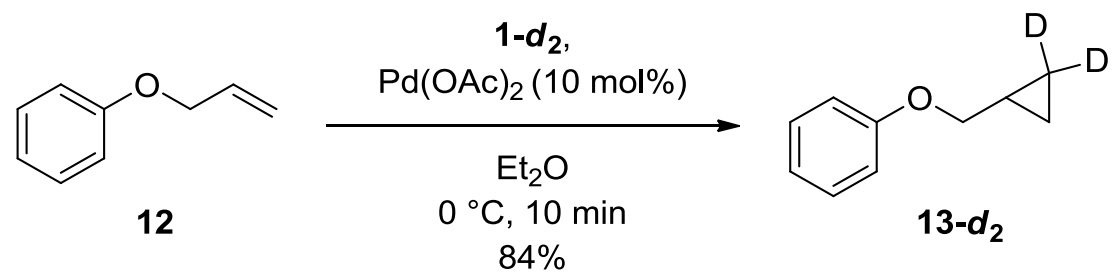

(Allyloxy)benzene $(0.106 \mathrm{~g}, 0.79 \mathrm{mmol})$ was dissolved in $\mathbf{1}-\boldsymbol{d}_{\mathbf{2}}$ solution $(15 \mathrm{~mL})$ and chilled in an ice/water bath for $10 \mathrm{~min}$. Then $\mathrm{Pd}(\mathrm{OAc})_{2}(12.0 \mathrm{mg}, 0.05 \mathrm{mmol})$ was added in one portion and vigorous gas evolution was observed. The orange mixture was stirred for a further $10 \mathrm{~min}$ in the cooling bath. Argon gas was bubbled through the solution for 10 min to remove any excess $\mathbf{1}-\boldsymbol{d}_{\mathbf{2}}$. The mixture was filtered over a short plug of silica and concentrated to give a yellow liquid $(0.126 \mathrm{~g})$. The crude material was purified by forced flow column chromatography $\left(2.5 \% \quad \mathrm{Et}_{2} \mathrm{O}\right.$ in hexanes $)$ to afford (cyclopropylmethoxy)benzene- $d_{2}$ as a clear oil $(0.10 \mathrm{~g}, 84 \%, 98 \% \mathrm{D})$.

$\boldsymbol{R}_{\boldsymbol{f}} 0.27\left(2.5 \% \mathrm{Et}_{2} \mathrm{O}\right.$ in hexanes, UV). ${ }^{1} \mathbf{H}$ NMR $\left(\mathrm{CDCl}_{3}, 400 \mathrm{MHz}\right): \delta$ 7.29-7.23 (m, 2H), 6.94-6.89 (m, 3H), $3.79\left(\mathrm{~d},{ }^{3} J=6.8 \mathrm{~Hz}, 2 \mathrm{H}\right), 1.26$ (quintet, $\left.{ }^{3} J=6.8 \mathrm{~Hz}, 1 \mathrm{H}\right), 0.62\left(\mathrm{t},{ }^{3} J=\right.$ $5.2 \mathrm{~Hz}, 1 \mathrm{H}), 0.33\left(\mathrm{t},{ }^{3} J=4.8 \mathrm{~Hz}, 1 \mathrm{H}\right) .{ }^{13} \mathbf{C}$ NMR $\left(\mathrm{CDCl}_{3}, 100 \mathrm{MHz}\right): \delta 159.0,129.4$, 120.6, 114.6, 72.6, 10.1, 3.0, 2.6 (quintet, ${ }^{1} J=24 \mathrm{~Hz}$ ). IR ( $\mathrm{NaCl}$ plate, $\left.\mathrm{cm}^{-1}\right): 3073,3029$, 2908, 2870, 1600, 1497, 1407, 1349, 1301, 1244, 1174, 1032, 811, 753. 


\subsubsection{6 ((cyclopropyl-2 $\left.-{ }^{13} \mathrm{C}\right)$ methoxy)benzene $\left(13-{ }^{13} \mathrm{C}\right)$}

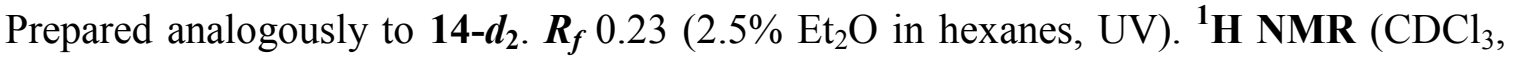
$300 \mathrm{MHz}): \delta$ 7.30-7.24 (m, 2H), 6.95-6.88 (m, 3H), $3.80\left(\mathrm{dd},{ }^{3} J=6.9 \mathrm{~Hz},{ }^{2} J=3.0 \mathrm{~Hz}\right.$, $2 \mathrm{H}), 1.32-1.23(\mathrm{~m}, 1 \mathrm{H}), 0.94-0.87(\mathrm{~m}, 0.5 \mathrm{H}), 0.68-0.57(\mathrm{~m}, 1.5 \mathrm{H}), 0.41-0.31(\mathrm{~m}, 1.5 \mathrm{H})$, 0.12-0.05 (m, 0.5H). ${ }^{13} \mathbf{C}$ NMR $\left(\mathrm{CDCl}_{3}, 75 \mathrm{MHz}\right): \delta 159.0,129.4,120.6,114.6,72.7$, 29.7, $10.3\left(\mathrm{~d},{ }^{1} J=12.8 \mathrm{~Hz}\right), 3.2$. IR $\left(\mathrm{NaCl}\right.$ plate, $\left.\mathrm{cm}^{-1}\right): 3076,3028,3005,2908,2870$, $1600,1585,1496,1243,1032,753$.

\subsubsection{1-cyclohexyl-2-diazoethanone-1- $d_{1}(14)$}

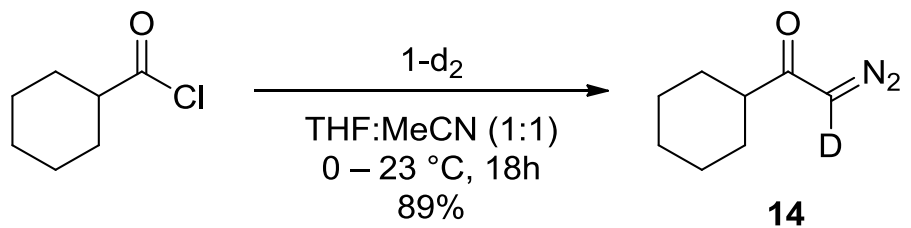

Diazomethane- $d^{2}$ solution $(34.5 \mathrm{~mL})$ was added to a solution of cyclohexylcarbonyl chloride $(0.51 \mathrm{~g}, 3.48 \mathrm{mmol})$ in $\mathrm{THF}(7 \mathrm{~mL})$ and $\mathrm{MeCN}(7 \mathrm{~mL})$ at $0{ }^{\circ} \mathrm{C}$. The dark yellow solution was allowed to warm to room temperature over $18 \mathrm{~h}$. Argon was bubbled through the solution to remove any excess diazomethane- $d_{2}$ before being washed with saturated aqueous $\mathrm{NH}_{4} \mathrm{Cl}(15 \mathrm{~mL})$, saturated aqueous $\mathrm{NaHCO}_{3}(15 \mathrm{~mL})$ and brine $(15 \mathrm{~mL})$. The organic layer was dried over anhydrous $\mathrm{Na}_{2} \mathrm{SO}_{4}$, filtered, and solvent was removed under reduced pressure to afford 15 as a dark yellow liquid $(0.48 \mathrm{~g}, 89 \%, 91 \% \mathrm{D})$. This material was used without further purification.

$\boldsymbol{R}_{f} 0.26\left(10 \%\right.$ EtOAc in hexanes, UV). ${ }^{1} \mathbf{H}$ NMR $\left(\mathrm{CDCl}_{3}, 400 \mathrm{MHz}\right): \delta 5.26(\mathrm{~s}, 0.09 \mathrm{H})$, 2.35-2.15 (m, 1H), 1.84-1.65 (m, 5H), 1.44-1.18 (m, 5H). ${ }^{13} \mathbf{C}$ NMR $\left(\mathrm{CDCl}_{3}, 75 \mathrm{MHz}\right): \delta$ 
198.4, 53.2, 49.4, 29.2, 25.7, 25.7. IR ( $\mathrm{NaCl}$ plate, $\left.\mathrm{cm}^{-1}\right): 2931,2855,2300,2101,1633$, $1450,1315,1264,1225,1066,959$.

\subsubsection{2-chloro-1-cyclohexylethanone-2,2- $d_{2}(15)$}

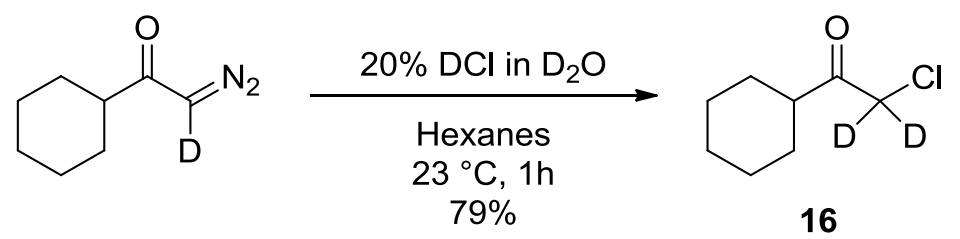

This protocol was adapted from a literature procedure. ${ }^{64}$ The crude cyclohexyl diazoketone $(0.1 \mathrm{~g}, 0.64 \mathrm{mmol})$ was dissolved in hexane $(1.3 \mathrm{~mL})$ and $\mathrm{DCl}(0.155 \mathrm{~mL}$, $20 \% \mathrm{DCl}$ in $\mathrm{D}_{2} \mathrm{O}, 0.98 \mathrm{mmol}$ ) was added slowly and vigorous gas evolution was observed. After $1 \mathrm{~h}$ sat. $\mathrm{NaHCO}_{3}(1 \mathrm{~mL})$ was added and stirred for a further $5 \mathrm{~min}$. The layers were separated and organic layer was washed with $\mathrm{H}_{2} \mathrm{O}(3 \times 3 \mathrm{~mL})$, dried over $\mathrm{Na}_{2} \mathrm{SO}_{4}$, filtered, and solvent was removed under reduced pressure to yield a pale yellow liquid $(0.09 \mathrm{~g})$. The crude material was purified by forced flow column chromatography (0-5\% EtOAc in hexanes) to afford 2-chloro-1-cyclohexylethanone-2,2- $d_{2}$ as a clear oil (0.08 g, 79\%, 93\% D).

$\boldsymbol{R}_{f} 0.29$ (5\% EtOAc in hexanes, UV, CAM). ${ }^{1} \mathbf{H}$ NMR $\left(\mathrm{CDCl}_{3}, 300 \mathrm{MHz}\right): \delta 4.15\left(\mathrm{t},{ }^{2} J=\right.$ $2.1 \mathrm{~Hz}, 0.07 \mathrm{H}), 2.69-2.59(\mathrm{~m}, 1 \mathrm{H}), 1.90-1.66(\mathrm{~m}, 5 \mathrm{H}), 1.45-1.15(\mathrm{~m}, 5 \mathrm{H}) .{ }^{13} \mathbf{C}$ NMR $\left(\mathrm{CDCl}_{3}, 100 \mathrm{MHz}\right): \delta 205.1,47.8,46.6$ (quintet, $\left.{ }^{1} J=22.7 \mathrm{~Hz}\right), 28.4,25.7,25.5$. IR $(\mathrm{NaCl}$ plate, $\left.\mathrm{cm}^{-1}\right): 2932,2855,1730,1450,1159,944$. 


\section{Publications arising from this thesis}

Shields, S. W. J.; Manthorpe, J. M. J.Labelled Comp. Radiopharm. In Press. DOI: $10.1002 /$ jlcr.3231 


\section{References}

(1) Gurr, M. I.; Hardwood, J. L. Lipid Biochemistry: An Introduction; 4 ed.; Chapman and Hall: London, 1991; pp. 1-12.

(2) Buist, P. H. Nat. Prod. Rep. 2004, 21, 249-262.

(3) Dyer, J. M.; Stymne, S.; Green, A. G.; Carlsson, A. S. Plant J. 2008, 54, 640-655.

(4) Jaworski, J.; Cahoon, E. B. Curr. Opin. Plant Biol. 2003, 6, 178-184.

(5) Dobrzyn, A.; Ntambi, J. M. Prostaglandins. Leukot. Essent. Fatty Acids 2005, 73, $35-41$.

(6) Bloch, K. Acc. Chem. Res. 1969, 2, 193.

(7) Buist, P. H. Comprehensive Natural Products II Chemistry and Biology; Mander, L.; Lui, H.-W., Eds.; Volume 1, .; Elsevier: Oxford UK, 2010; Vol. 1, pp. 5-33.

(8) Shanklin, J.; Somerville, C. Proc. Natl. Acad. Sci. U. S. A. 1991, 88, 2510-2514.

(9) Lindqvist, Y.; Huang, W.; Schneider, G.; Shanklin, J. EMBO J. 1996, 15, 40814092.

(10) Blanksby, S. J.; Ellison, G. B. Acc. Chem. Res. 2003, 36, 255-263.

(11) Zhang, X. J. Org. Chem. 1998, 3263, 1872-1877.

(12) Buist, P. H.; Behrouzian, B. J. Am. Chem. Soc. 1996, 7863, 6295-6296.

(13) Behrouzian, B.; Shanklin, J.; Buist, P. H. Chem. Commun. 2001, 401-402.

(14) Zhou, J.; Kelly, W. L.; Bachmann, B. O.; Gunsior, M.; Townsend, C. a; Solomon, E. I. J. Am. Chem. Soc. 2001, 123, 7388-7398.

(15) Tremblay, A. E.; Whittle, E.; Buist, P. H.; Shanklin, J. Org. Biomol. Chem. 2007, $5,1270-1275$.

(16) Schaus, S. E.; Brandes, B. D.; Larrow, J. F.; Tokunaga, M.; Hansen, K. B.; Gould, A. E.; Furrow, M. E.; Jacobsen, E. N. J. Am. Chem. Soc. 2002, 124, 1307-1315.

(17) Hofmann, K.; Lucas, R. J. Am. Chem. Soc. 1950, 72, 4328-4329.

(18) Grogan, D. W.; Cronan, J. E. Microbiol. Mol. Biol. Rev. 1997, 61, 429-441. 
(19) Glickman, M. S.; Cox, J. S.; Jacobs, W. R. Mol. Cell 2000, 5, 717-727.

(20) Yano, I.; Morris, L. J.; Nichols, B. W.; James, A. T. Lipids 1972, 35-45.

(21) Nunn, J. R. J. Chem. Soc. 1952, 313-318.

(22) Stuart, L. J.; Buist, P. H. Tetrahedron: Asymmetry 2004, 15, 401-403.

(23) Gaydou, E. M.; Ralaimanarivo, A.; Bianchinit, J. J. Agric. Food Chem. 1993, 41, 886-890.

(24) Gomez, F. E.; Bauman, D. E.; Ntambi, J. M.; Fox, B. G. Biochem. Biophys. Res. Commun. 2003, 300, 316-326.

(25) Hofmann, K.; Panos, C. J. Am. Chem. Soc. 1957, 79, 3608.

(26) Tocanne, J. F. Tetrahedron 1972, 28, 363.

(27) Palko, J. W.; Buist, P. H.; Manthorpe, J. M. Tetrahedron: Asymmetry 2013, 24, $165-168$.

(28) Thibodeaux, C. J.; Chang, W.; Liu, H. Chem. Rev. 2012, 112, 1681-1709.

(29) Maclean, B.; Buist, P. H. Can. J. Chem. 1981, 828.

(30) Iwig, D. F.; Grippe, A. T.; McIntyre, T. a; Booker, S. J. Biochemistry 2004, 43, $13510-13524$.

(31) Bender, D. M.; Peterson, J. a; McCarthy, J. R.; Gunaydin, H.; Takano, Y.; Houk, K. N. Org. Lett. 2008, 10, 509-511.

(32) Hofmann, A. K.; Doering, W. E. J. Am. Chem. Soc. 1954, 6162.

(33) Czako, B.; Kurti, L. Strategic Applications of Named Reactions in Organic Synthesis; Hyhurst, J., Ed.; 1st ed.; Elsevier: Burlington, USA, 2005; pp. 1-500.

(34) Smith, R.; Simmons, H. J. Am. Chem. Soc. 1959, 104, 4256.

(35) Abramovitch, A.; Fensterbank, L.; Malacria, M.; Marek, I. Angew. Chem. Int. Ed. Engl. 2008, 47, 6865-6868.

(36) Lou, Y.; Horikawa, M.; Kloster, R. a; Hawryluk, N. a; Corey, E. J. J. Am. Chem. Soc. 2004, 126, 8916-8918.

(37) Andersen, K. K. Tetrahedron Lett. 1962, 93. 
(38) Andersen, K.; Gaffield, W.; Papanikolaou, N.; Foley, J.; Perkins, R. J. Am. Chem. Soc. 1964, 86, 5637.

(39) Toledo, H.; Pisarevsky, E.; Abramovich, A.; Szpilman, A. M. Chem. Commun. (Camb). 2013, 49, 4367-4369.

(40) Yoshida, Y.; Sakakura, Y.; Aso, N.; Okada, S.; Tanabe, Y. Tetrahedron 1999, 55, 2183-2192.

(41) Criegee, R. Angew. Chem. Int. Ed. Engl. 1975, 14, 745.

(42) Geletneky, C.; Berger, S. European J. Org. Chem. 1998, 1998, 1625.

(43) Still, W. et al. J. Org. Chem. 1978, 43, 2923-2925.

(44) Pedersen, D. S.; Rosenbohm, C. Synthesis (Stuttg). 2001, 2001, 2431-2434.

(45) Gao, X.; Hall, D. G. J. Am. Chem. Soc. 2005, 127, 1628-1629.

(46) Ishihara, K.; Hanaki, N.; Yamamoto, H. J. Am. Chem. Soc. 1993, 115, 1069510704.

(47) Mihailescu, M.; Vaswani, R. G.; Jardón-Valadez, E.; Castro-Román, F.; Freites, J. A.; Worcester, D. L.; Chamberlin, a R.; Tobias, D. J.; White, S. H. Biophys. J. 2011, 100, 1455-1462.

(48) Satoh, T.; Oohara, T.; Ueda, Y.; Yamakawa, K. J. Org. Chem. 1989, 54, 3130 3136.

(49) Brebion, F.; Goddard, J. P.; Fensterbank, L.; Malacria, M. Synthesis (Stuttg). 2005, $2449-2452$.

(50) Sakaguchi, S.; Yamamoto, Y.; Sugimoto, T.; Yamamoto, H.; Ishii, Y. J. Org. Chem. 1999, 64, 5954-5957.

(51) Cryle, M. J.; Hayes, P. Y.; De Voss, J. J. Chemistry 2012, 18, 15994-15999.

(52) Savile, C. K.; Reed, D. W.; Meesapyodsuk, D.; Covello, P. S.; Buist, P. H. J. Chem. Soc. Perkin Trans. 1 2001, 1116-1121.

(53) Najera, F.; Delouvrie, B.; Fensterbank, L.; Malacria, M. J. Organomet. Chem. 2002, 644, 130-135.

(54) Marshall, J. A.; Garofalo, A. W. J. Org. Chem. 1993, 58, 3675-3680.

(55) Motoyoshi, H.; Ishigami, K.; Kitahara, T. Tetrahedron 2001, 57, 3899-3908. 
(56) Sammakia, T. Diazomethane http://onlinelibrary.wiley.com/doi/10.1002/047084289X.rd017/pdf (accessed Dec 19, 2013).

(57) Boer, T.; Backer, H. Org. Synth. 1954, 34, 96.

(58) Gassman, P.; Greenlee, W. Org. Synth. 1973, 53, 38.

(59) Aldrich Tech. Bull. AL-180.

(60) Shields, S. W.; Manthorpe, J. M. J. Label. Compd. Radiopharm. 2014, in press.

(61) Corominas, A.; Montaña, Á. M. Synth. Commun. 2013, 43, 2062-2072.

(62) Wu, Q.; Hu, J.; Ren, X.; Zhou, J. Chemistry 2011, 17, 11553-11558.

(63) Gowrisankar, S.; Neumann, H.; Beller, M. Angew. Chem. Int. Ed. Engl. 2011, 50, 5139-5143.

(64) Kong, H. Il; Crichton, J. E.; Manthorpe, J. M. Tetrahedron Lett. 2011, 52, 3714 3717. 